\title{
THE RUINS OF ELOQUENCE
}

\author{
A THESIS SUBMITTED TO THE VICTORIA \\ UNIVERSITY OF WELLINGTON IN PARTIAL \\ FULFILMENT OF THE REQUIREMENTS FOR \\ THE DEGREE OF MASTER OF INTERIOR \\ ARCHITECTURE
}

VICTORIA UNIVERSITY OF WELLINGTON 2015

ANTONY HEMBROW 

AN INVESTIGATION OF HOW MIXED REALITY CAN ALTER AND INFORM INTERIOR ARCHITECTURE TO INCREASE AWARNESS OF HISTORICAL IMPORTANTANCE WHEN APPLIED TO THE CONTEXT OF DESTRUCTED BUILDINGS WITHIN CHRISTCHURCH. 

FOR MY BEST FRIEND

FOR MY SISTER

FOR OLIVIA 



\section{Contents:}

\section{Introduction}

\section{Site}

2.1 Site and Location

2.2 Despair and Scope

2.3 Photographic Analysis

\section{Circulation}

\section{Mixed Reality}

\subsection{Mixed Reality}

4.2 Real Environment

4.3 Augmented Reality

4.4 Augmented Virtuality

4.5 Virtual Reality

\section{Precedents of Mixed Reality}

5.1 Precedents and Applications of MR in Architecture

5.2 The Wall - Gibson Group

5.3 Museum of London

5.4 Augmented Structures v2.0

\section{Precedents of Architetcure}

6.1 Four public squares, The Tower of Leonforte

6.2 Warehouse 17C

6.3 The Waterhouse

\section{Technologies}

7.1 Near Field Communcation, NFC

7.2 Transparent LCD Touch Screens

8. Preliminary Design

9. Design

10. Appendix

10.1 Bibliography 



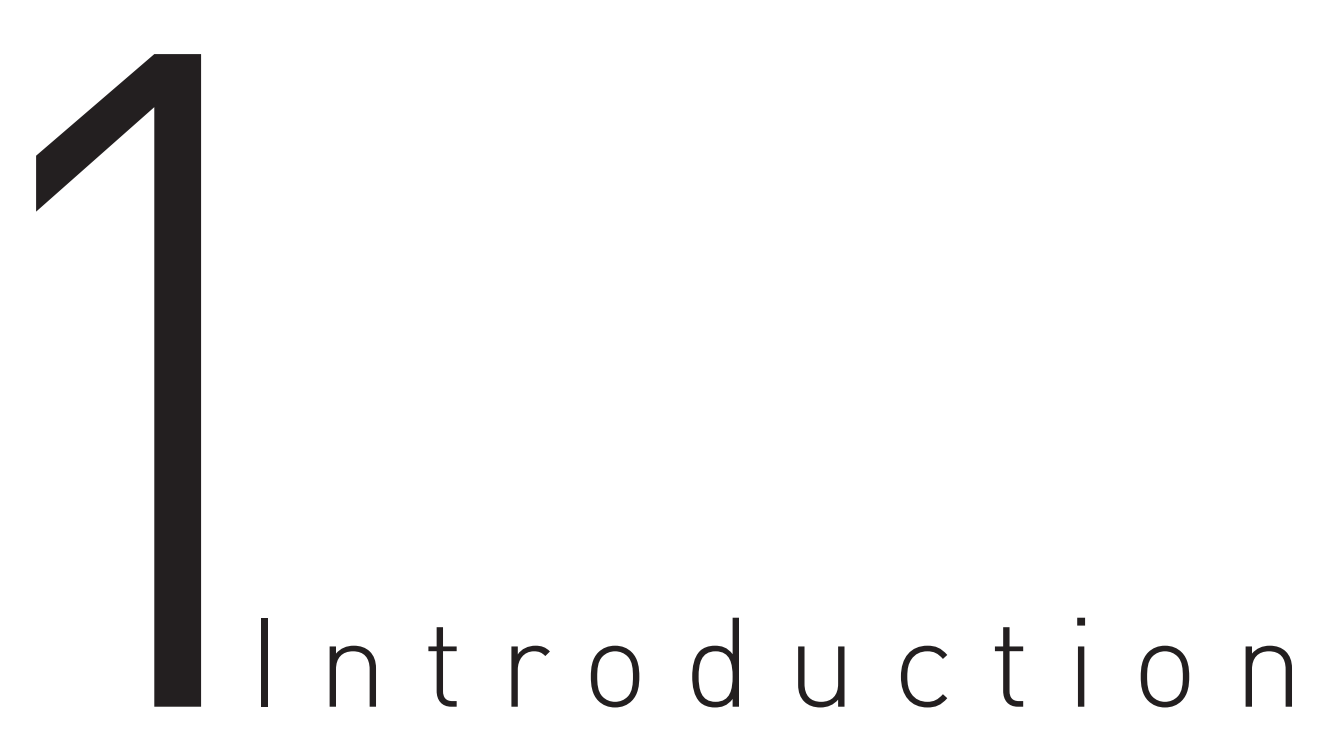


On the 22nd of February, 2011 the city of Christchurch, New Zealand was crippled by a colossal earthquake. 185 people were killed, thousands injured and what remained was a city left in destruction and ruin. Thousands of Christchurch properties and buildings were left damaged beyond repair and the rich historical architecture of the Canterbury region had suffered irreparably.

This research will conduct an investigation into whether the use of mixed reality can aid in liberating Christchurch's rich architectural heritage when applied to the context of destructed buildings within Christchurch.

The aim of this thesis is to formulate a narrative around the embodiment of mixed reality when subjected to the fragmentary historical architecture of Christchurch. Mixed reality will aspire to act as the defining ligature that holds the past, present and future of Christchurch's architectural heritage intact as if it is all part of the same continuum.
This thesis will focus on the design of a memorial museum within a heavily damaged historical trust registered building due to the Christchurch earthquake. It is important and relevant to conceive the idea of such a design as history is what makes everything we know. The memories of the past, the being of the now and the projection of the future is the basis and fundamental imperative in honouring the city and people of Christchurch. Using the technologies of Mixed Reality and the realm of its counter parts the memorial museum will be a definitive proposition of desire in providing a psychological and physical understanding towards a better Christchurch, for the people of Christchurch.

This thesis serves to explore the renovation possibilities of the Canterbury provincial council building in its destructed state to produce a memorial museum for the Christchurch earthquake. The design seeks to mummify the building in its raw state that sets and develops the narrative through the spaces. The design intervention is kept at a required minimum and in doing 
so manifests a concentrated eloquence to the derelict space. The interior architecture unlocks the expression of history and time encompassed within a destructive and industrialised architectural dialogue. History is the inhabitant of the building, and using the physical and virtua worlds it can be set free.

This thesis informs a design for a museum in central Christchurch that celebrates and informs the public on past, present and future heritage aspects of Christchurch city. Using mixed reality technologies the spatial layout inside will be a direct effect of the mixed reality used and the exploration of the physical and digital heritage aspects of Christchurch. The use of technology in today's world is so prevalent that incorporating it into a memorial museum for Christchurch would not only be interesting and exploratory but also offer a sense of pushing forward and striving beyond for a newer, fresher Christchurch. The memorial museum will showcase a range of different exhibitions that formulate around the devastating Christchurch earthquake. Using mixed reality technologies these exhibitions will dictate the spaces inside dependant on their various applications of mixed reality as a technology for architecture. Research will include; what the people of Canterbury are most dear to in regards to Christchurch's historical environment; the use of mixed reality to visualise digital heritage, and the combination of the physical and digital to serve as an architectural mediation between what was, what is and what there could be. 



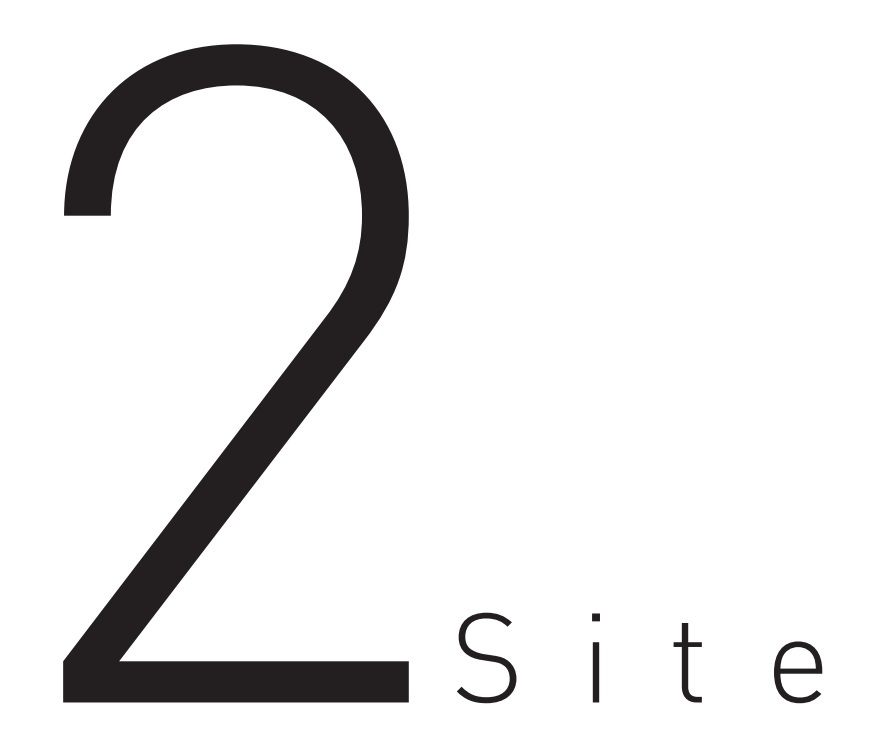




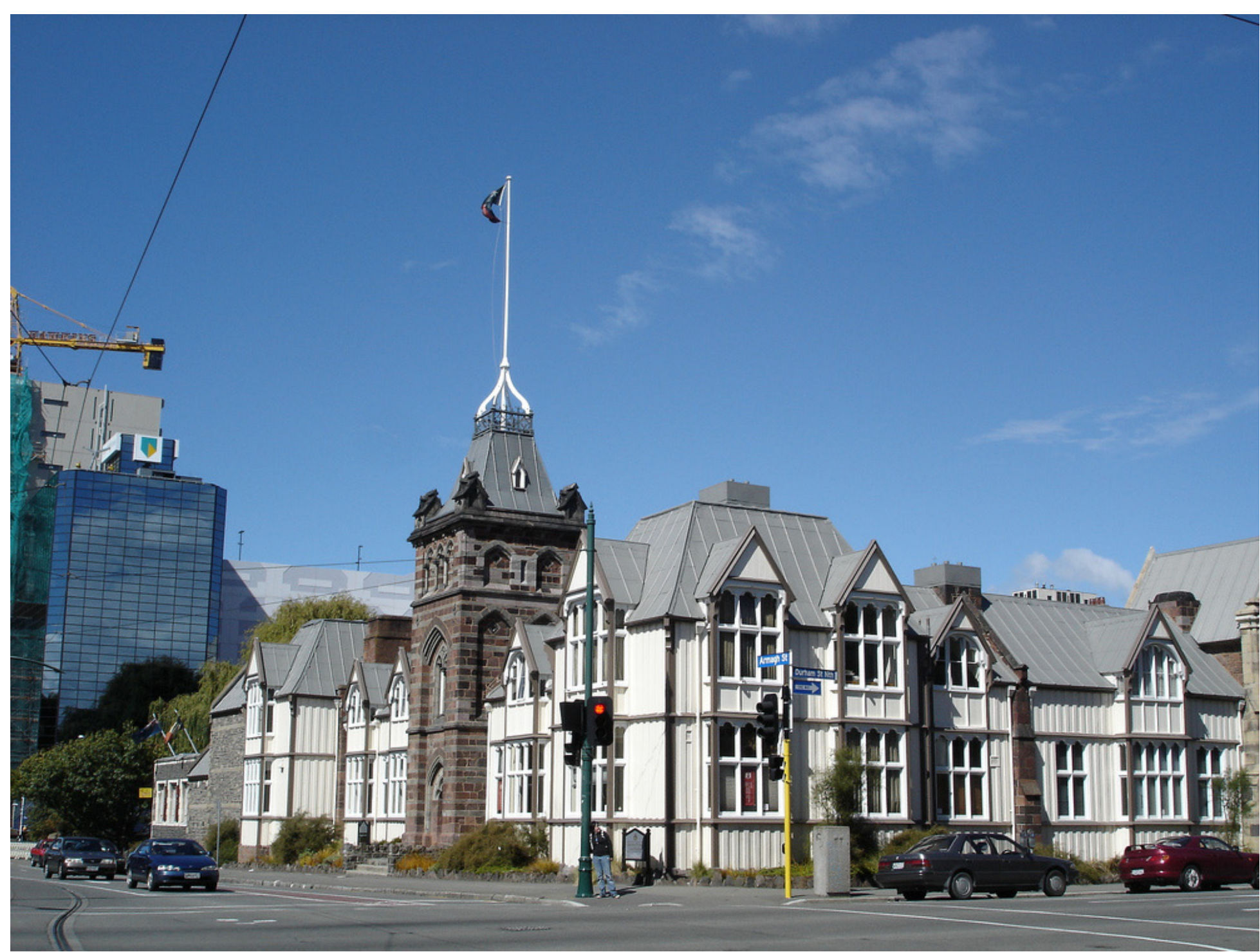

This chapter will explore the site of the "Canterbury Provincial Council Buildings" and the current state the building resides in after the earthquakes. It will also address the need for this architectural intervention and why this site is appropriate to develop alongside my research question.

A photographic analysis of the exterior and interior will express and make light of the current situation of despair the "Canterbury Provincial Council Buildings" encompasses. 


\section{1 \\ Site and Location}

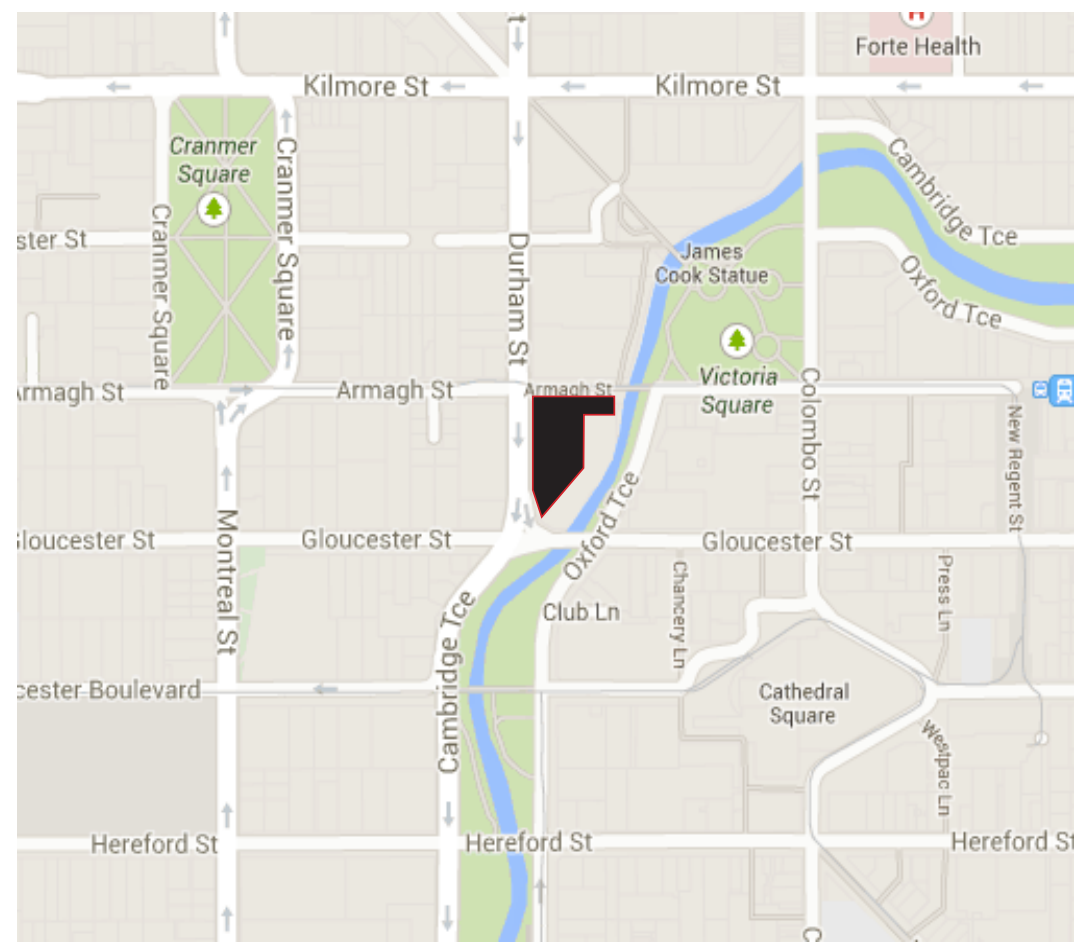

Image 2
The Canterbury Provincial

Council Buildings (CPCB) started construction during the year of 1858 and was designed by the architect Benjamin Mountfort. The building was constructed to house the Canterbury Provincial Council and was completed in its 3 part entirety in 1865 . The site is located in the Christchurch CBD and it is a 5 min walking distance to the Christchurch Cathedral Square. The buildings and grounds occupy the block surrounded by Armagh Street, Durham Street, Gloucester Street and The Avon River. The interior architectural intervention of a memorial museum discussed in this thesis uses the areas of the building that run along the northern side of Armagh Street and the western side of Durham Street. 


\section{2}

\section{Despair and Scope}

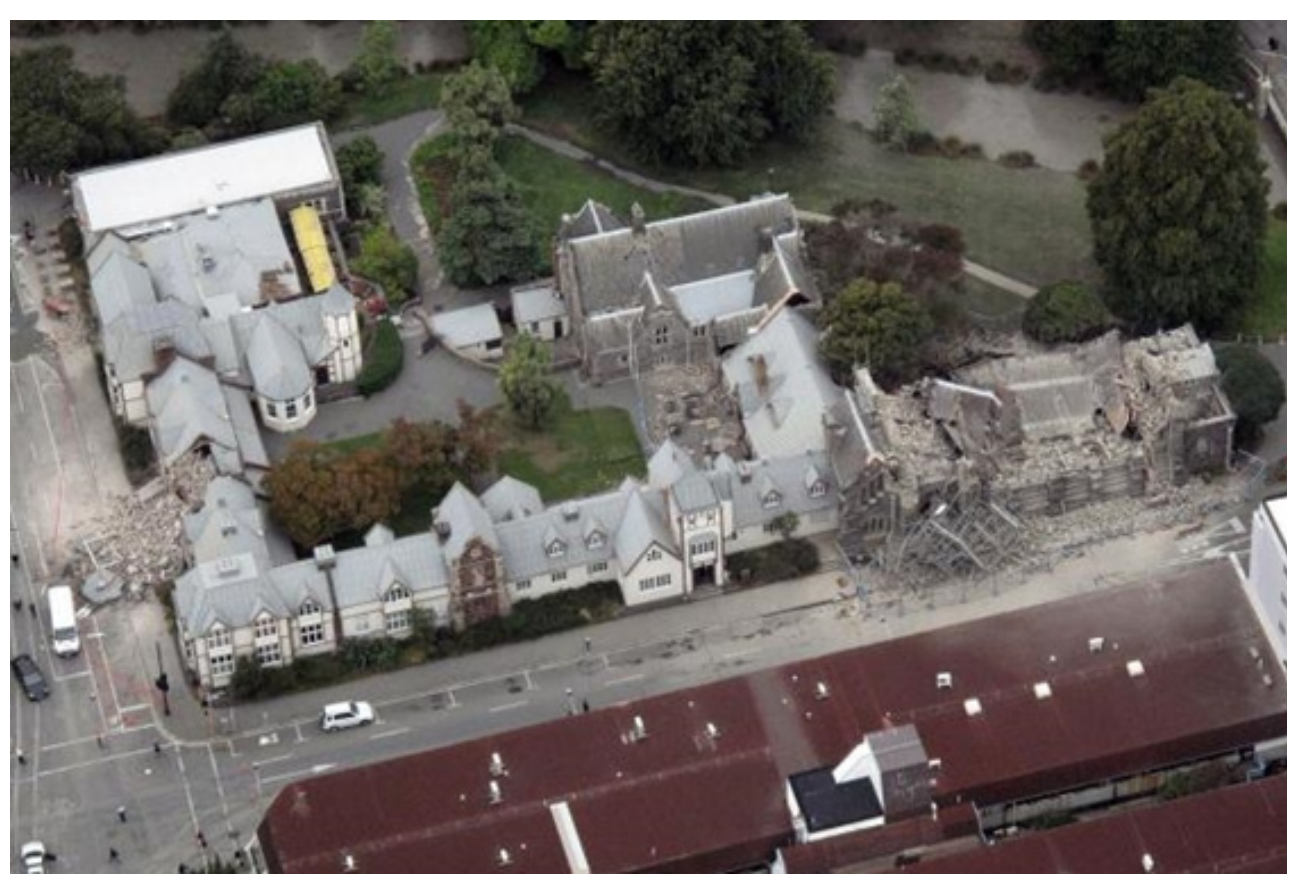

The Canterbury Provincial Council Buildings (CPCB) which was severely damaged in the Christchurch earthquakes of February, 2011 is an ideal site to explore and develop upon my research question. There was vast damage to all areas of the building and particularly the two stone chambers and their towers that sat on Armagh Street and Durham Street respectively. Dr lan Lochead, Associate Professor of Art History at the University of Canterbury, said that "The Stone Chamber is for many the single biggest heritage loss of the February earthquake".

This site sets an appropriate scene for my research question as the CPCB is the only purpose built provincial government buildings still in existence in New Zealand and its vitality to survive is pertinent in maintaining a part of Christchurch's rich heritage. These buildings are drenched in history and will offer an ideal framework to explore the physical and digital interventions of my design encompassed within a highly destructed building. I am asking my research question within the CPCB to explore other avenues of 'rebuild' within Christchurch where the notion of knocking down and rebuilding is rejected. The CPCB extends a prodigious platform for my research to allow the subtleties of physical and digital architectural dialogues to intertwine. 
2.3

Photographic Analysis
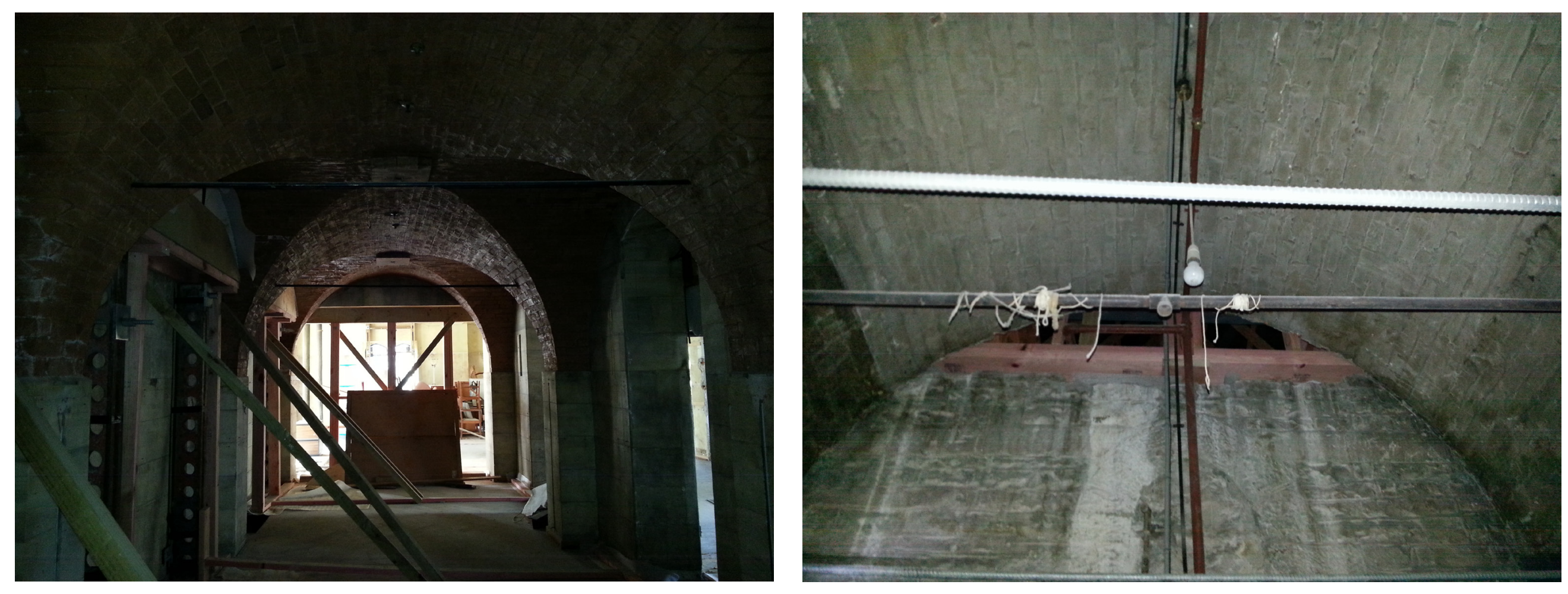

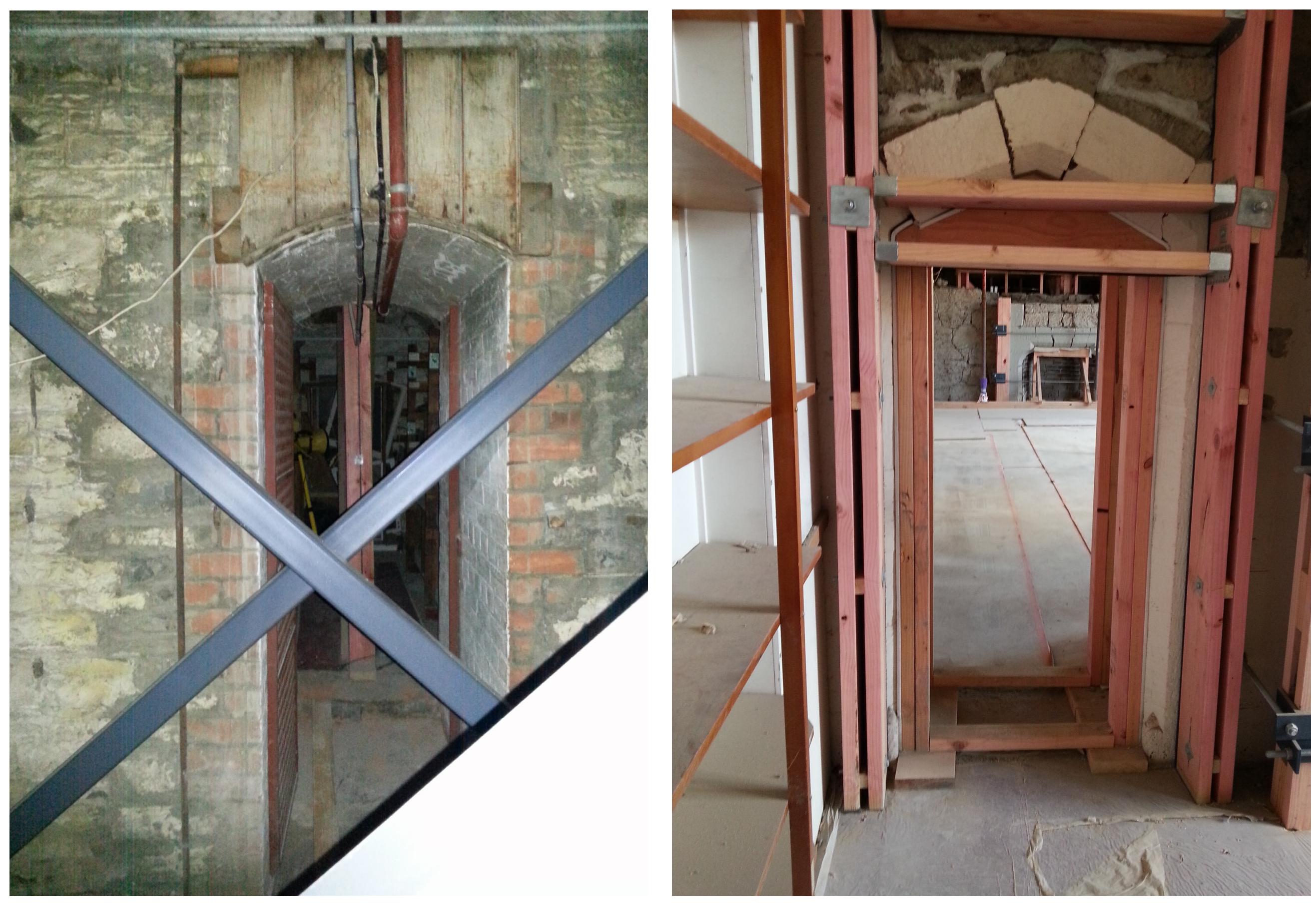


3.

\section{Circulation and Internal Layout}

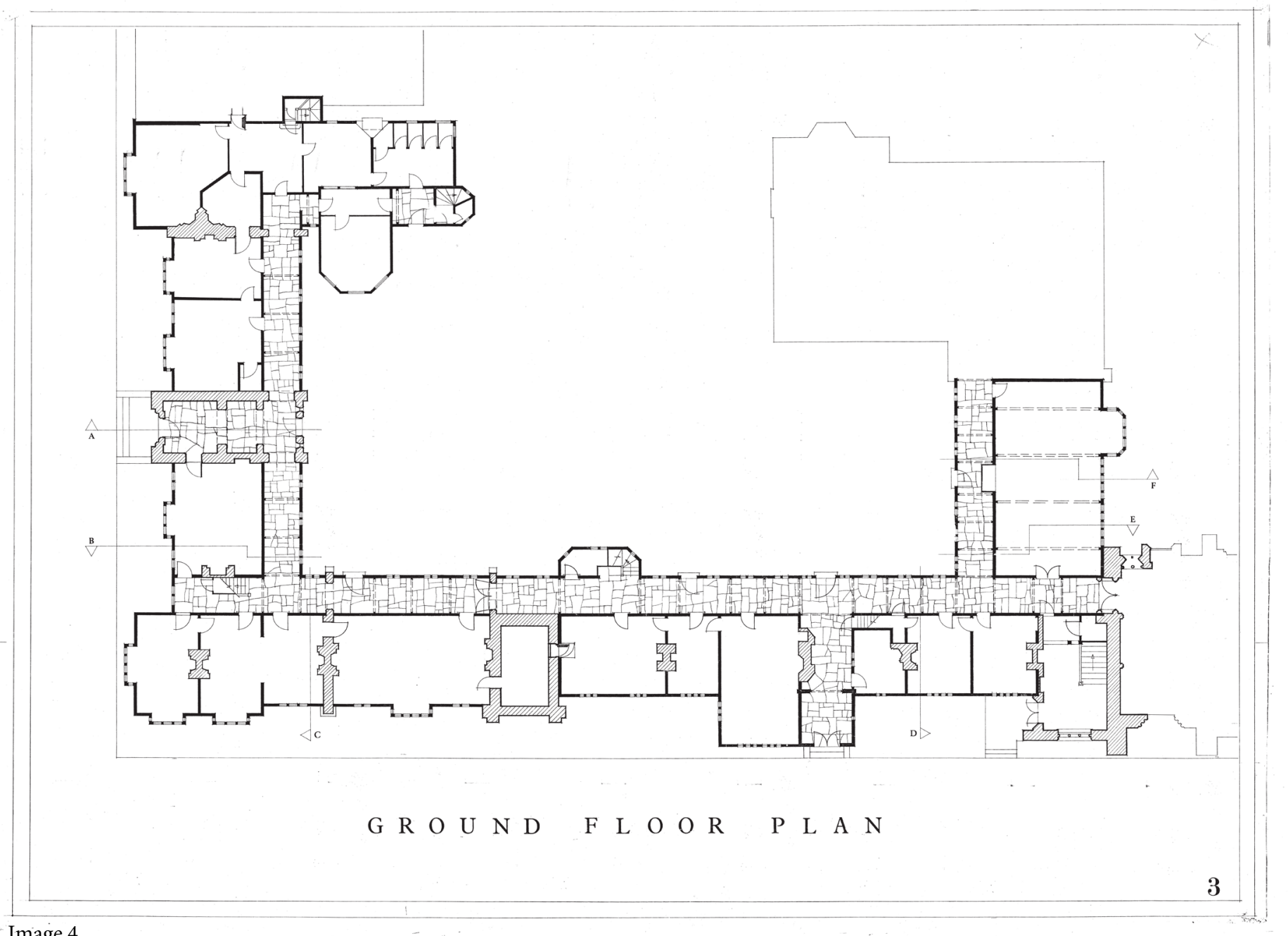

The single most important aspect of space and building functionality is circulation. The Canterbury Provincial Council Building was designed to house what were the Canterbury provincial government and then the Canterbury provincial council. In recent years the building and its rooms were rented out to individuals as offices. Due to the nature of destruction to the building all realistic and circulatory pathways were destroyed and would need to be rebuilt. Figure 1 shows the original circulation path of the main building and all its adjoining rooms 
Entry to Building

Entry to Memorial Museum

Exit from Memorial Museum
Proposed in the new design is the articulation of a clear pathway through the spaces along the northern and western side of the building where existing doorways connect each space together which is shown in Figure 2. These existing doorways where always present within the building but were seldom used due to the individual nature of their occupiers purpose. The southern and western stone towers that stood respectively along their dictated axis were

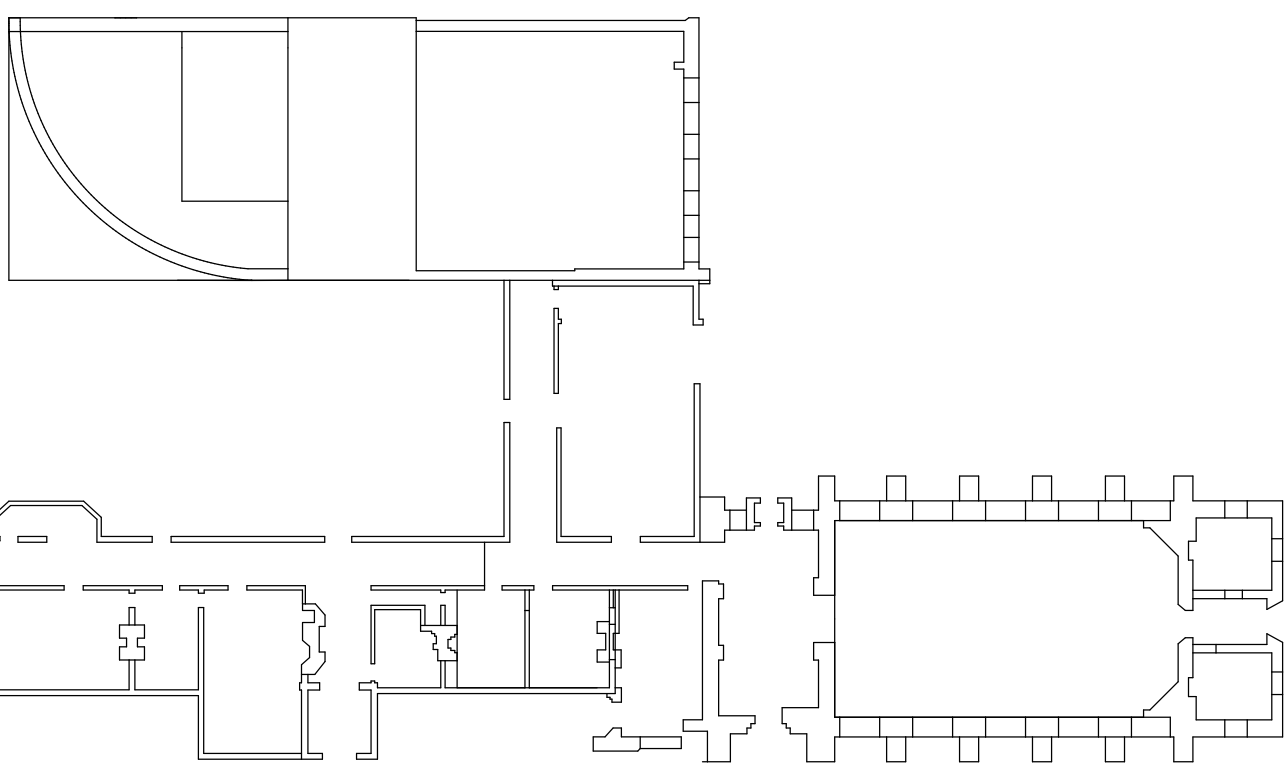

unfortunately rendered to a pile of rubble and in the interest of architectural rejuvenation I have designed two flumes that stand tall and interact with the mixed reality narrative of the memorial museum. There are moments where circulation has to be controlled and the insertion of interior architectural interventions take place to guide the user on their mixed reality journey.
政

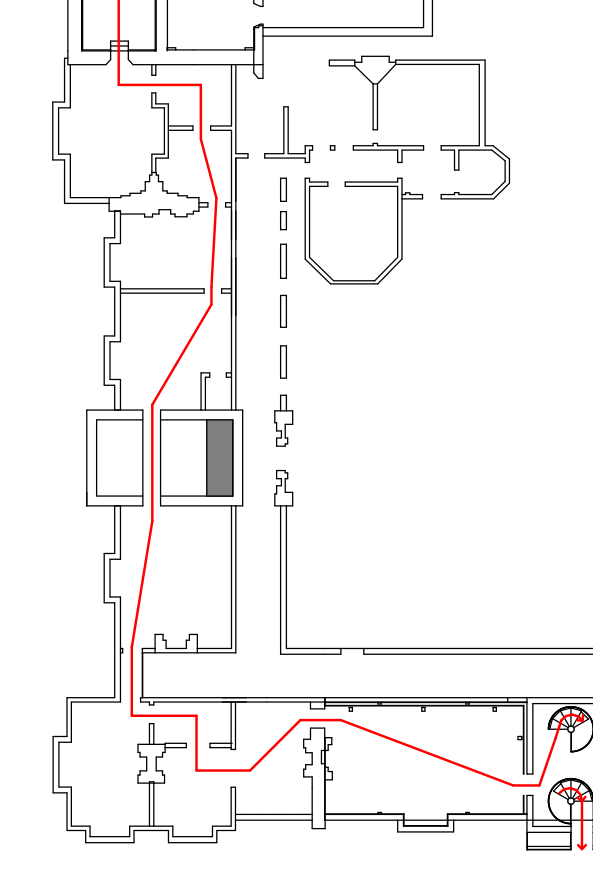


There are four major parts to my design that instigate and set the journey through the MR spectrum (figure 3). The spaces have been divided up to coincide with the passing and entering of new MR realms. The triggers are the two rebuilt towers, where the first tower on the northern side sits on its own as an architectural response to memory and death and plays as the first piece that activates the movement from the reality/real world environment to the digital/augmented environment of the subsequent spaces. The second tower sits along the western side of the building and is the final act to the narrative where it stands inside a physical form detached from the real world. Moments of historical Christchurch architecture of the past, present and future of Christchurch's architectural heritage and future can be realised at the top of this tower through the accompaniment of an augmented virtuality world.

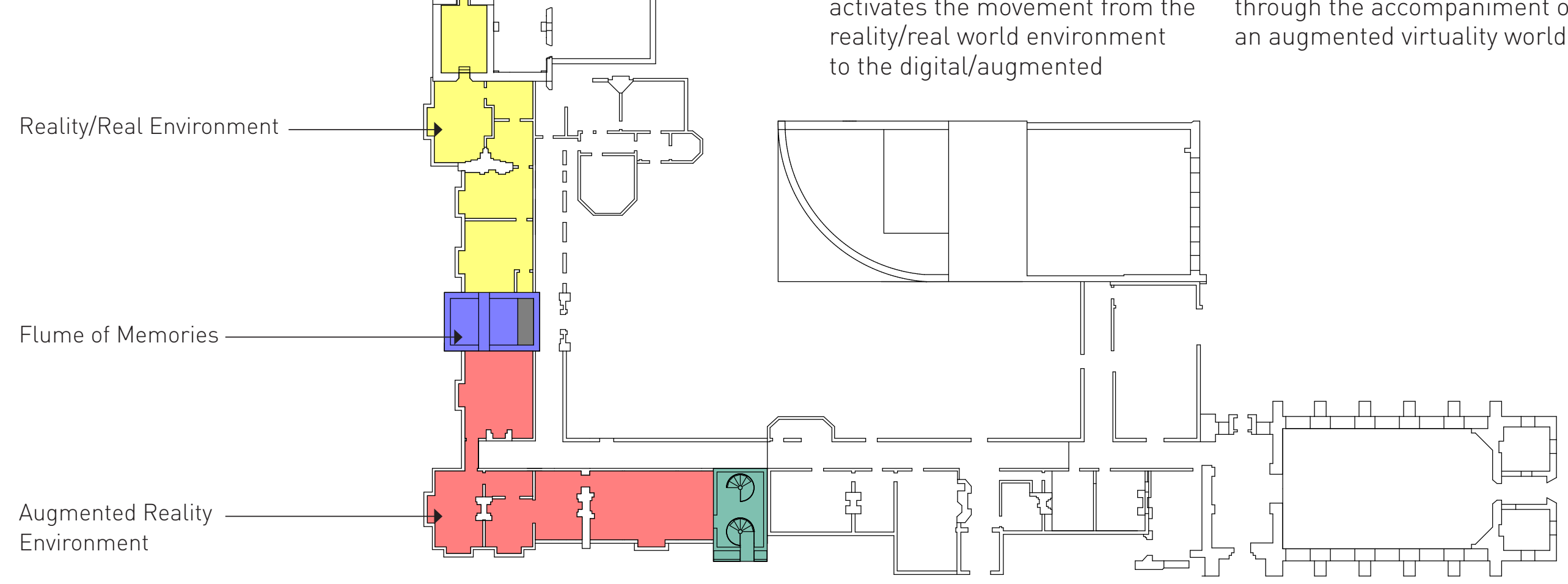

Flume of Existance

Augmented Virtuality Environment 




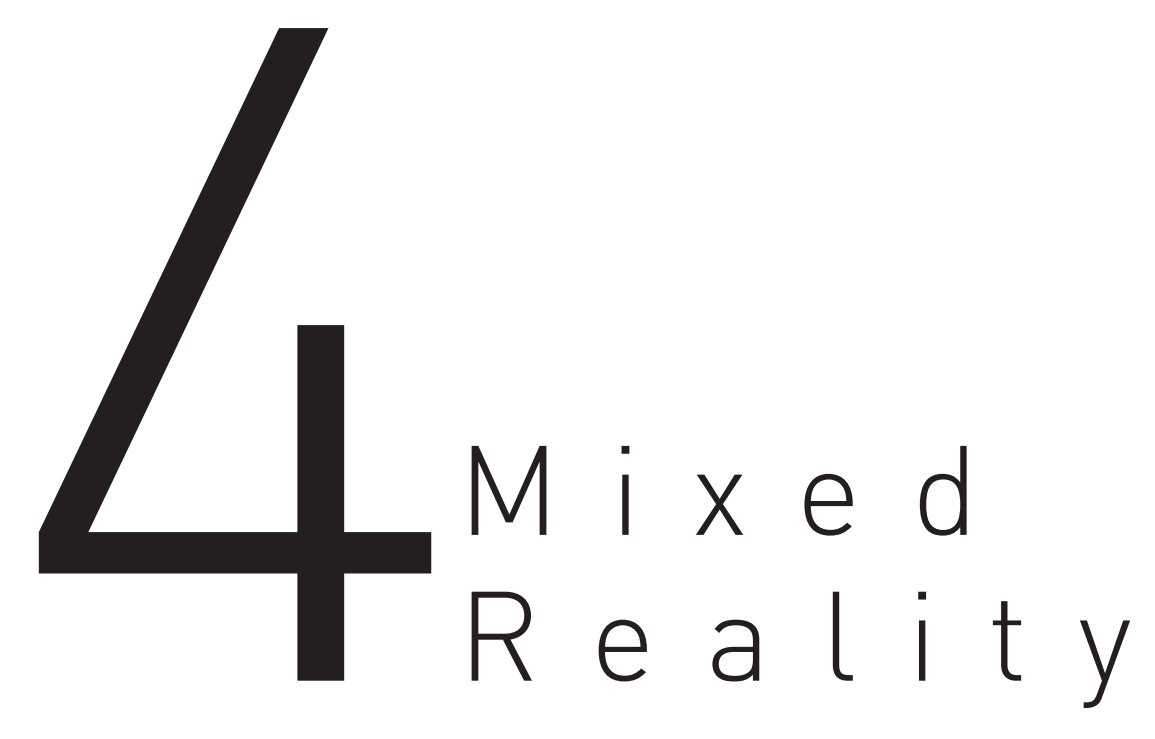




\section{1 \\ Mixed Reality}

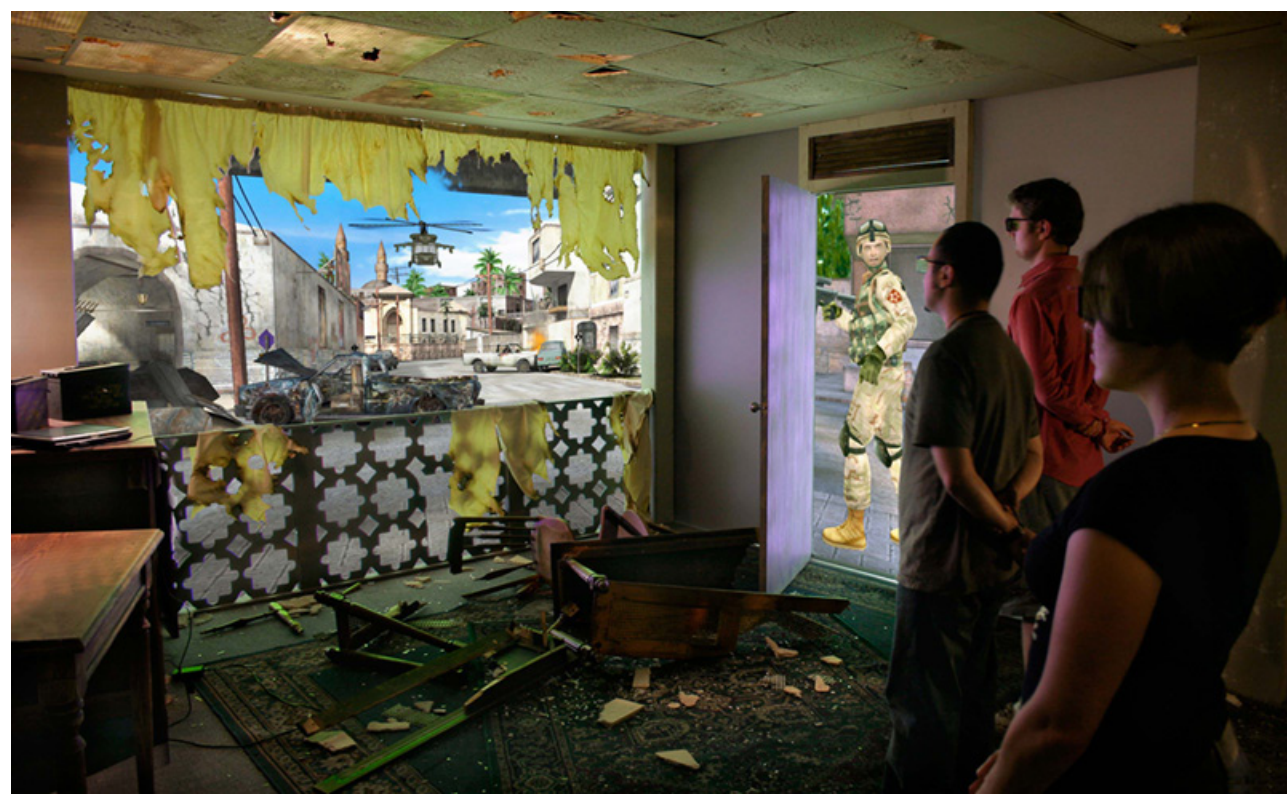

Image 5
Paul Milgram and Fumio Kishino discuss that the term Mixed Reality (MR) denotes the assimilation of the real environment and the virtual environment. It progresses an instance of real and virtual worlds that coexist to produce an environment for human visualisation that are unseen in just the physical or digital world alone. MR is the encompassing whole of the physical and digital environmental spectrums,

where it is simplified into 4 parts that follow a Reality-Virtuality continuum (Milgram \& Kishino, 1994).

MR in essence is the fusion of all realms and as the author Mark B. N. Hansen points out; "All reality is mixed reality! Though we see the world in three dimensions, throughout most of history, we've only been able to depict it in two." (Hansen, 2006). Hansen is suggesting that with the invention of the first motionpicture cameras in the 1890's and emergence of film production companies around the same time it informed a new representation of human visuality. In the golden age of filmmaking in 1952 the movie 'Bwana Devil' became the first 3D colour film where users contributed to their own experience by wearing 3D

glasses (Schedeen, 2010). It is at this moment you can assimilate a real participation to the lineage of MR. It is only appropriate to clarify the 4 major parts of MR outlined by Milgram and Kishino. 


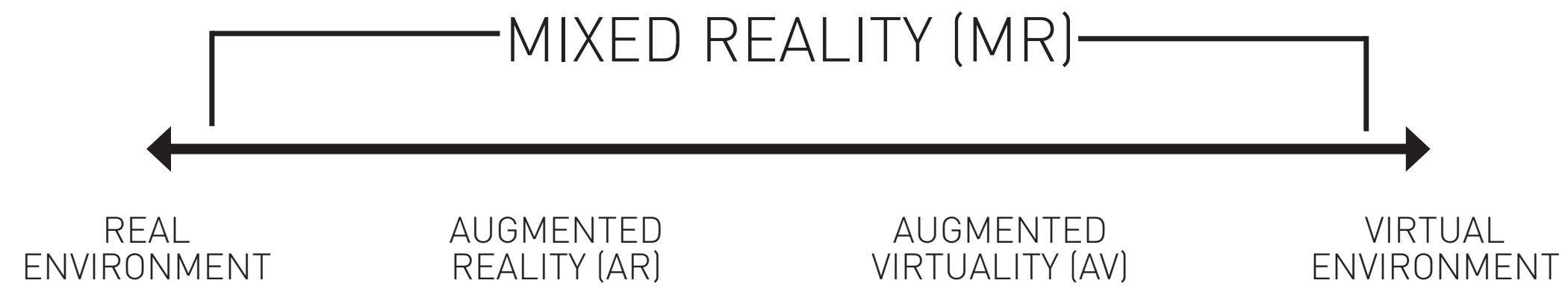




\section{2}

\section{Real Environment}

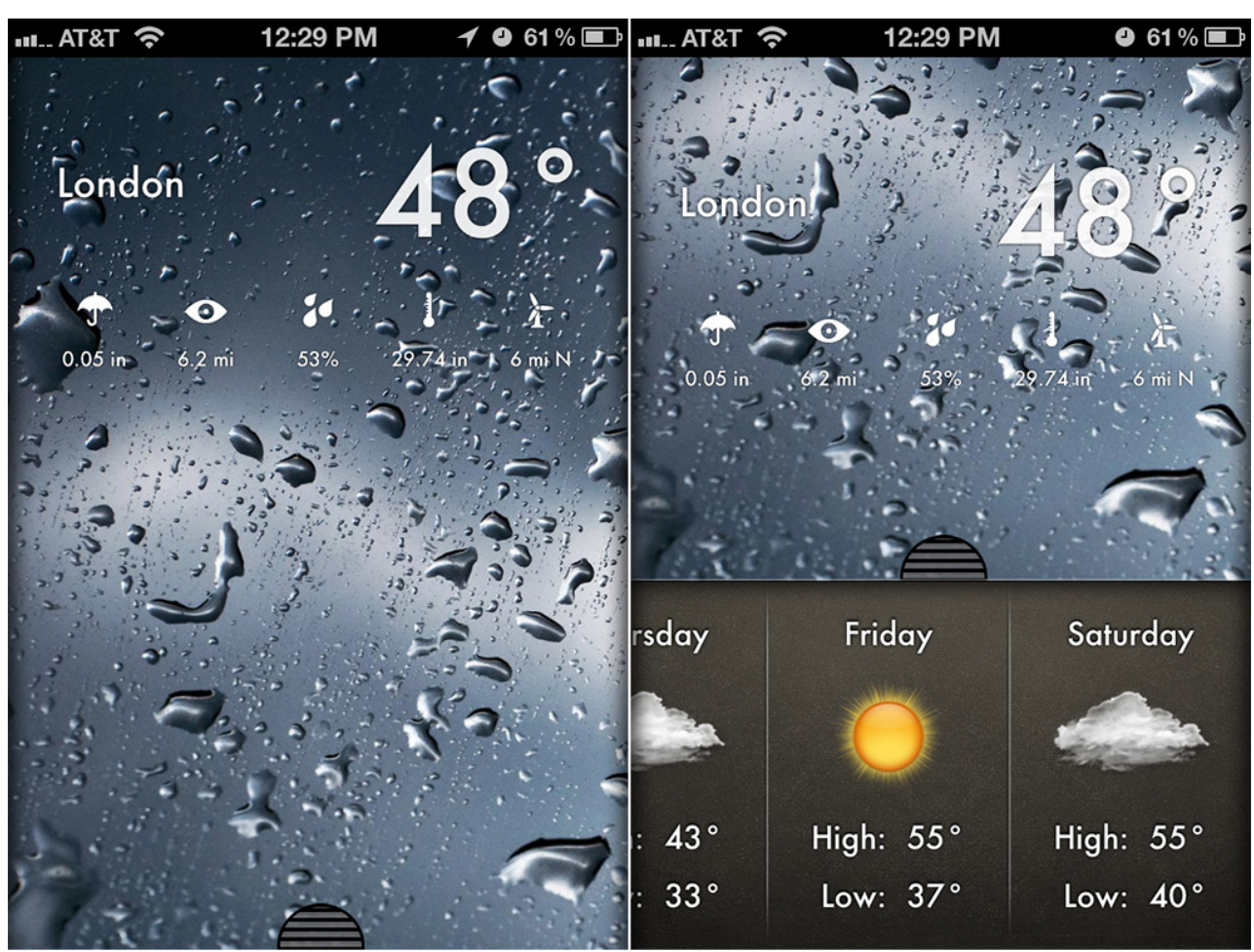

Image 6
The 'Real Environment' is not as straightforward as one may think. Everything that is physical and can be seen by the eye appears to fall into this category, but not all, the emergence of technologies in the last 60 years applies some form of MR to our daily lives. An everyday example of MR is the use of a smart phone. Being inside with the curtains closed and wanting to know what the weather is like outside is easily obtained from your cell phone. It offers you information from temperature, humidity levels, wind strength/direction and right to the point of your GPS location or at a location half way across the world. It can even go as far to show you a generically rendered image of your current location and portray the look of water running down your screen with dark clouds in the background, all in the comfort of your bed at the simple touch of a button. This application of information borders the fringe of what is known under another instance of MR as Augmented Reality. 
4.3
Augmented Reality (AR)

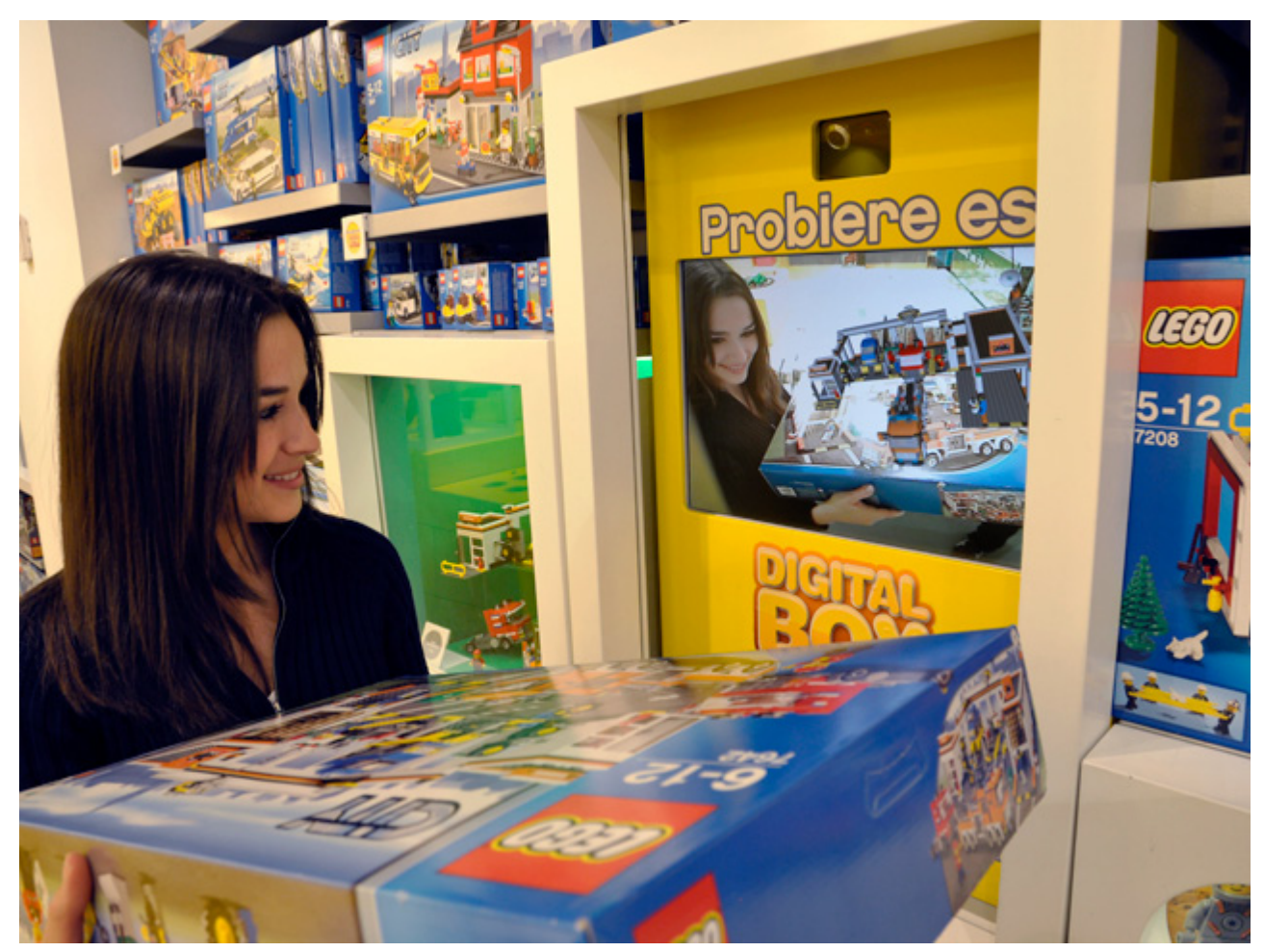

Image 7
Augmented reality (AR) is

the fusion of synthetic digital

information into the real world environment. AR is a far more complex technology where it doesn't supress the real environment but actually defines how the virtual supplements will interact with it (Bimber \& Raskar, 2005). The effect is to enrich and heighten ones current perception of reality to be used in a realtime display that ultimately uses technology to redefine space, applying layers of the virtual world over the physical world (Drell, 2012). There are many examples of AR in today's world and they are becoming increasingly more popular. LEGO ${ }^{\circledR}$ has implemented the use of AR technologies throughout some of its larger department store stockists. The idea is the user can hold the unopened box of $\angle E G O{ }^{\circledR}$, lay it flat in their hands towards a 'Digital Box' and watch a $3 \mathrm{D}$ animation of the product, from any angle and in every detail (Metaio, 2010)

This LEGO $®$ box technology is a direct example of how you can embed the virtual world into the physical/real environment achieving the fundamental basis 
4.4

\section{Augmented Virtuality (AV)}

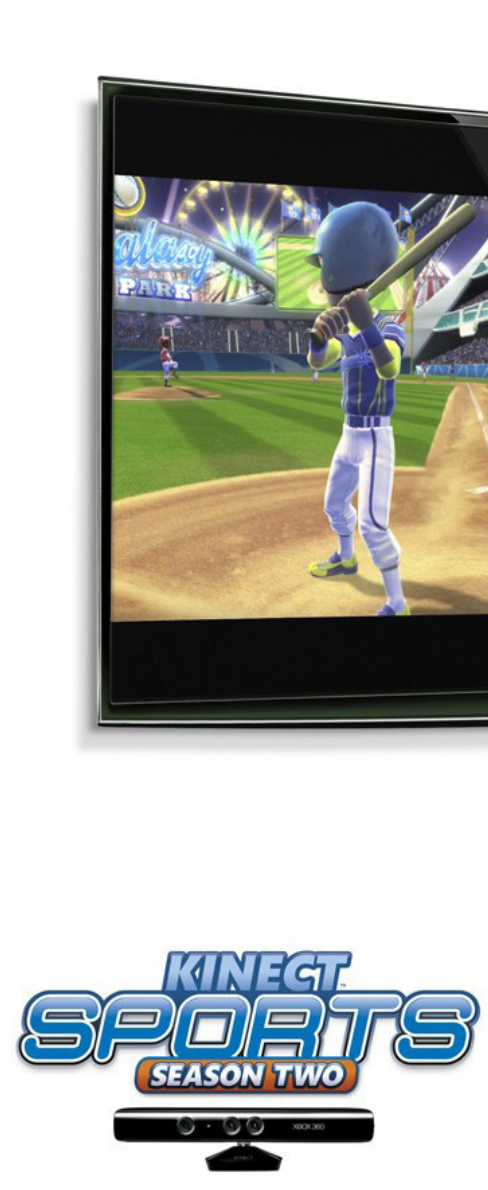

Image 8
Augmented Virtuality (AV) is the third rung along the RealityVirtuality continuum of MR. It is similar to AR where it merges the real and virtual worlds but sits in juxtaposition to it, where a physical, real world object is brought into a completely virtual world. In applications that apply AV the perception of virtual engagement is imperative. A user can navigate through a completely synthetic world and have the choice to interact with either illusory or real objects in real time (Ternier, Klemeke, Kalz, Ulzen, \& Specht, 2012) The Kinect for Xbox 360 is a motion controlled gaming system that allows the user to interact within a vast array of different applications for the product. To name a few, games such as bowling and tennis require the user to stand in front of a television screen while a sensory chip measures light, pixels and depth to perceive and identify objects and the user in real time (Carmody, 2010). 


\section{5 \\ Virtual Reality}

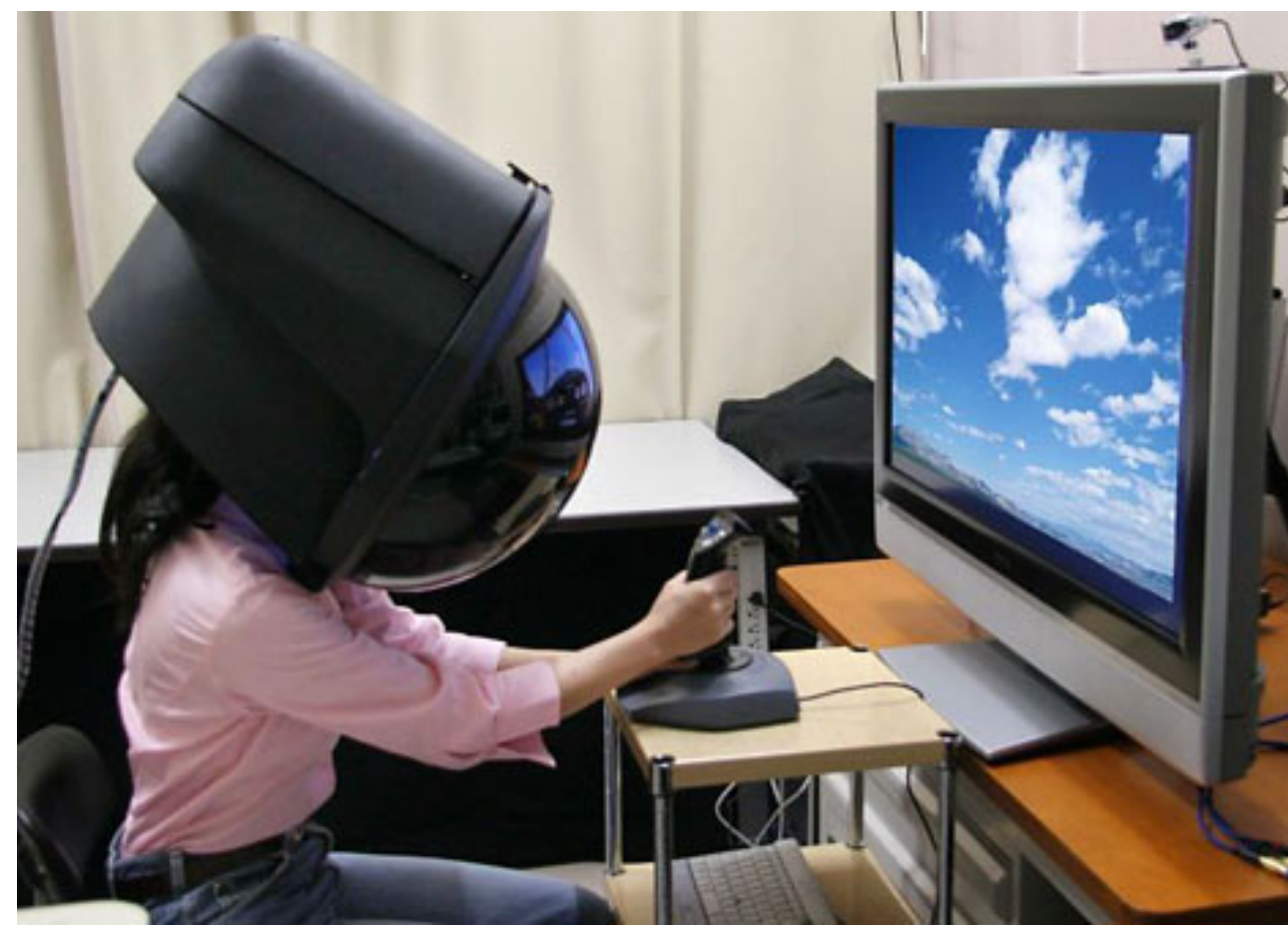

Image 9
The Virtual Reality (VR)

environment is one where the user can only participate when under total immersion of a synthetic environment. The VR surroundings seen by the user may imitate and offer sensory approaches of the physical world but cannot be controlled and used in cohesion with it. However, VR has the possibility to manipulate and surpass all the physical laws we know to create an environment of endless possibilities (Milgram \& Kishino, 1994). VR in its simplest form is a simulated medium where the user can interact with a virtual model in realtime, Author Jennifer Whyte states to '..... present the user with a perspective image which changes as he moves'. Contact within the medium of VR can be seen through varying viewing perspectives and navigation modes where boundaries of physical reality do not hinder what the user sees (Whyte, 2002). Of the four categories VR would be the least seen in the world we live in today, but it cannot be discounted as without it MR and the inclusions AR and AV would not exist. Reality and Virtual Reality make up the sum of parts that is Mixed reality. To experience VR the user would usually wear a headset with a built in screen and headphones to immerse them into a fictitious environment. 



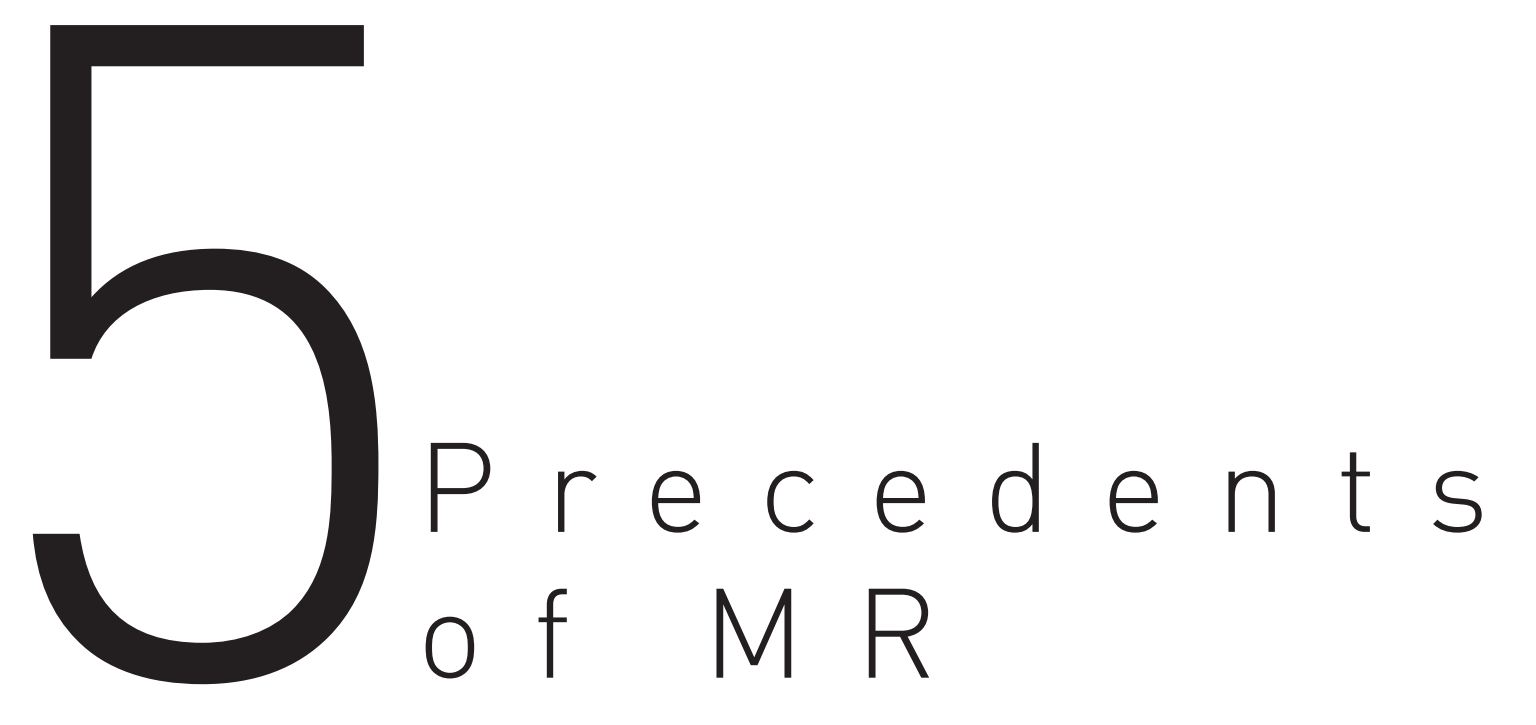




\section{1 \\ Precedents and applications of MR in architecture}

Mixed reality within the built environment can have many uses in today's world as an emergent technology to accentuate architecture for human interaction. New technologies and relatively simple (public access) software it is becoming more and more user friendly as a mechanism to push the boundaries of what defines real world architecture within the world we live today. Augmented spatiality refers directly to a given space that can be seen larger than it actually is; where MR is not a secondary layer to the physical but a fundamental part for a human being to read a spatial arrangement of architecture itself, through the use of the widespread technological tools of tablets and phones. The past, present and future can combine to provide a visual time continuum through a new spatial awareness of architecture.

An affirmative response for my proposal is to accept architectural theory, history and social aspects of Christchurch to produce an architecture that offers psychological and built meaning through mixed reality within the past, present and future. The past pertaining to what was, the present to offer what is/has happened and the future to offer hope for what is to come. Just as the 'Star Walk for iPad' application does for astronomy I would like to implement into a Museum for Christchurch and its broken city. The information age has informed us to experience the physical world in a whole new light, triggering senses and altering perceptions of the mind to accept different understandings and learning's we never thought possible. 


\section{2}

\section{The Wall}

Gibson Group and the Museum of Copenhagen
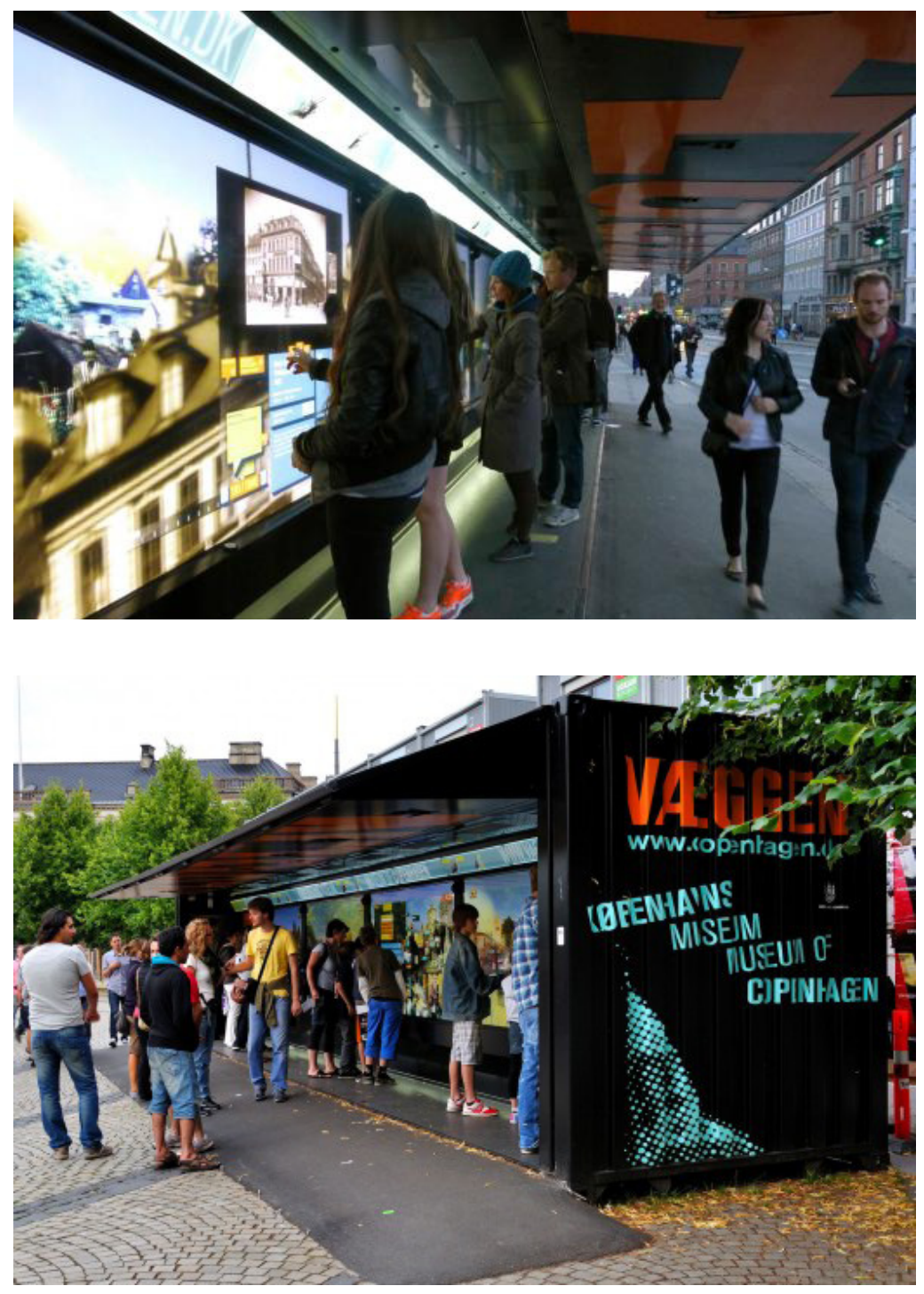

Image 10 \& 11
The Wall or as it's known in Danish, Væggen was designed and built by the Gibson Group in partnership with the museum of Copenhagen. The Wall is a 12 metre long and 2 metre high moveable interactive plasma screen that allows multiple users to navigate through the city of Copenhagen. It uses a trademarked interface engine to produce $3 \mathrm{D}$ visualisations the user can experience in realtime by swiping there hand over the screen in the same way you would with a phone or tablet. The Wall not only acts within the current context of the present but also allows the user to travel back to a specific point in Copenhagen's history and see which or what buildings, monuments or streets existed at that point in time. Not only does the full 3D cityscape appear upon the screen at the date chosen but by tapping on specific "hot spots' in the 3D model you can gain information about that feature you wish to know more about. The Wall also responds in a socially interactive setting where the user can leave notes and thoughts on their chosen positions to personalise their experience with the digital city; which in turn others can access when they come across that particular image or setting. Users also have the option of uploading their own images to The Wall via USB or their mobile phone creating a constant feed of new information.

The Wall provides a lot of the distinct characteristics that will be implemented as part of my design, it demonstrates a real connection with

augmented reality that incites public curiosity and acts as an enjoyable learning tool for the wider public to interact with. The execution of the touch screens in my design would have to perform at this level, offering digital visualisations into the past, present and future of Christchurch whilst also extending on the idea to provide a take home, access wherever, interactive learning tool. The concept of being able to scuttle through architectural history being received by the user through a digital interface is a fundamental part of this thesis. 


\section{3 \\ Museum of London}

NFC Enabled Exhibits
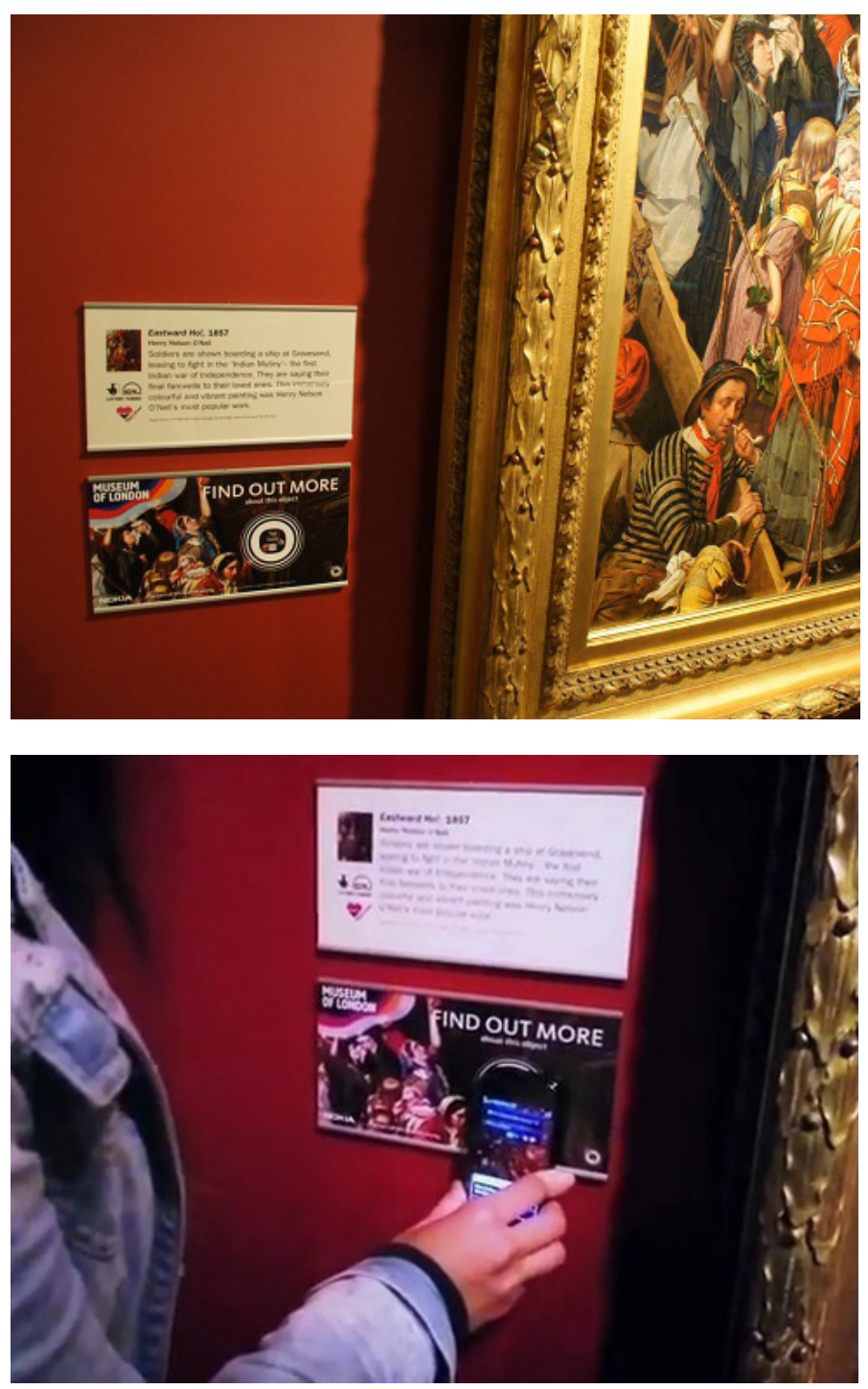

Image $12 \& 13$
The Museum of London offers visitors with NFC capable phones to interact with their exhibits at a greater level. The idea is rather simple and consists of you placing your phone against the NFC tags located near the exhibits to transmit information that allows you to unlock additional information about the exhibit for a more in-depth understanding. The information passed from the NFC tags to the phone sends a signal to connect online to receive the information through their phones. The information correlates specifically to the exhibit the user has just tapped with their phone.

This feature using your NFC enabled phone at the Museum of London also allows for:

- Access to discount vouchers for the Museum cafés and shops

- The option to buy digital books related to London's history

- Instant like, share and check-in notifications to your Facebook, Twitter and Foursquare accounts

- Downloads to a range of Soundtracks provided by the
Museum of London

- General visitor information on access to the varying exhibits

NFC technology used in this way makes the exhibits more interactive and provides more information to the people using it. It helps gain a better understanding and produces a more involved experience with the Museum as a whole. The augmentation of reality and an exponential growth in the NFC market place provides the museum to reach and contact users at a far deeper level than before. These are all key components to being part of a wider culmination to form this thesis. 


\section{4}

\section{Augmented Structures v2.0}

Refik Anadol and Alper Derinbogaz

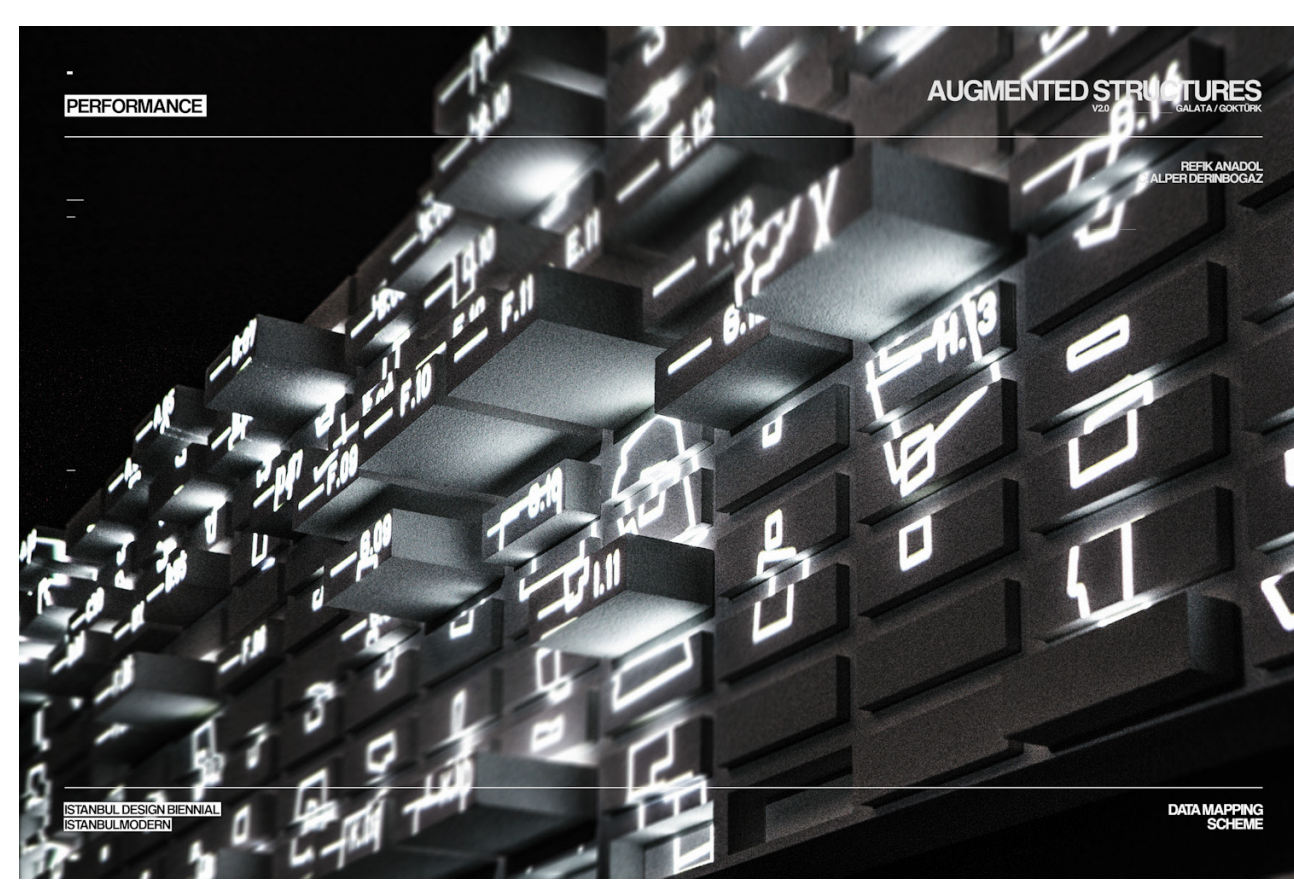

Image 14
Augmented structures v2.0 is a refined urban experience project that concentrates on two contrasting regions of Istanbul, Turkey. The project sets to demonstrate the

characteristics and textures of the two regions city centres that have both undergone a recent transformation in adapting to suburban gated communities. The work involves data mapping and the ever present soundscape of humanised communities to try and understand the two regions in a new light. A new context of understanding is realised when the underlying invisible information of the two regions combines and suggests an alternative way of existence for urbanized environments when looked through new media technologies. The Augmented Structures v2.0 team bring together contrasting disciplines like sound, architecture and the visual arts to develop and re-examine how the world is visualised in aesthetic terms. The structure reacts with itself when exposed to the three disciplines, taking on different shapes, producing different sounds and contrasting graphics. Anadol and Derinbogaz describe the augmented structure as "transforming sound into mathematics, mathematics into architecture and architecture into a living structure". This installation provides the user to experience a new media that is multi-levelled, produces sound, moves and breathes.

This installation still adheres to rules of mixed reality but doesn't directly associate itself with the user. The augmentation of reality is produced pre-exhibit when gathering the information of sound and data mapping but is relayed to the viewer through this new media experience.

The use of these techniques is important to this thesis to gain the experience of the augmented virtuality world seen in the final act of the design. 



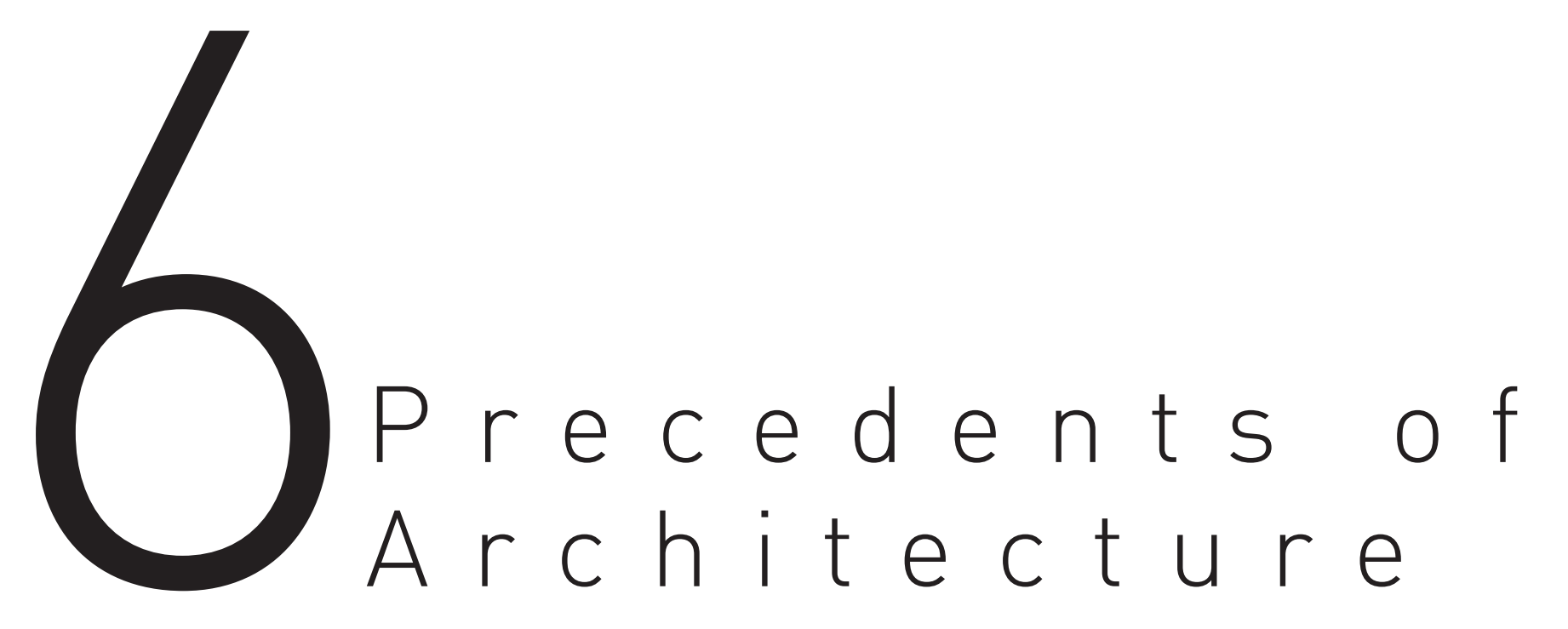




\section{1}

\section{Four Public Squares, The Tower of Leonforte.}

\section{Rodolfo Machado and Jorge Silvetti}

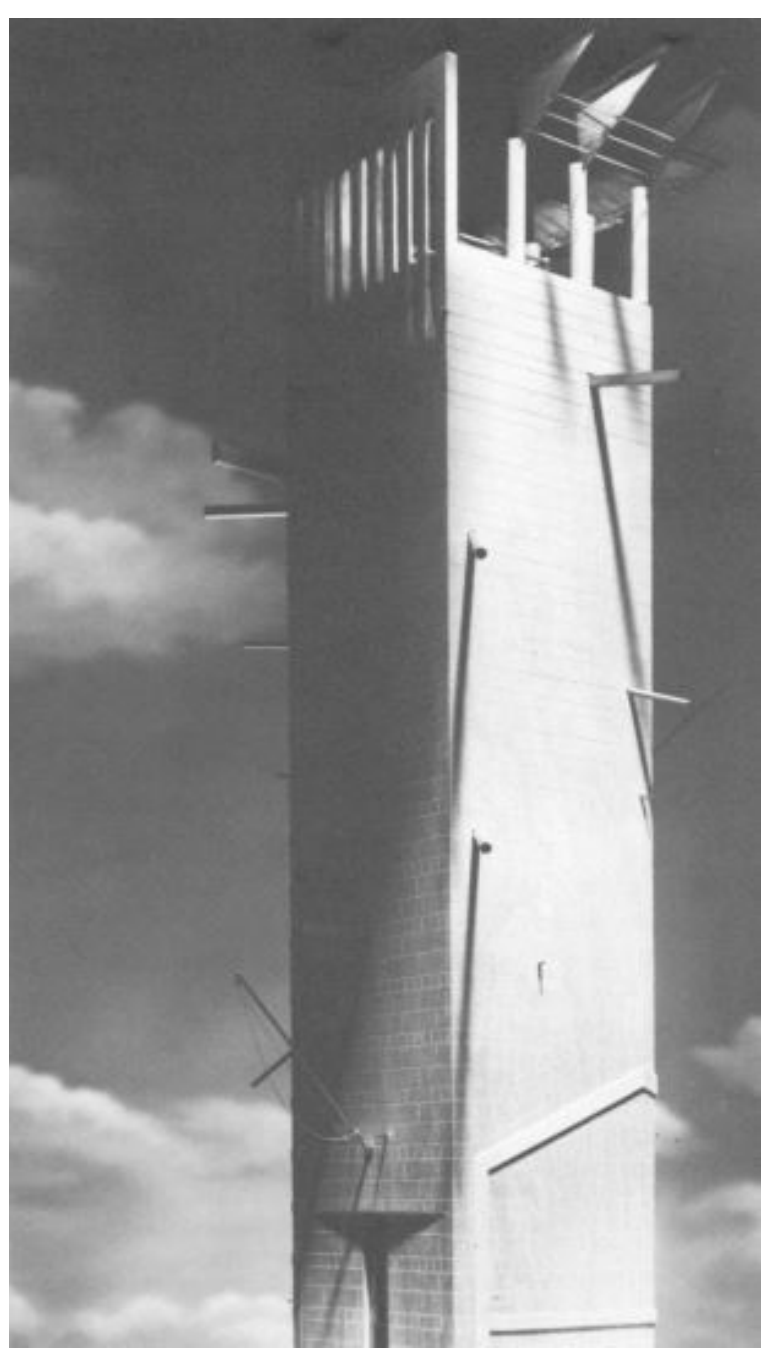

Image 15
Four Public Squares was a master planning proposal and tower design for the city of Leonforte, Sicily. The city's program requirements called for the reorganisation and redesign of four existing public spaces.

The architects Rodolfo Machado and Jorge Silvetti attended to the proposal and also put forward a design for a distinguishing tower to stand tall over the city (Rowe, 1989). A reintegration and rejuvenation of the old centre with the old city was the primary concern among Machado and Silvetti, to bring back what once was to fruition again.

Sight lines of city significance dictated the understanding of the intervention, and the analysis of the iconography and typology of the cities architecture deliver avenues for the intended choices Machado and Silvetti made for their intervention in relation to the existing buildings of the city. (Silvetti, 1986)

The tower itself is unmistakably the most important architectural element to the overall scheme and is where this thesis engages with this proposal. The tower is concerended via a long spiral staircase and due to its precise location the tower acts as a marker of reinvention for the city of
Leonforte. The notion to extrapolate key visions and important events of the city are experienced through the tower by allowing telescopes to pierce the towers exterior and reach into engage the user as they ascend. Dominance is projected through the architectural dialogue of the towers height but its functional value provides much more to the city as a new perspective engagement of personal rejuvenation for the city of Leonforte (Rowe, 1989).

"The tower reunites a dislocated, twentieth-century Leonforte by bringing together its most important monuments and urban events." (Silvetti, 1986)

This act of uniting important aspects of the cities heritage and engaging the public through an architectural dialogue is the fundamental basis for the final space of my design. 


\section{2}

\section{Warehouse 17C}

\section{Matadero, Madrid}

\section{Arturo Franco Diaz}
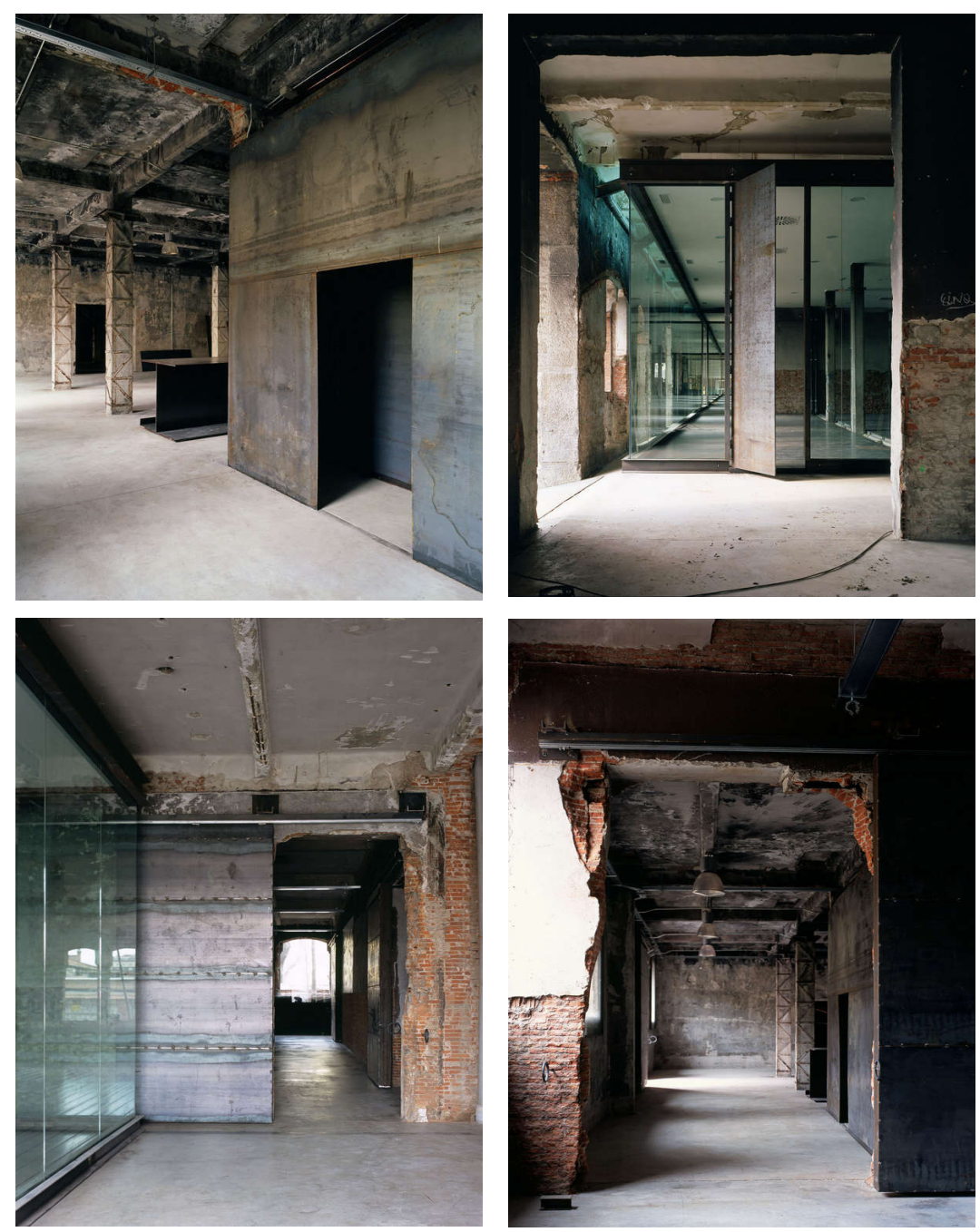

Warehouse $17 \mathrm{c}$ is located in Matadero, Madrid; it is an ongoing project of innovative interiors encapsulated within a neglected slaughterhouse. The city council and the city arts council operated together as clients to investigate a new usage for the derelict spaces. (de Goeij, 2011) The warehouse $17 \mathrm{c}$ responds programmatically to the needs and promotion of contemporary creation by means of a program of scholarships and initiatives involving artistic production and public contribution.

The intervention is the opportunity of the designer to explore the possibilities of refurbishment to elevate patrimony whilst keeping the design dialogue reduced to a necessary minimum.

"We made no concessions concerning refurbishment, respecting the ruin, boosting its values with minimum intervention. A constant dialogue has been established with the new and the old, without mixing them up, together but not blended" (Franco, 2011)

This understanding of a project that rejects the notion of saturation and application of major architectural interventions actually alleviates and progresses the space as its intended program. The light touches of

design intervention relates perfectly with this thesis to pay homage and not detract from the crumbled beauty inside. 


\section{3}

\section{The Waterhouse Boutique Hotel, Shanghai, China}

Lyndon Neri and Rossana Hu
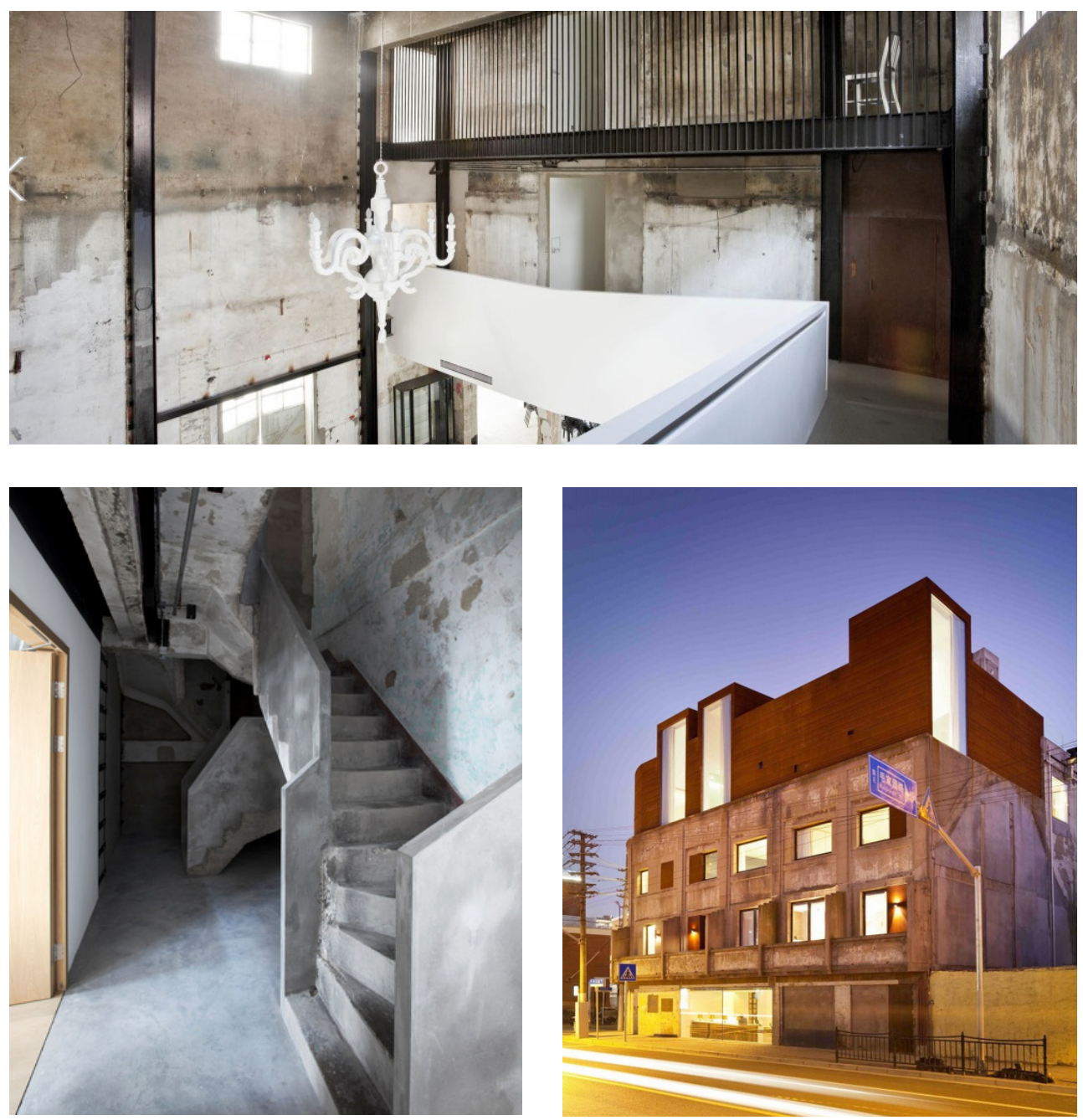

Image 20, 21 and 22
Located in the South Bund

District of Shanghai a boutique hotel design by Lyndon Neri and Rossana Hu comes to life within an ex Japanese Army headquarters. The original 1930's concrete building has been left in its raw state with Neri \& Hu's renovation projecting a clear contrast between the old and the new. This 19-room boutique hotel investigates taking an old rundown concrete structure and reinventing its purpose whilst also adding new additions that are built over the existing structure with Cor-Ten steel. Neri \& Hu discuss the structural addition to the fourth floor as providing a contextual link to local culture and history that resonate with the old industrial nature of the ships that pass through the river.

The design of the interior of the hotel is described as being purposefully disorientating to offer a fresh spatial experience where lines are blurred between the public and private realms as well as an inversion of exterior and interior spaces. The public spaces allow small apertures into the private rooms whilst the private spaces offer views inwards towards the main dining hall and over other public arenas. This architectural move by Neri and Hu forces the user to confront the conditions of the local shangai urban condition itself with all its visual corridors and tight spatial qualities it has to offer.

The Waterhouse is a really sound example of the design direction that seemed fitting to this thesis. It doesnt completely remove itself from the original structure, only coating and guiding the user through its new spaces, touching the building lightly whilst offering a fresh dynamic. 




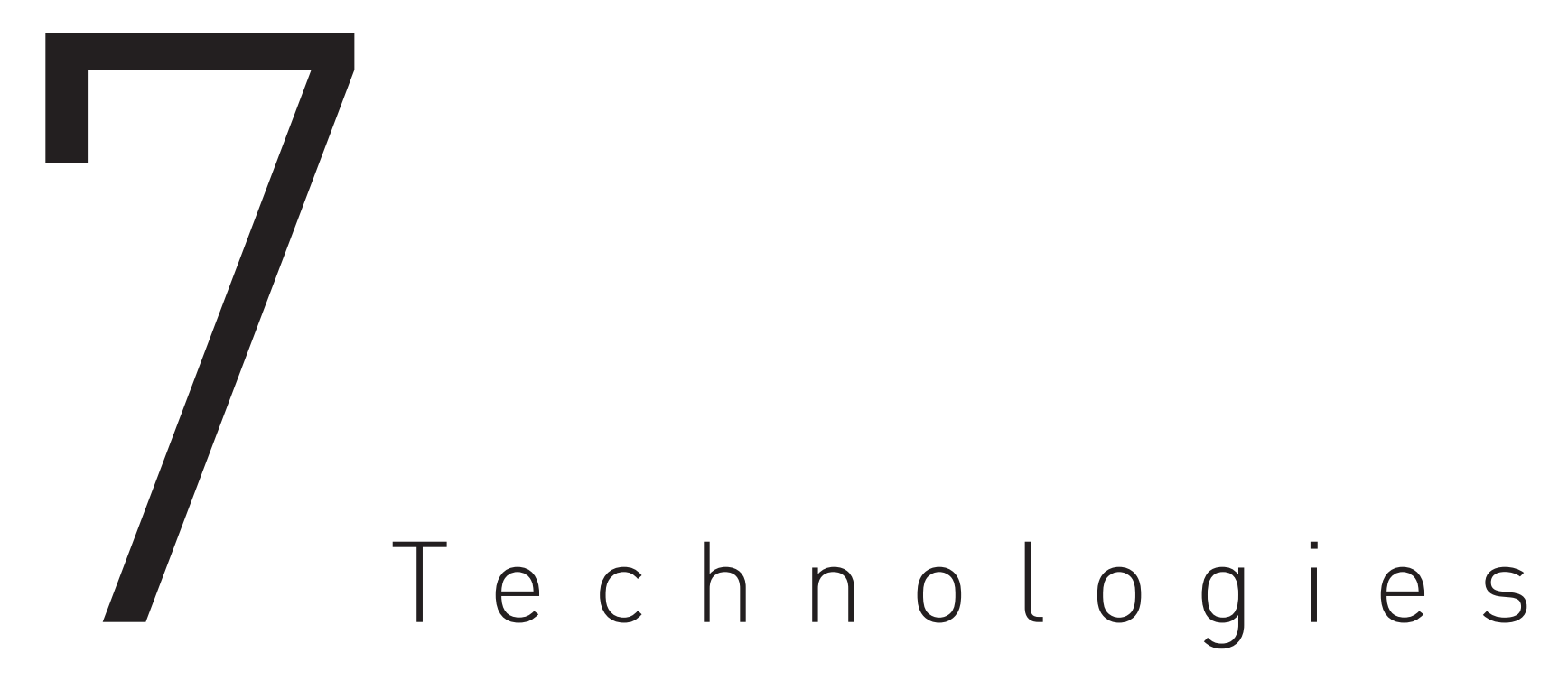




\section{1}

\section{Near Field Communication (NFC)}

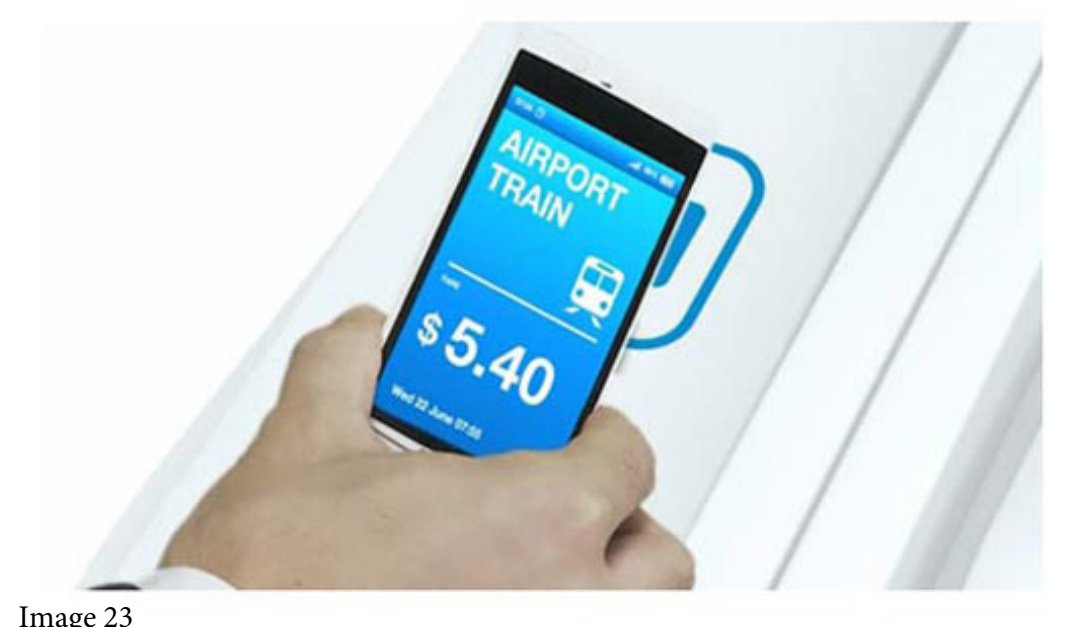

Near Field Communication (NFC) is a short range, low power consumption technology that allows two devices to respond to each other. Using magnetic induction technology NFC generates a radio-wave field that allows the two devices to share information with each other (Nosowitz, 2011). NFC sounds much like Wi-Fi or Bluetooth technology that has been available throughout the world and within our homes for some years but has a few distinct advantages. NFC has a very low time connection speed of 0.1 seconds compared to Bluetooth which takes 6 seconds. The 'Near Field' aspect to the NFC technology refers to the wireless connection only being available when the device and NFC tag are approximately $4 \mathrm{~cm}$ away from each other, if this length is exceeded the connection is terminated. Other than turning the NFC on inside the phones settings it involves no other user configuration. When the NFC capable device connects to a NFC chip which is placed near or on an object, this connection then initiates a download to the device consisting of information like audio, video, photos or text related to that object.

The NFC technology will be a key application in my design to provide a link between the outside digital world and the users connecting within the space. NFC technology allows the museum to set the rules in what the user participates in throughout the space as it will only let the user to have information stored on their phones that relate to the wall display the can interact with. When the user's device is connected to the NFC technology portals it will send a signal to engage the use of the transparent multi-touch LCD displays. If the device is removed from the NFC connection hotspot then the LCD displays turn off and goes back to its original transparent appearance. When the device is connected the information the user is scrolling through or looking at on the LCD screens will be loaded onto their device so that they can engage with it at a later date. 
7.2

\section{Transparent Multi-Touch LCD Displays}

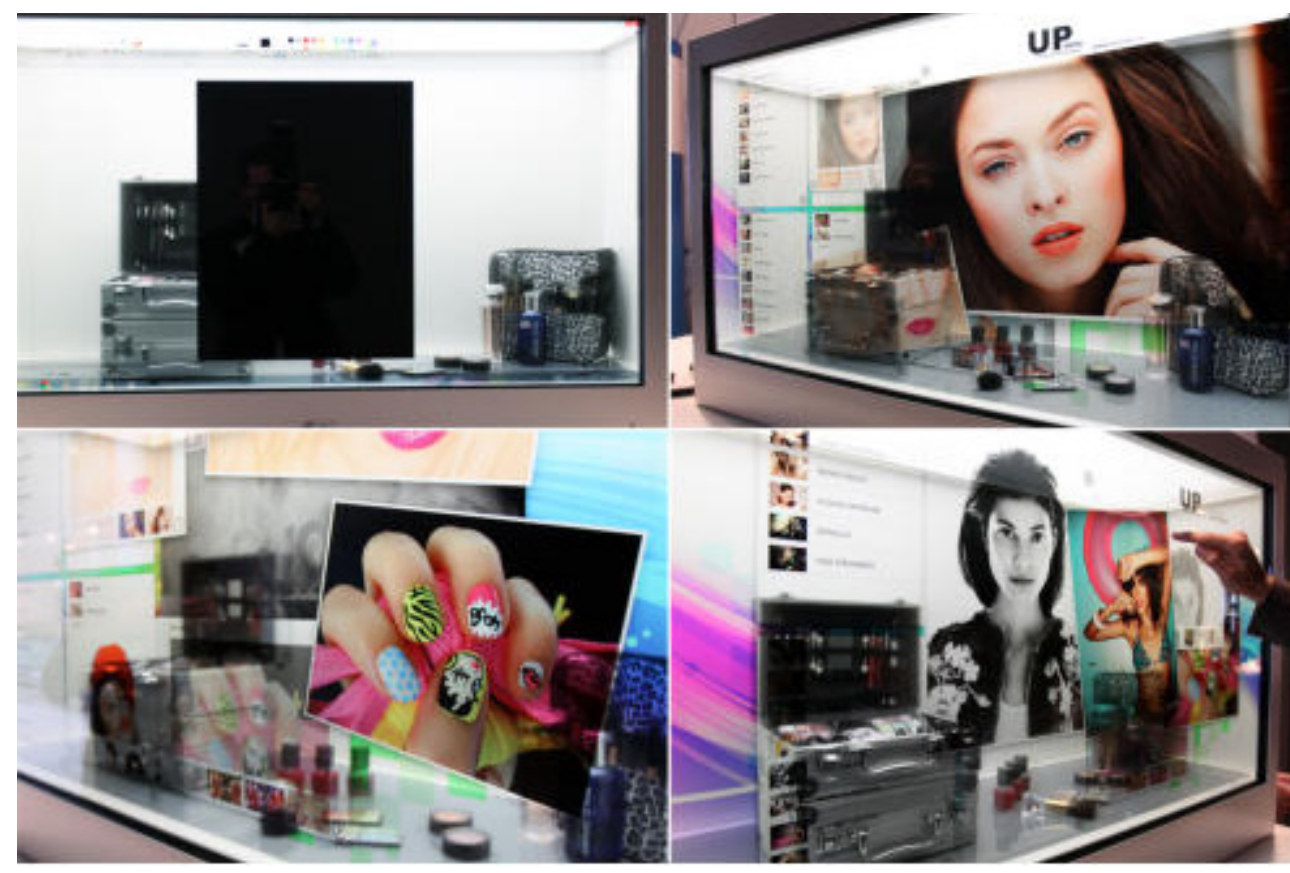

Image 24
Transparent multi-touch LCD displays contain technology that is unseen but vital in devices such as smart phones, televisions, tablets and other multi-touch screens (Poor. 2012). Transparent displays are a relatively new technology that lets the presenters display real life objects behind them whilst playing digital content on the glass itself. The display acts in exactly the same way as you would use your Ipad, tablet or phone by swiping through to access the content you need. This technology is vital to this thesis logic by allowing historical content to be present across two realms, the digital and the physical. By laying this screen in front of a derelict wall the user will be able to see right through it as well as access content right on the face of it.

Placing the transparent touch screens over destructed walls in the CPCB will offer a sense of being able to see the present original history while being able to access digital history at the same time. 

Preliminary

Designs 

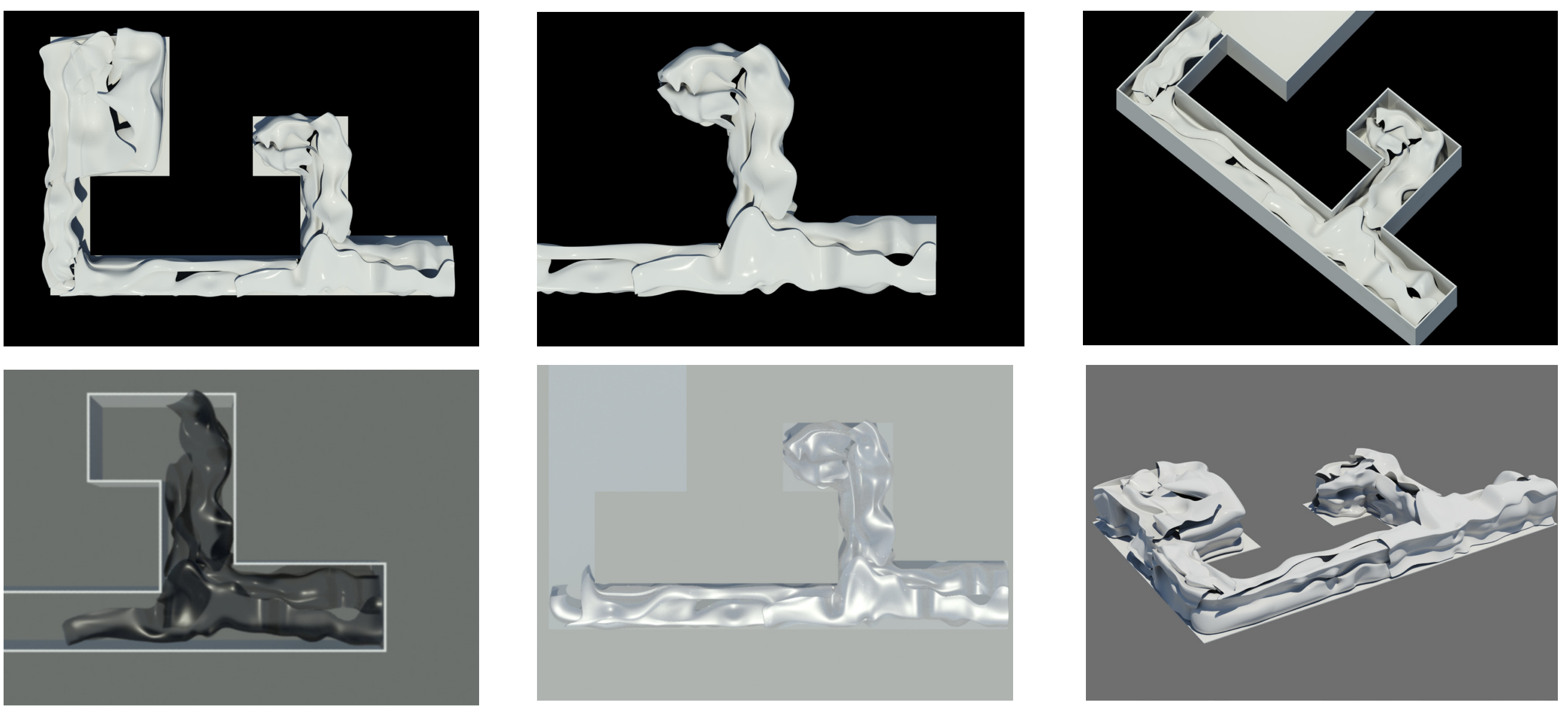

An expermentation of free flowing forms that would act like a new second skin, holding the destructive nature of the building at bay. This initiative whilst exploratory receeded the idea of memorialising the current history of the spaces. 

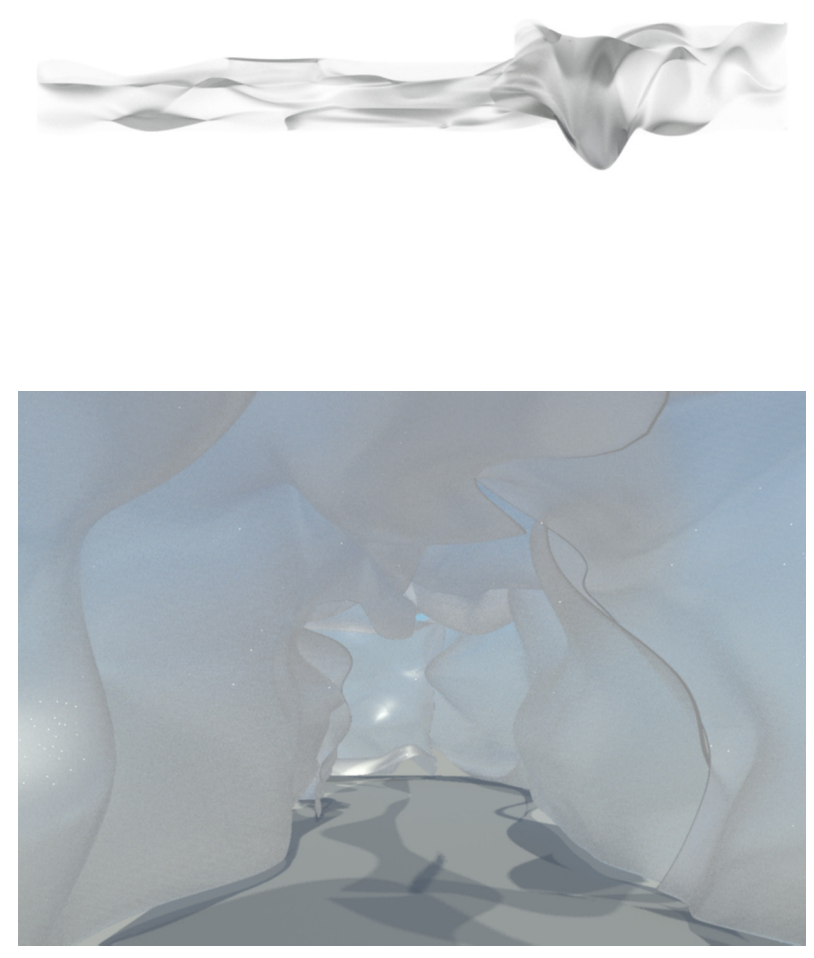
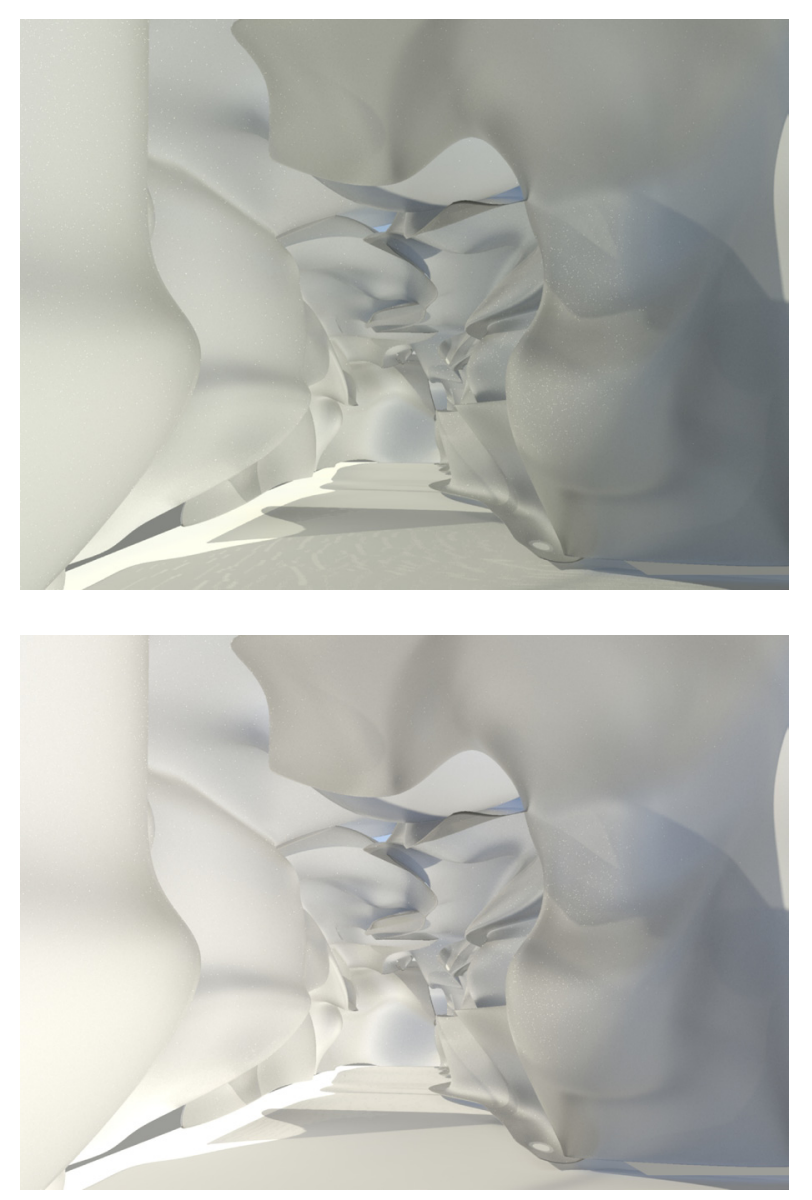
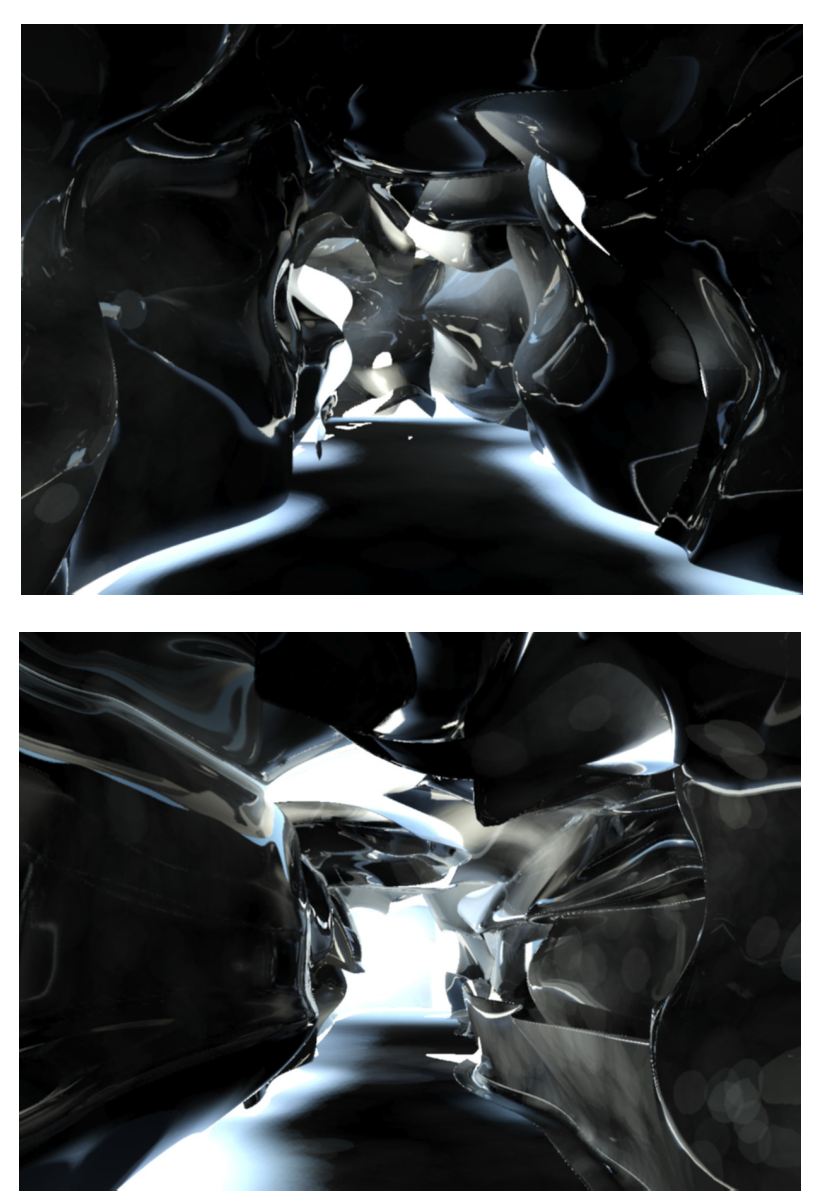

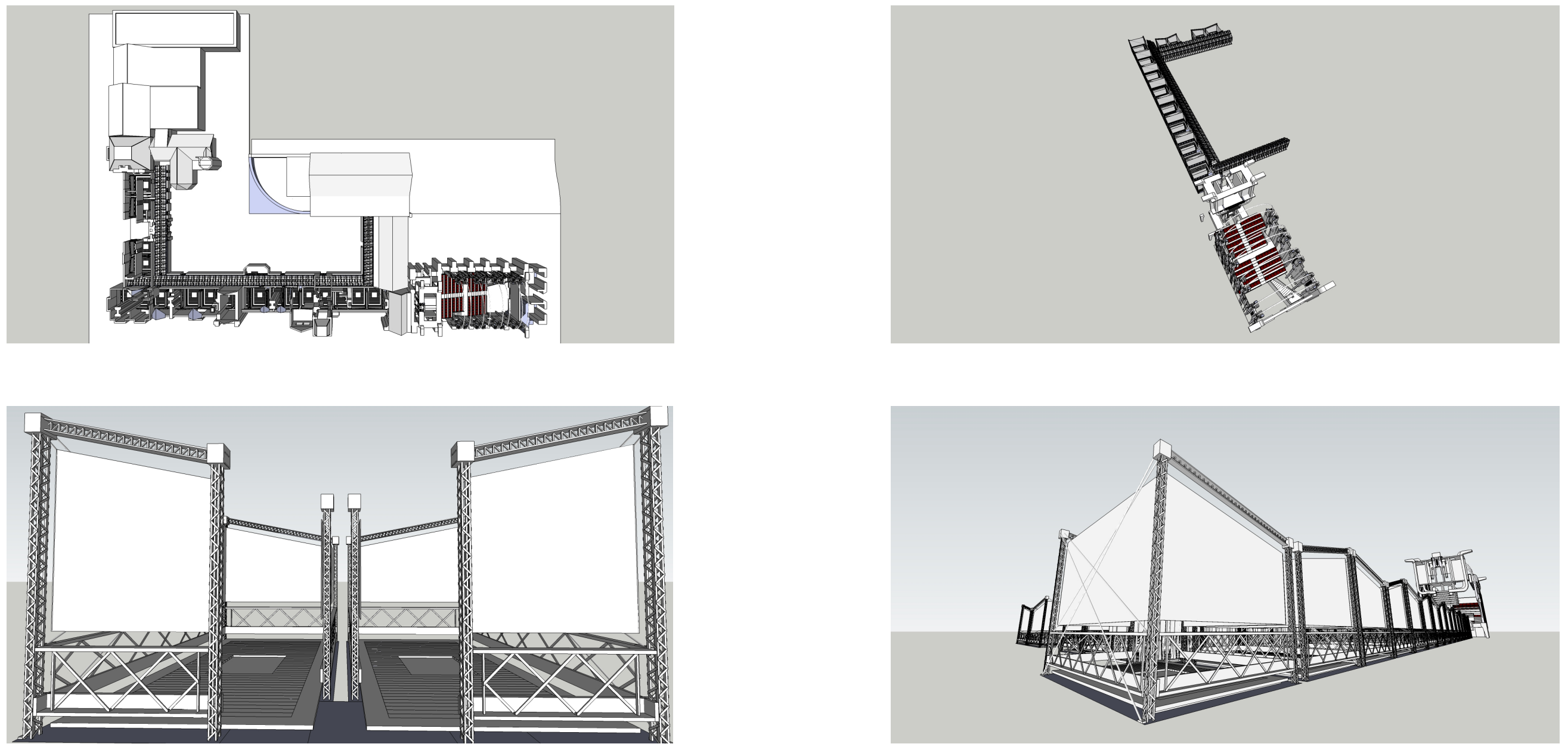

This was an attempt to create a mechanical type of architetcural intervention that would offer the idea of creating new bones for the building. I was too rigid and formalised in its appearance and detracted from the overall idea of accepting the buildings itself. 

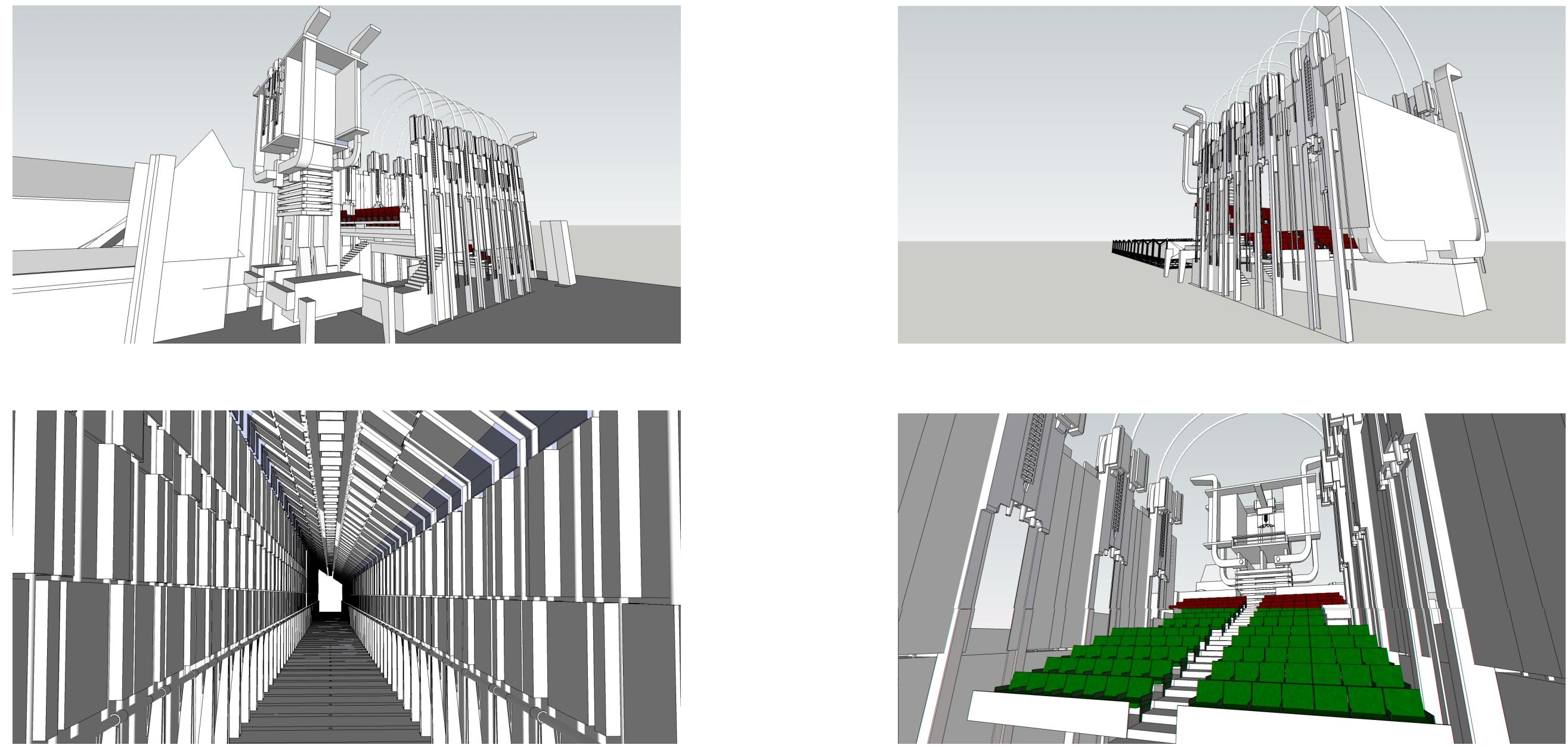

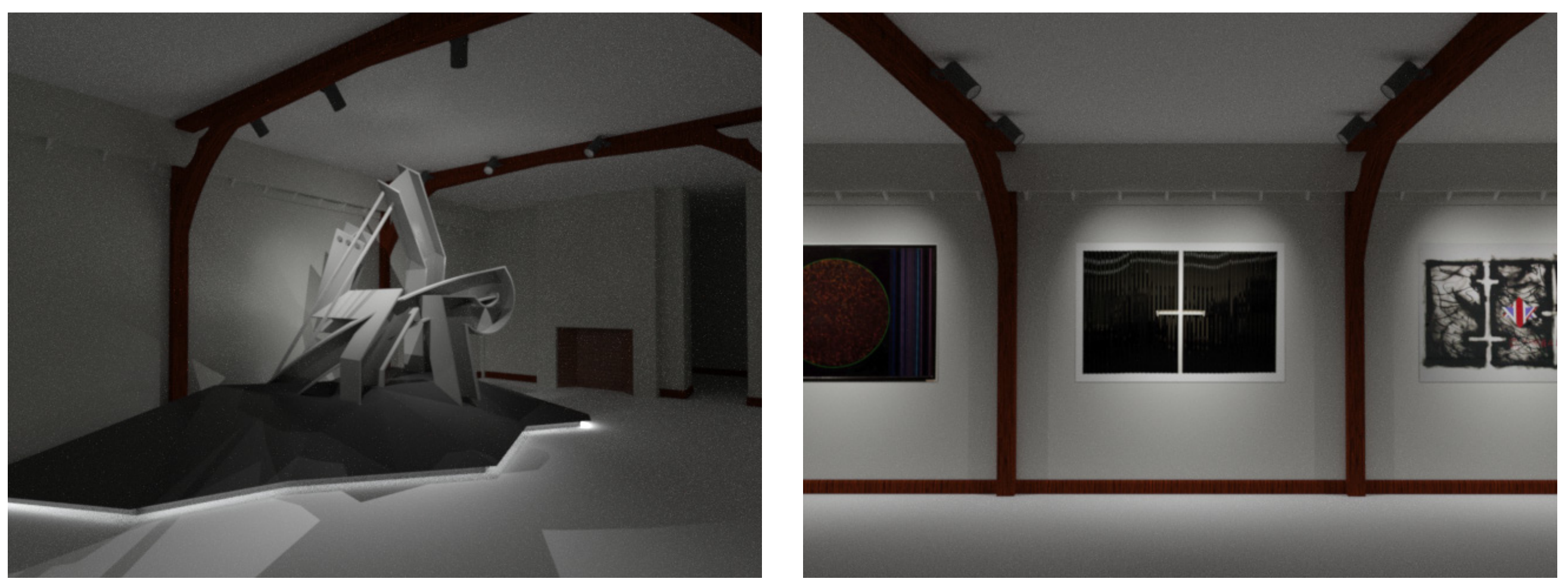

These images played towards a design idea that consisted of a public art space where it would interchange and become a new buildign to house artworks that would interchange over time. This idea was detrimental to the thesis plan as building to expose past, present and future heriatge learnings about Christchurch. 



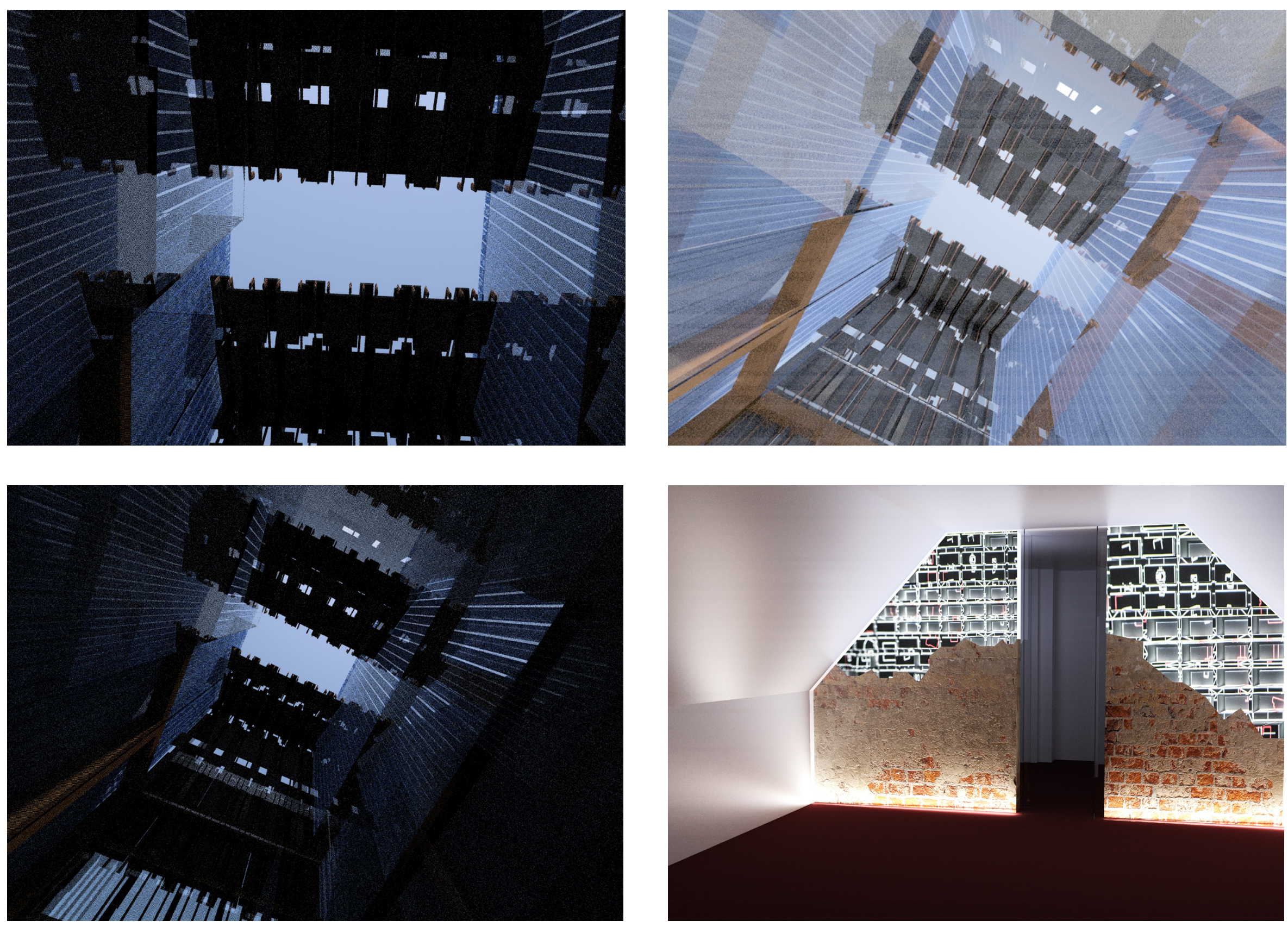



These were a series of mixed reality experiments of how solid objects could be test with the digital and try to perform in the same realm. It was misleading and overall took away from the buildings purpose, aside from looking visually quite radical and inventive the content would be lost in translation. 

Design 


\section{1 \\ Design Introduction}

This chapter will focus on the physical intervention of an interior architecture within the Canterbury Provincial Council Building. It will discuss the tangible infiltrations as an instigator to define spatial pathways throughout the memorial museum's MR experience.

A series of interventions within the spaces will be discussed and a narrative restored to offer a new life to the derelict space. The four points of MR from chapter 3 combined with the application of architectural forms will apprise the circulation journey from entry to exit within the building. This will all culminate to inform a new existence for the CPCB as a MR memorial museum for Christchurch.

As the CBPC is so incredibly damaged the interior architectural intervention takes place along the northern and western sides of the buildings ground floor. The areas comprise the region of the building constructed of timber and interior brick which managed to sustain complete demise so to be able to form an interior architecture for this thesis

This chapter will follow a visual and descriptive journey through the major points of the memorial museums spaces. The journey will expel and progress on researched precedents talked about in this thesis. Combining the use of the physical and digital interventions this design produces an interior architecture that works as a medium to provide insight and understanding about the lost built environment to the city of Christchurch and the devastation it has endured. This design will also provide a greater understanding of Christchurch's past, present and future that will inspire hope and knowledge for the people of Christchurch. 
9.2

Circulation Plan

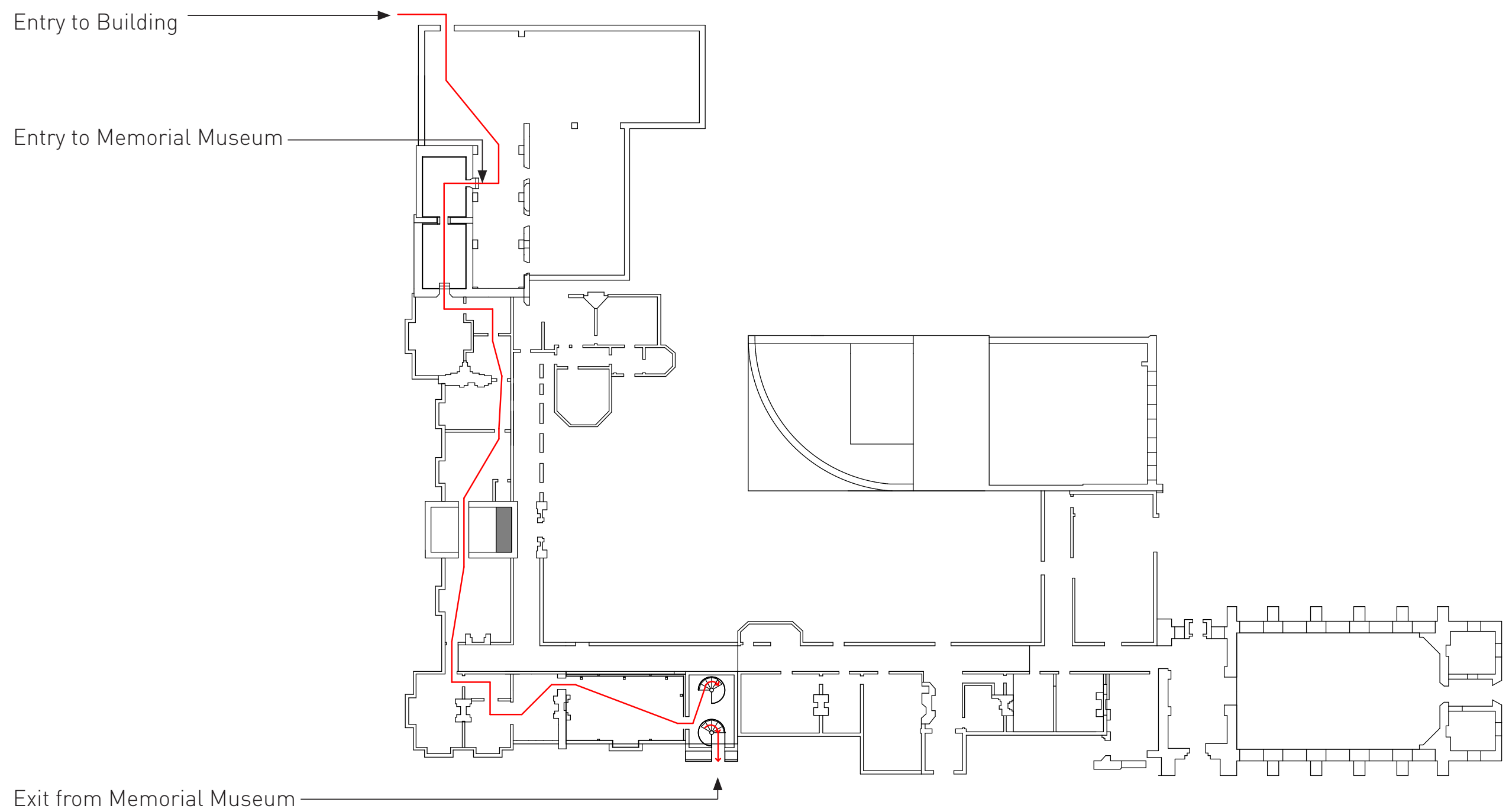




\section{3}

Mixed Reality

Narrative Plan

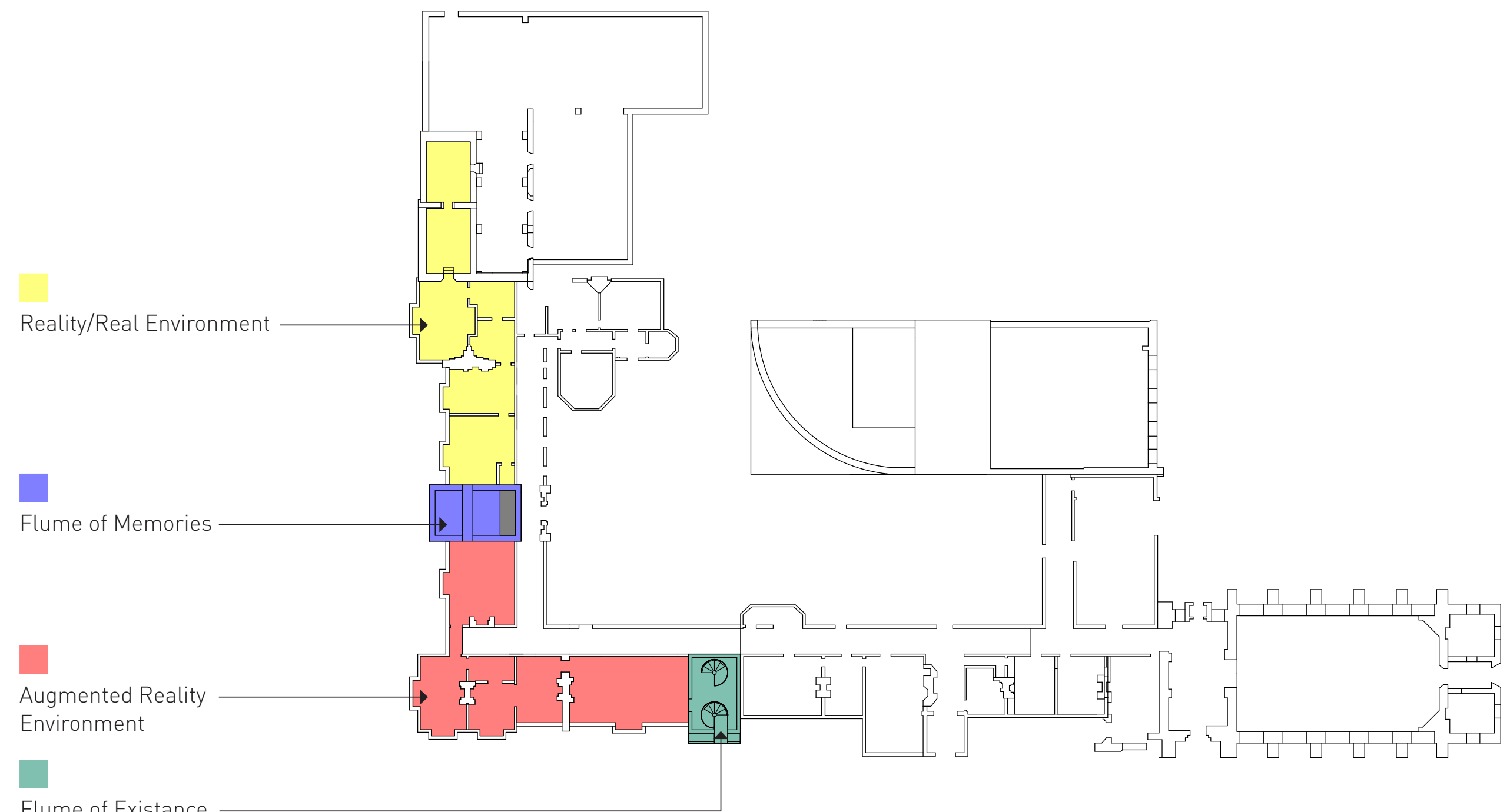

Augmented Virtuality Environment 
9.4

Sections and Elevations

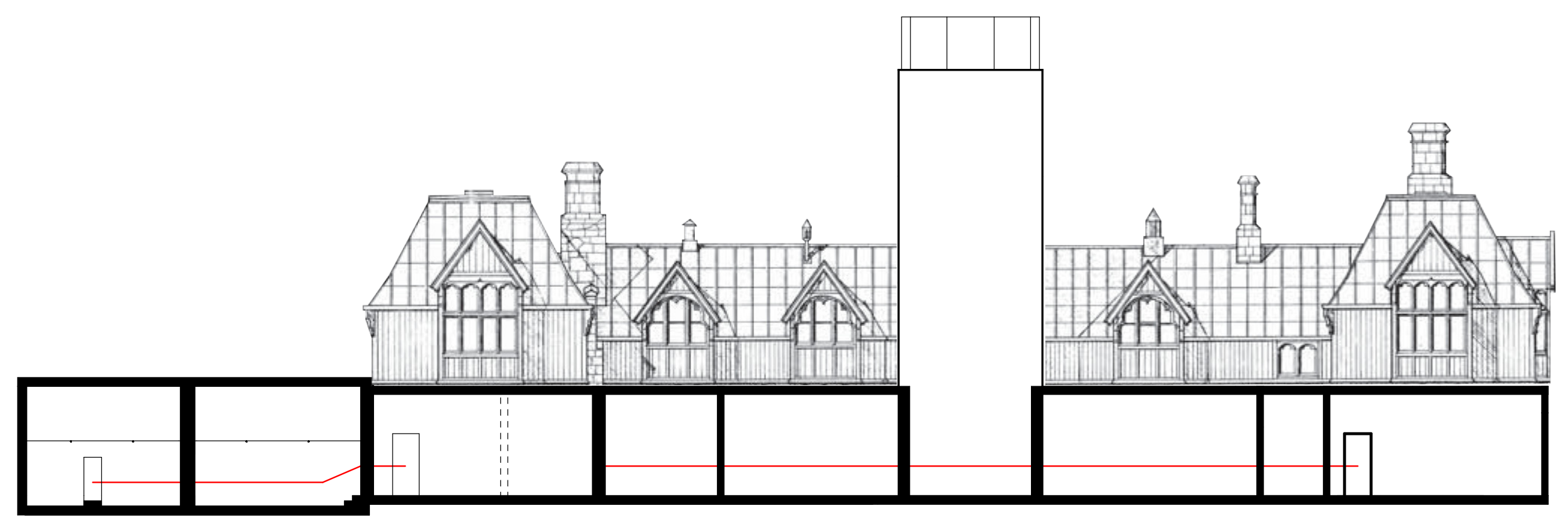




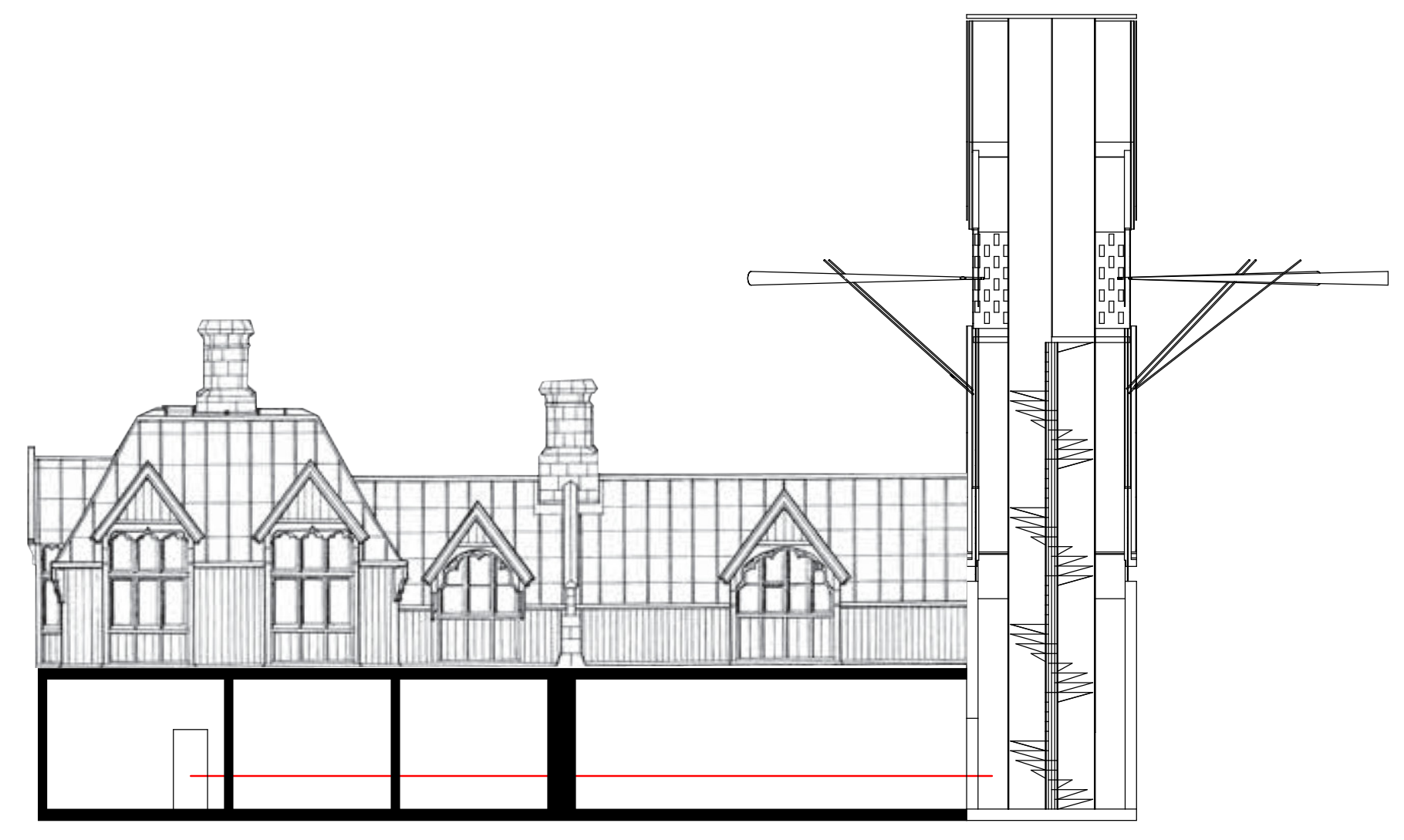





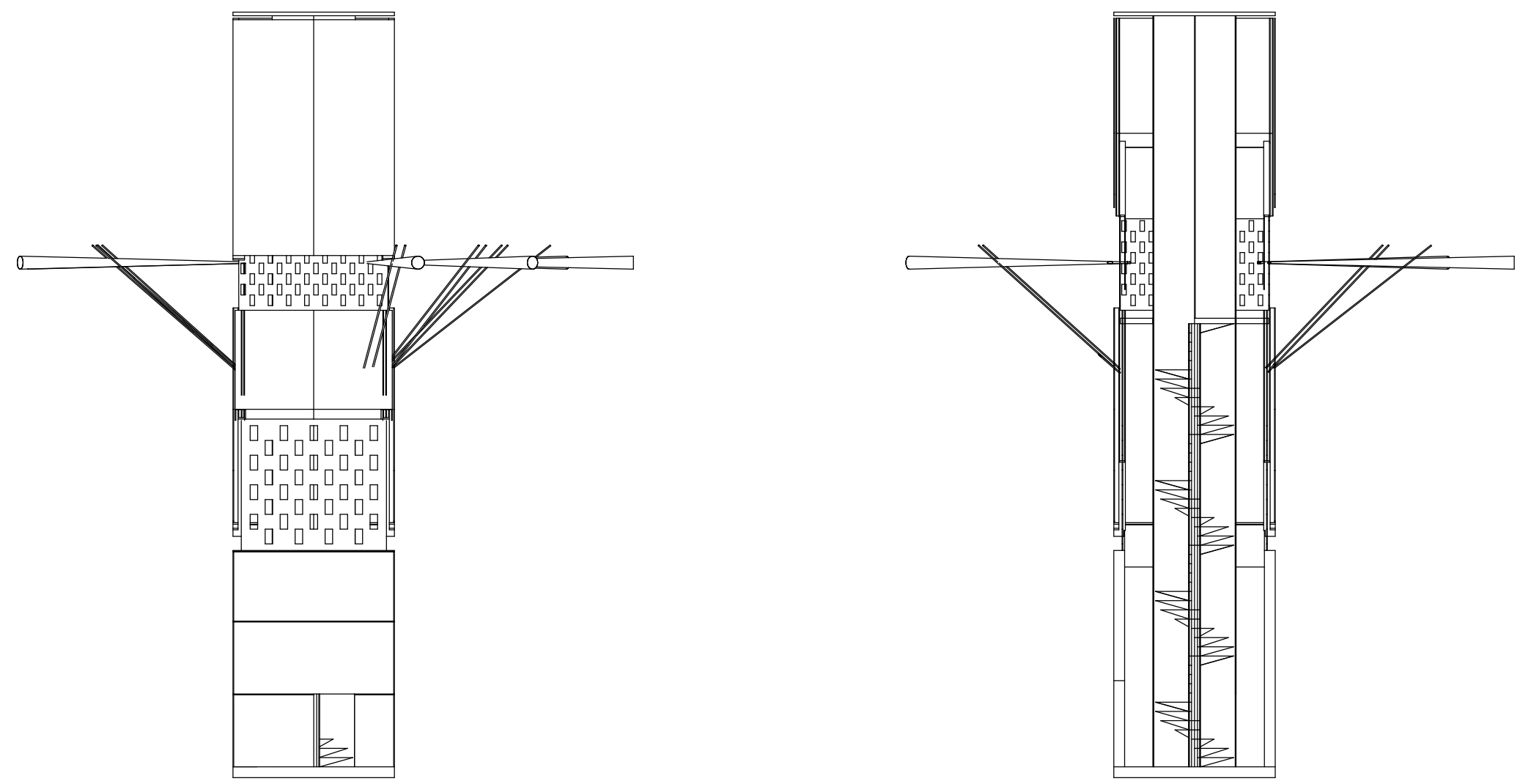

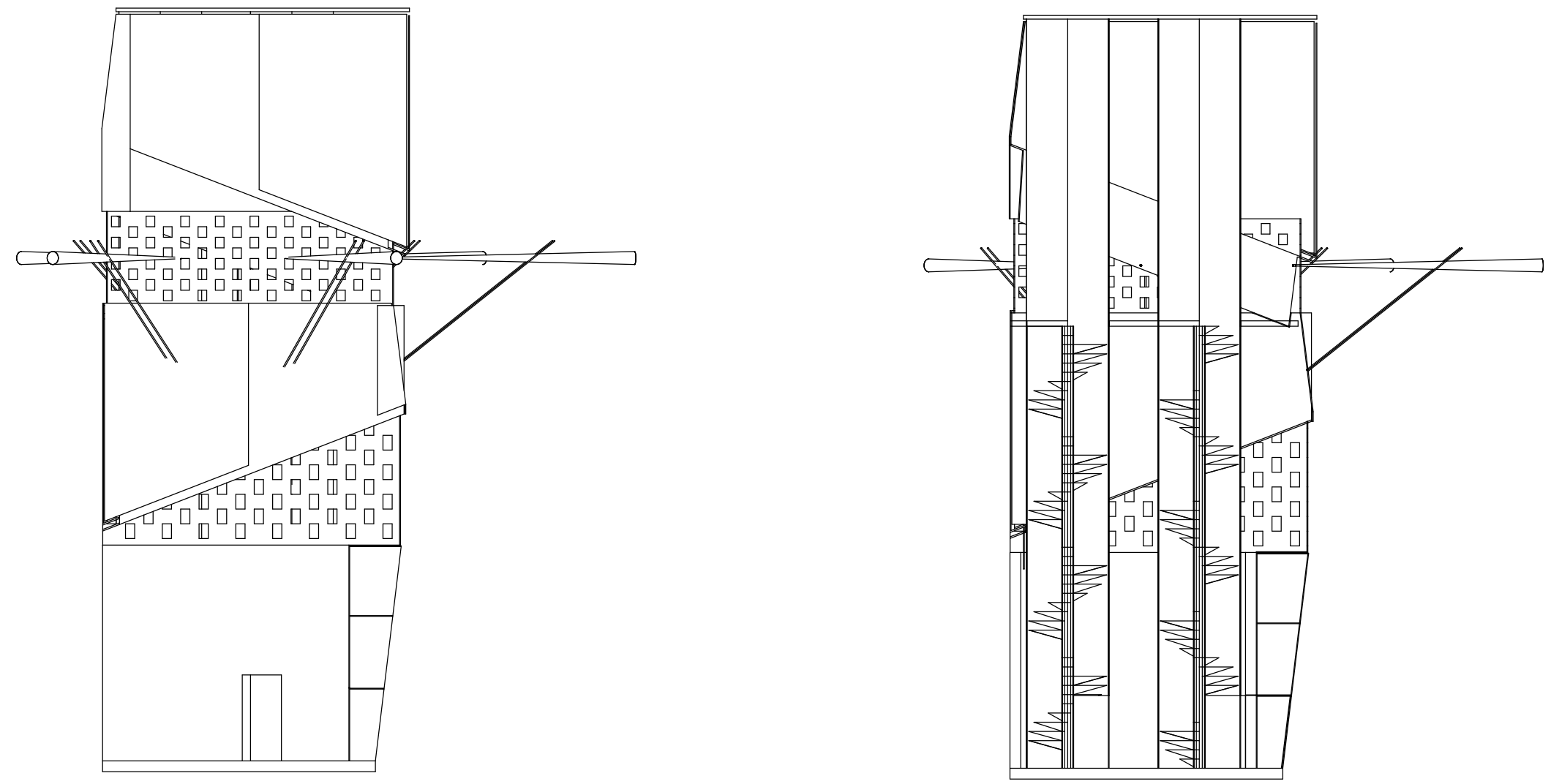


\section{5}

\section{Design Narrative}

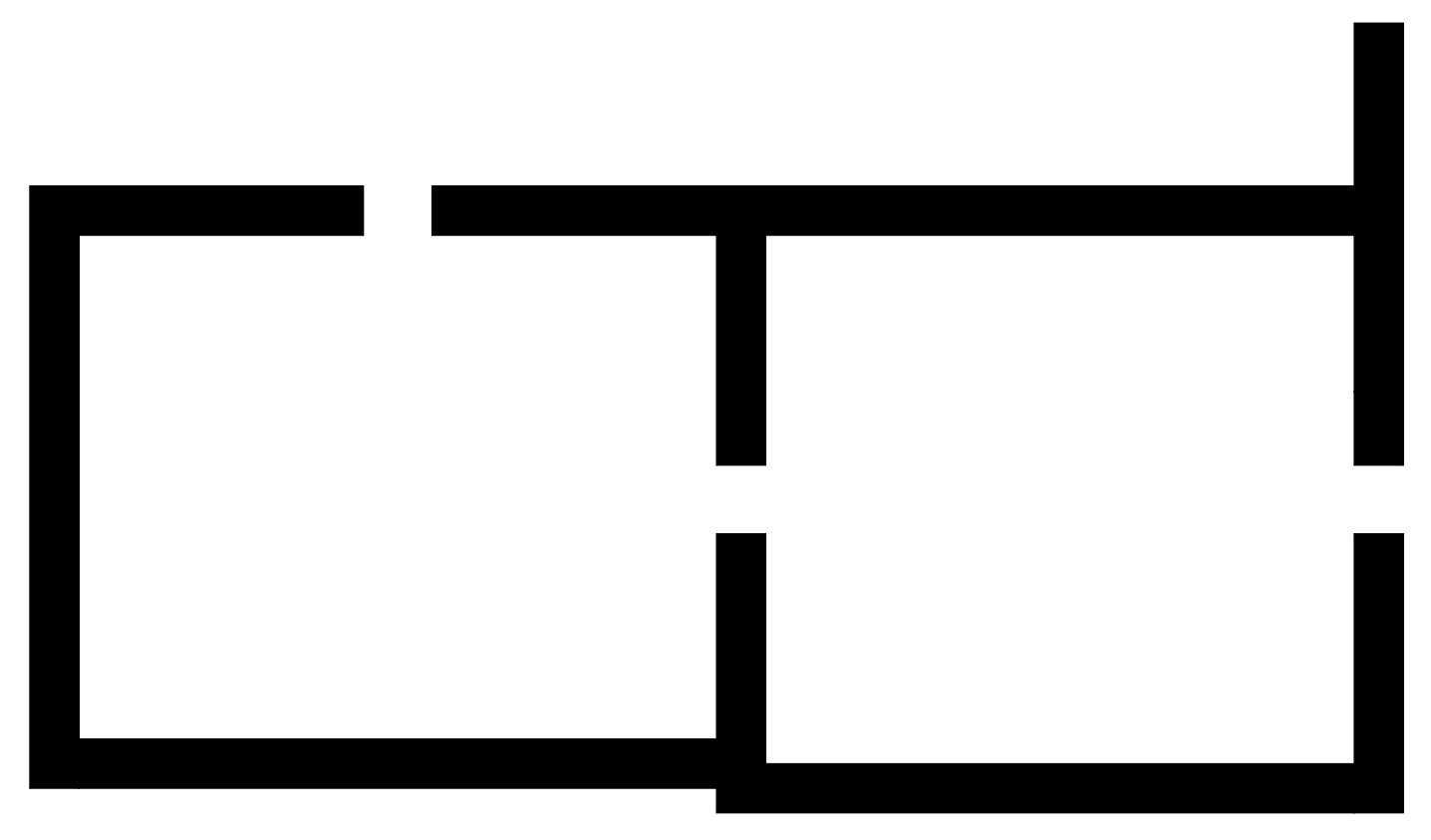

The first space the user enters is an old vaulted stone and brick den. The space has been left to near originality to set the tone and historical sensations I want made aware for the participator to the memorial museum. Two ground set halogen light bars are recessed into the floor to penetrate through the layers and uncover the walls around the room. This use of light exposes the moulded brick, dirty stone floor and rusted pipes to create a sense of participatory realism to the importance and age of the building. The minimality of an interior architectural intervention to this first space attributes to the power and emotion the dilapidated space can achieve on its own with the use of light. This is the opening space that accentuates and plays on the ideals of the building being the exhibit on display. 





The second space is accessed through a slight opening from the back off the vaulted brick den. Due to severe damage the design restores the room to partial originality. All the brick interior walls and the containing fireplace have been left as they are today to show an insight into the severity of the destruction. It is these moments that are highlighted by the use of fixed ceiling spotlights set at controlled lumens which are important for the user to mindfully engage with the space. The windows are covered by $10 \mathrm{~mm}$ Cor-Ten steel plate as a relationship and notion towards the 1000's of buildings throughout Christchurch city that had their windows bordered up with ply wood to protect what was left of the interior. This gives the opportunity in the design to dictate the use of light by artificial means but also allows small rays of exterior lighting to sidle into the rooms to offer a sub conscious connection to the outside world. The use of Cor-

Ten steel as a material promotes and adapts to the conditions of the space due to its rustic and worn appearance. Seating has been added to the design to inform a bay window setting where the public has a place to sit and reflect within the space. There is an exit point to the left of the room as you enter that initiates the circulatory path the person will follow. These exit points are all designed in a similar way to engage with the building but stand alone as it's own design mechanism to the space. 


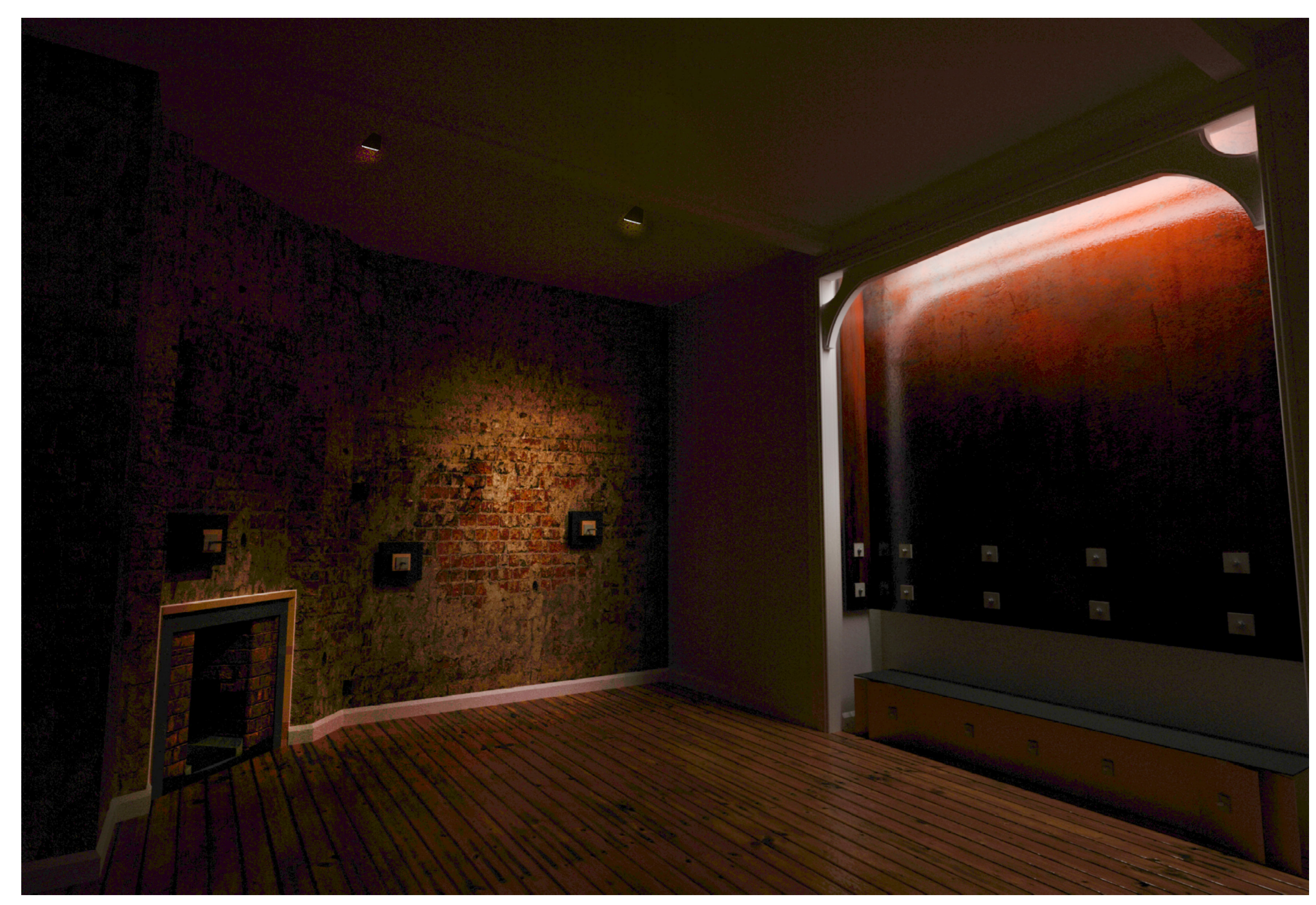



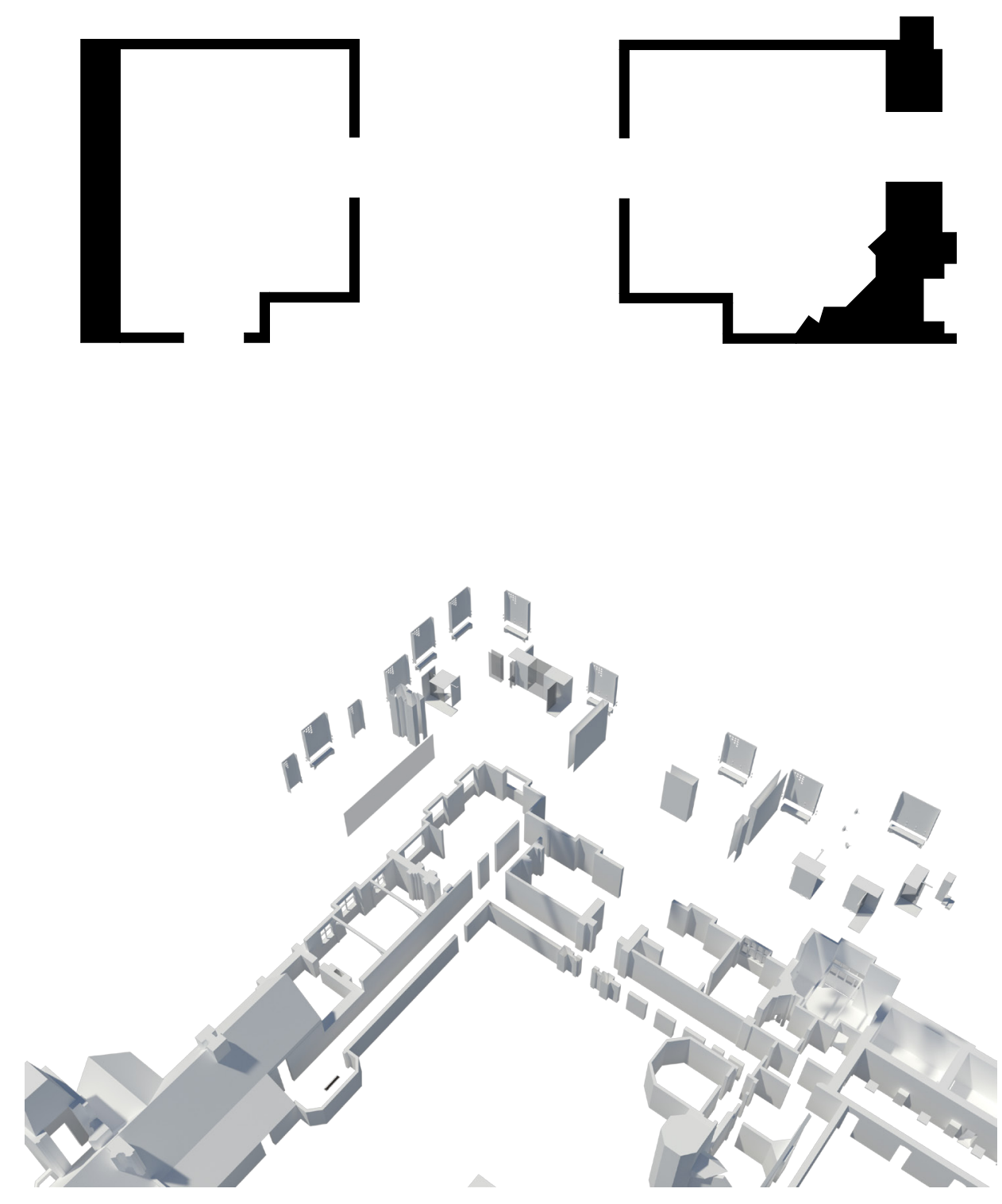

There are nine pathway design interventions that dictate spatial circulation throughout the building, they control flow and movement from space to space. Each of the markers are slightly different in design but are all made up of the same material form of $20 \mathrm{~mm}$ Cor-Ten steel plates and $20 \mathrm{~mm}$ blackened steel base plates. The use of materials is to adhere to the similarities of decay within the adjoining rooms of the Canterbury Provincial

Council Buildings. The use of the gateways also intend to act as a resetting of scene between the spaces, a re-gathering of thoughts point that then sends you into a new realm along your pathway. Small LED lighting strips are inserted into the negative detail between the steel base plate and Cor-Ten Wall. The ceiling plate and wall plates are all slightly removed from the original brick work and stone work throughout the building. This movement is also suggesting a transitional resetting as if walking in to see a completely new exhibit. There was a need to replace some formal type of entry/exit point throughout all the adjoining rooms as the original doorways were irreparable. The look and feel of steel acts also as a safety conscious mechanism to provide an assurance of safety and strength as a structural material inside such a dilapidated building for the user. 


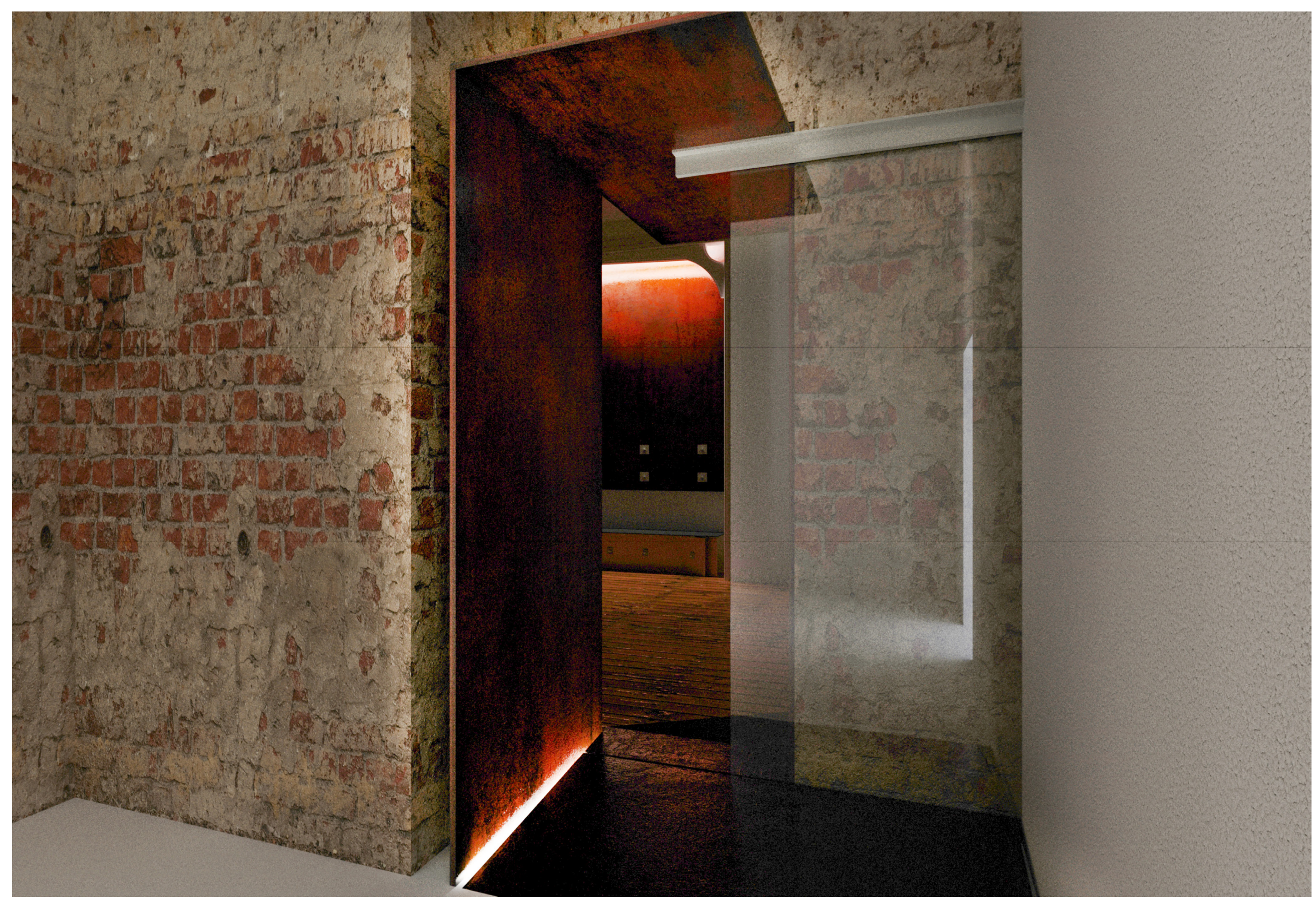



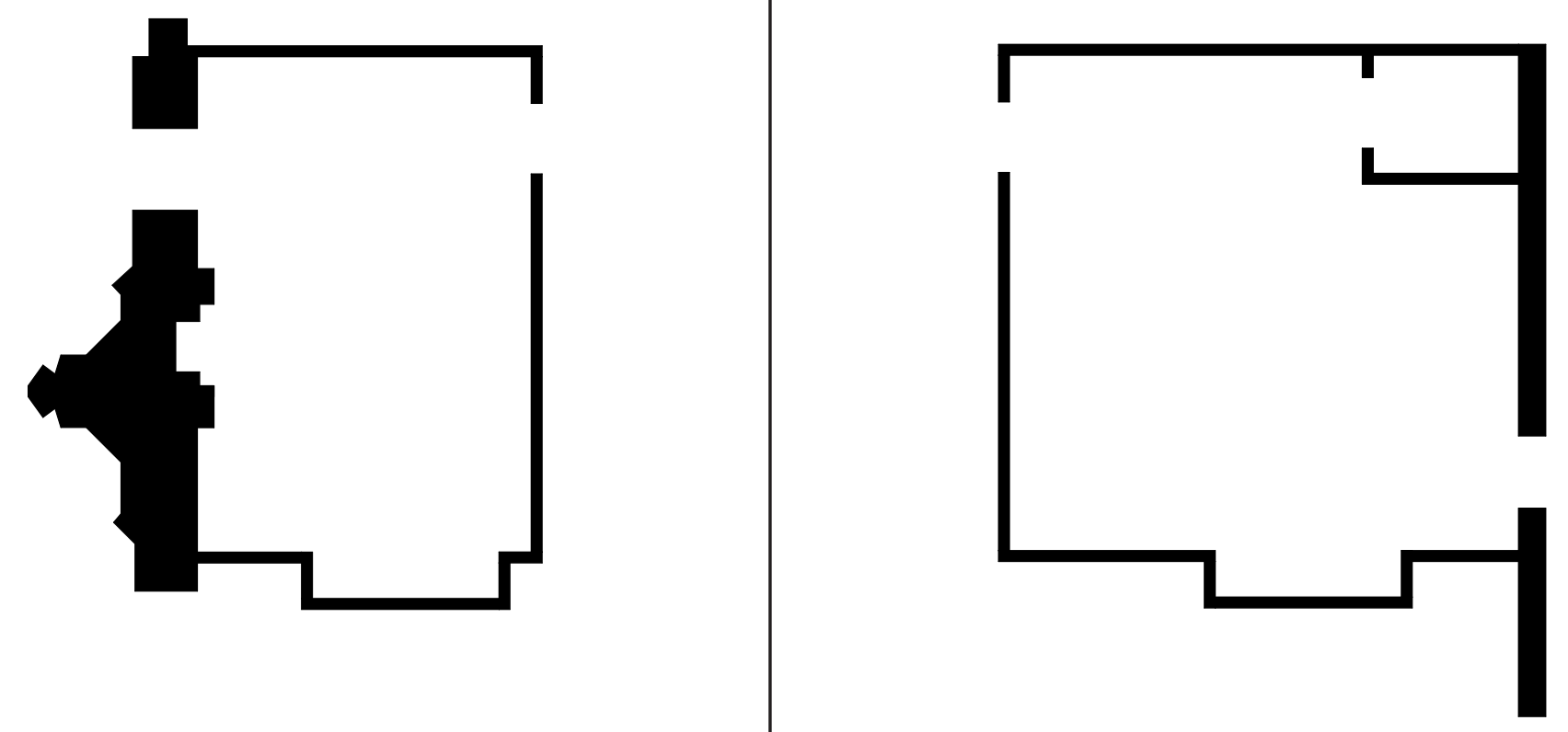

The next image is a defining moment as a transitional period within the real environment, this is where the ideas this thesis discusses of making the building become the exhibit really come to fruition. The badly damaged interior walls to the rooms are all wrapped in $12 \mathrm{~mm}$ glass from floor to ceiling. There are voids cut into the timber floor boards and building slab between the glass around the stone and brick interior walls, these cuts will

house halogen light bars. This lighting shoots light up between the glass and the walls to project and highlight the battered stone and brick walls. Using light and glass to highlight the inner buildings materials will provide the user an experience and understanding that the first stanza of the Memorial Museum is dedicated to the building itself. This expression of minimal architectural moves doesn't oversaturate the space to change and define it as something else but pushes a further realisation into the richness that is Canterbury's architetcural history. 


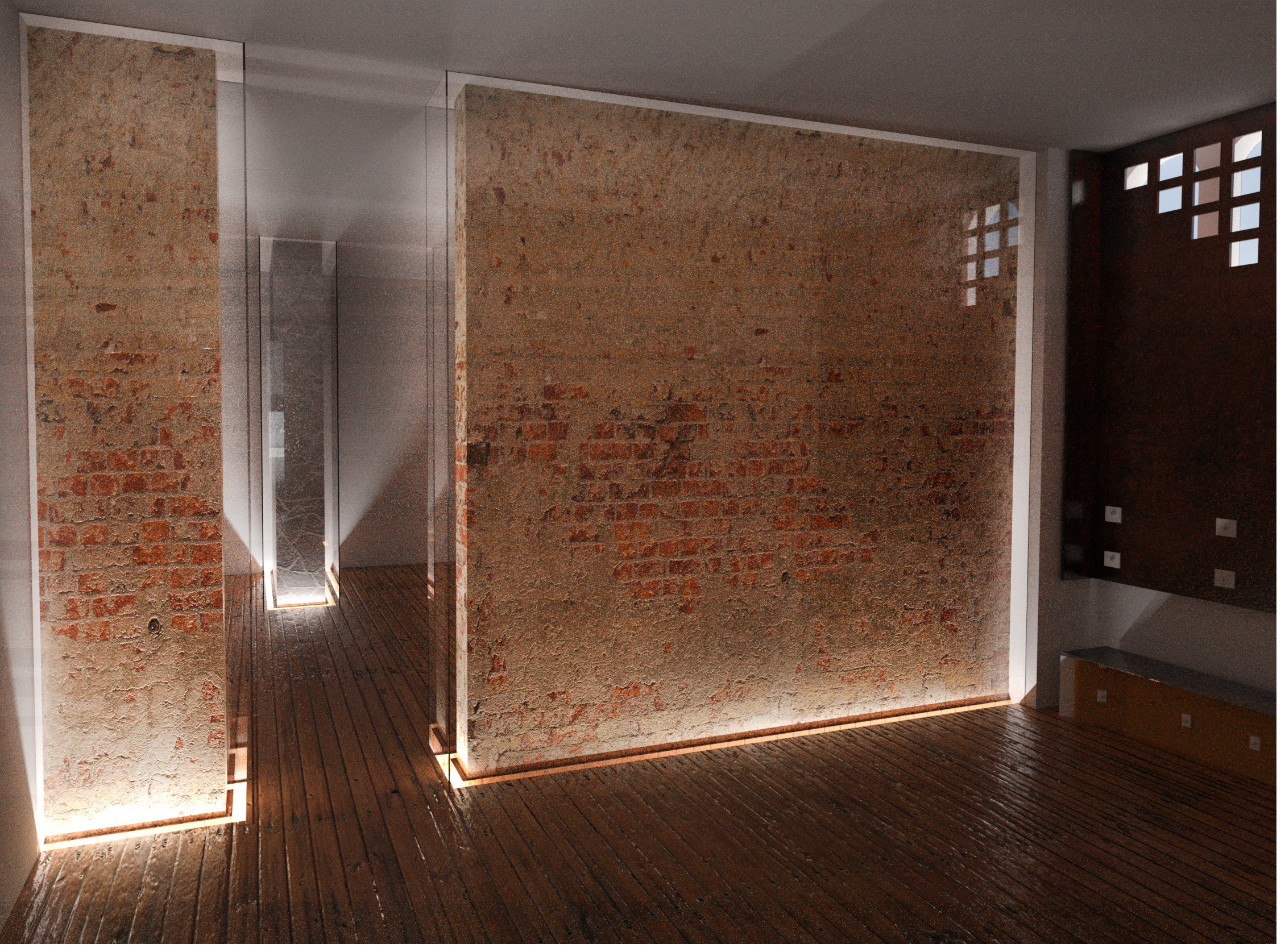


The importance of rebuilding a new Northern side tower was pertinent to add to the overall scope of this thesis and vital to replace and memorialise the buildings lost structure and the regions lost people. The tower is made up of four main materials, Cor-Ten steel plate, board-

formed concrete, light and water. The towers main design driver is a memorial to exhibit and pay tribute to the lost lives of the

Christchurch earthquake.

The first image of the tower space projects the pathway entry and channel crossing in which you walk through the space. Board-formed concrete walls line the towers base and steps covered with pools of water distinguish the route that the user must take to get across. The materiality choice for the boardformed concrete walls applies to a need of structure and solidity that is still uncertain in the minds of the people of Christchurch.

The imprint that that the timber boards leave in the concrete are a design movement that offers an underlying impression to the re-build of the city, a leaving your mark attribute that provides a subtle notion towards the revitalisation of the city. The pools of water that cover the steps leading down is a conception of pushing forward and not looking back as an act

to cover and conserve what was lost. Streams of light cascade down the concrete walls and into the pools below too accentuate the spaces overall dynamic.

The remaining images offer views up inside the tower and bring to light the laser cut Cor-Ten steel plates that form the walls and ceiling of the tower and its parts. The words that are cut into the steel plates are the names of the 185 people that were killed in the Christchurch earthquakes. The names are written so to be seen backwards from the interior views to allow an idea of imprint from the heavens, where the names have been sent back and stamped in place so to not forget the ones that were lost. The CorTen as a material coincides with the interior architecture of the circulation path mechanisms as well as representing a strong and bold look. Natural light filters down into the space through the laser cut voids and saturates the space around it in infrequent patterns determined by the time of day. The tower has been left open and reasonably exposed to the elements to provide a link with the 'real world' nature of its aforementioned spaces. Water pumps provide appropriate water levels for the pools that cover the stairs so to not flood the spaces and to keep the installation at a constant. 


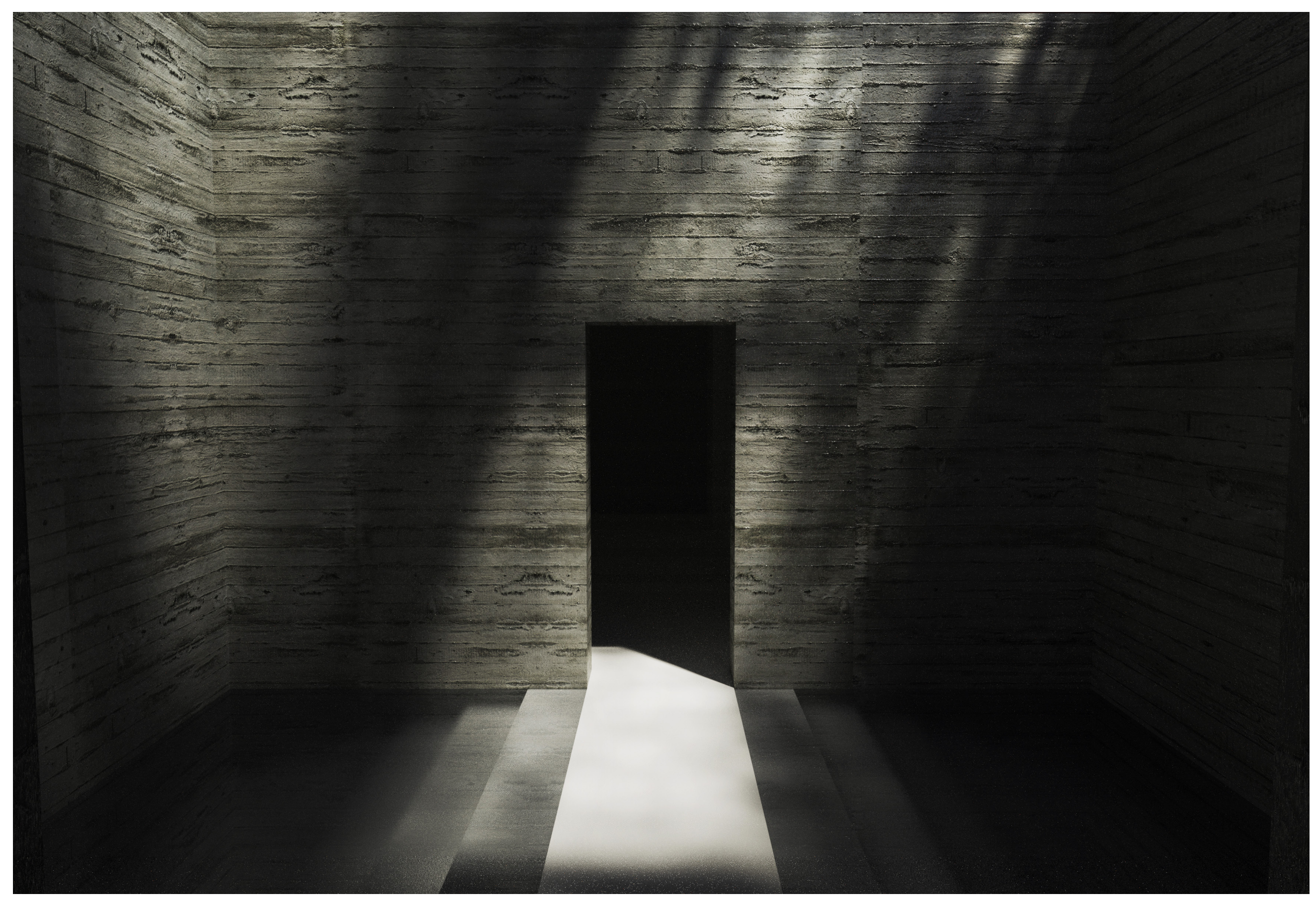




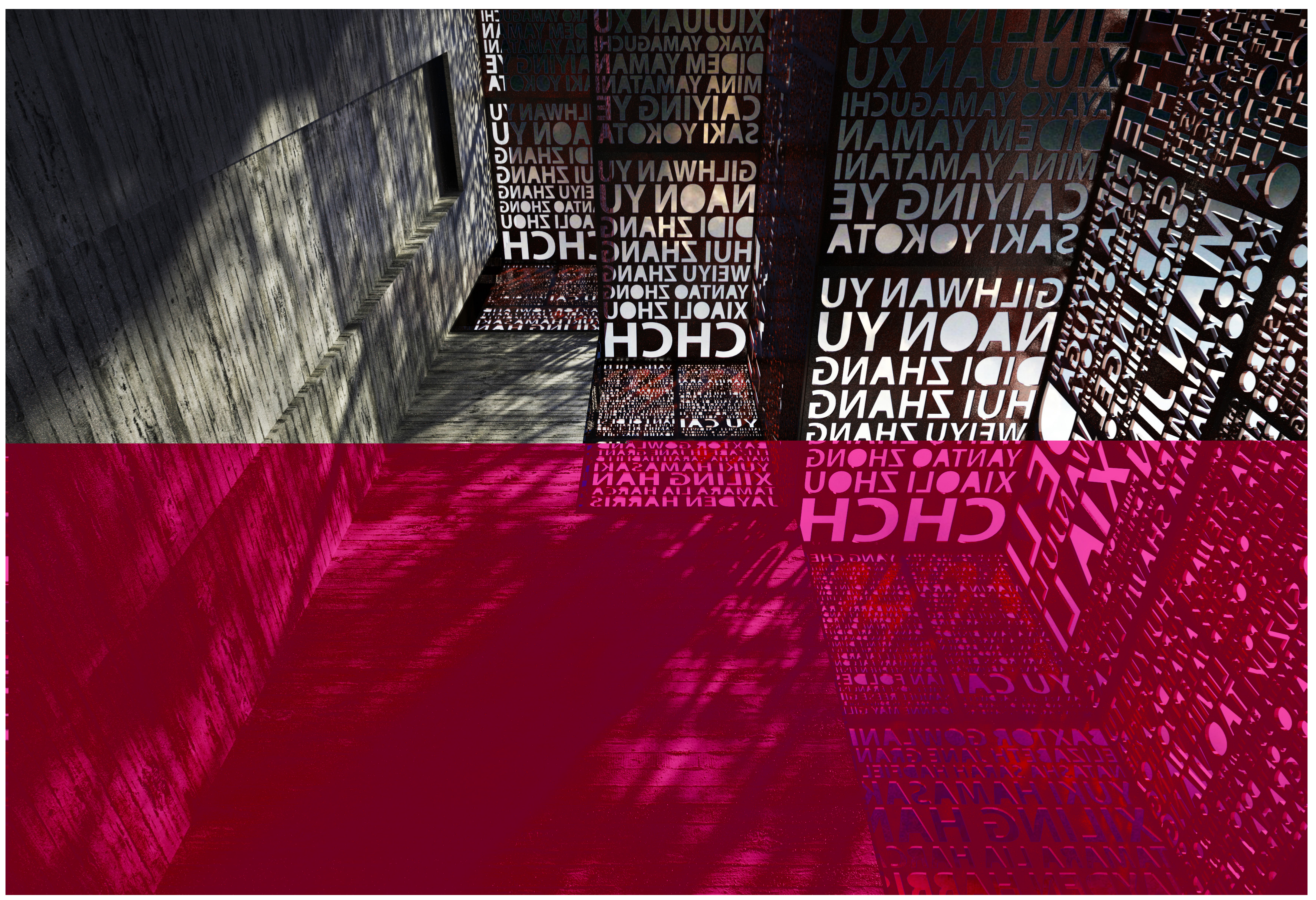



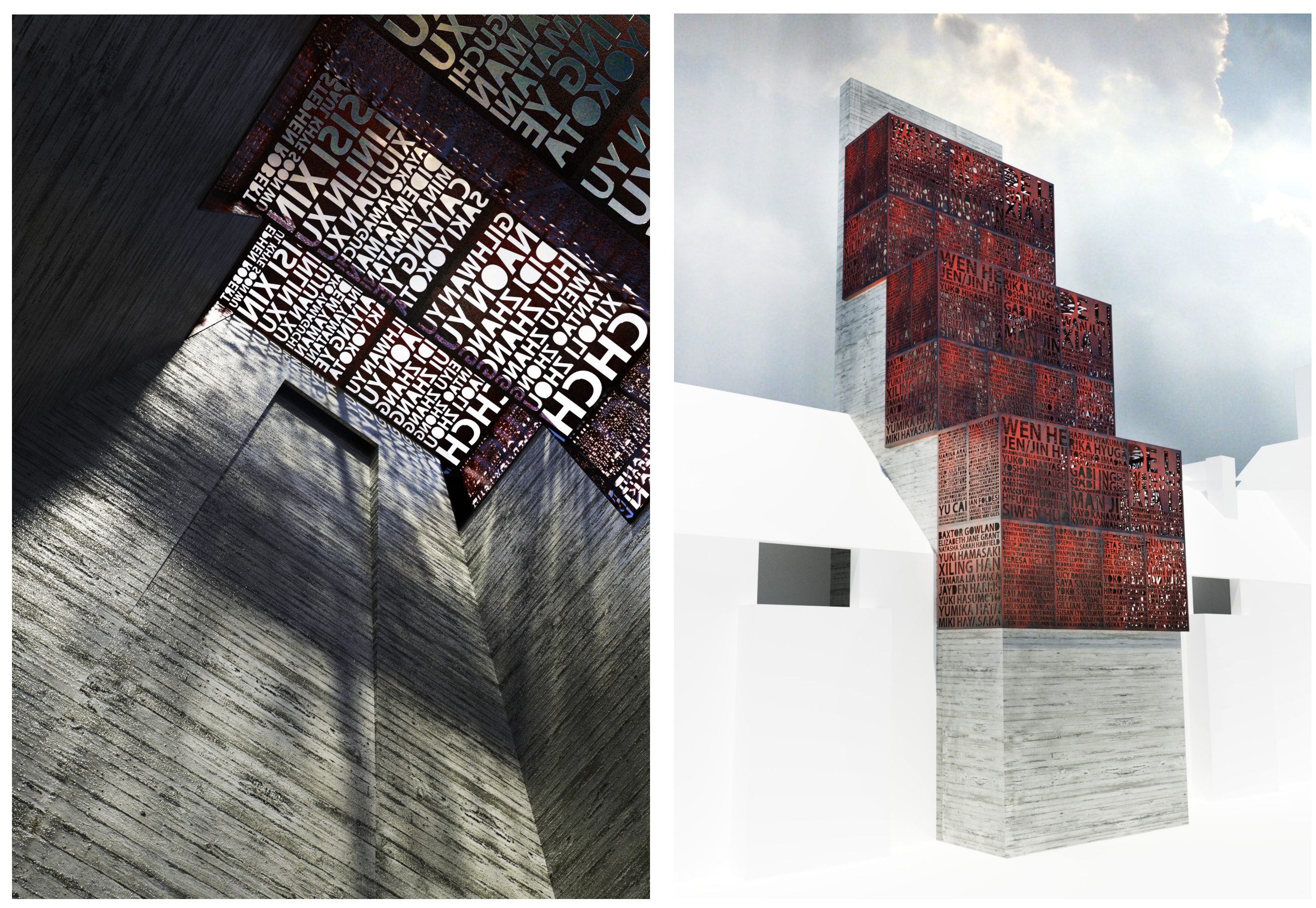


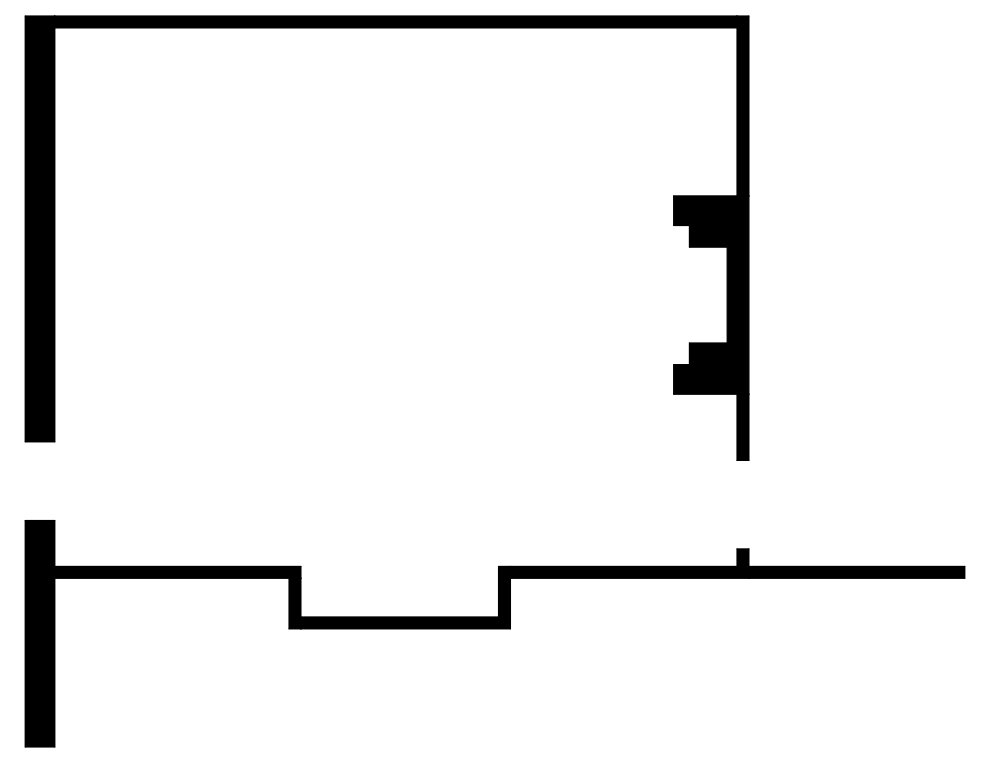




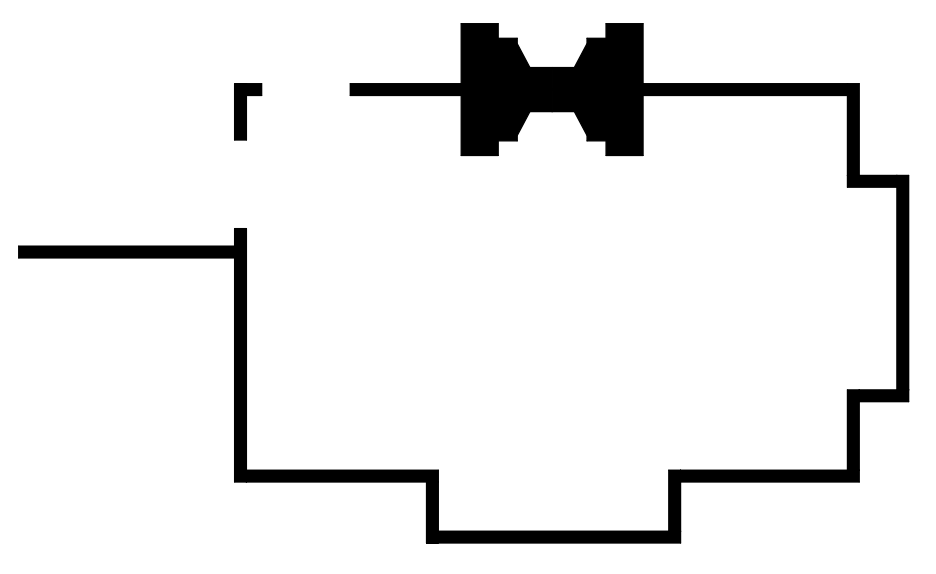


These are the augmented reality spaces where similar to past spaces there is a projection of the old and refurbished new. Points of interest are still highlighted and appear very similar to what was seen in the 'real world' spaces. One major digital intervention here is the overlaying of a transparent multi-touch LCD display across the walls where they become interactive tools for learning and information about the museum, Christchurch, historical Christchurch architecture and major events. The use of this technology allows users to engage with the exhibit itself by swiping across the screens and looking in to parts of the city that interest them. The key point here is the use of NFC technology that instigates this whole process. Nearly every phone produced today is NFC capable and by having this function turned on and placing it on one of the registered NFC plinths the transparent multi-touch LCD display comes to life in front of you. If the phone is removed from the plinth the screen immediately goes back to its transparent state revealing the broken bones of the buildings interior. The act of having your phone on the NFC recognised plinth not only initiates the screen but also electronically stores whatever you are learning and looking at on the screen to your mobile device.

Architectural builidng history is represented on a physical and digital level within this space where one or the other is viewed at seperate times or in unison. This feature allows the museum to control a real participatory engagement with the exhibits and what the information being sent is. It also allows for the user to access museum registered websites and more information on the agendas they were experiencing within the touch screens while they are at home on their mobile devices. This idea is in reference to hiring a library book but as well as just hiring it you can also access more legitimate research based museum software and information outside of the museum. 


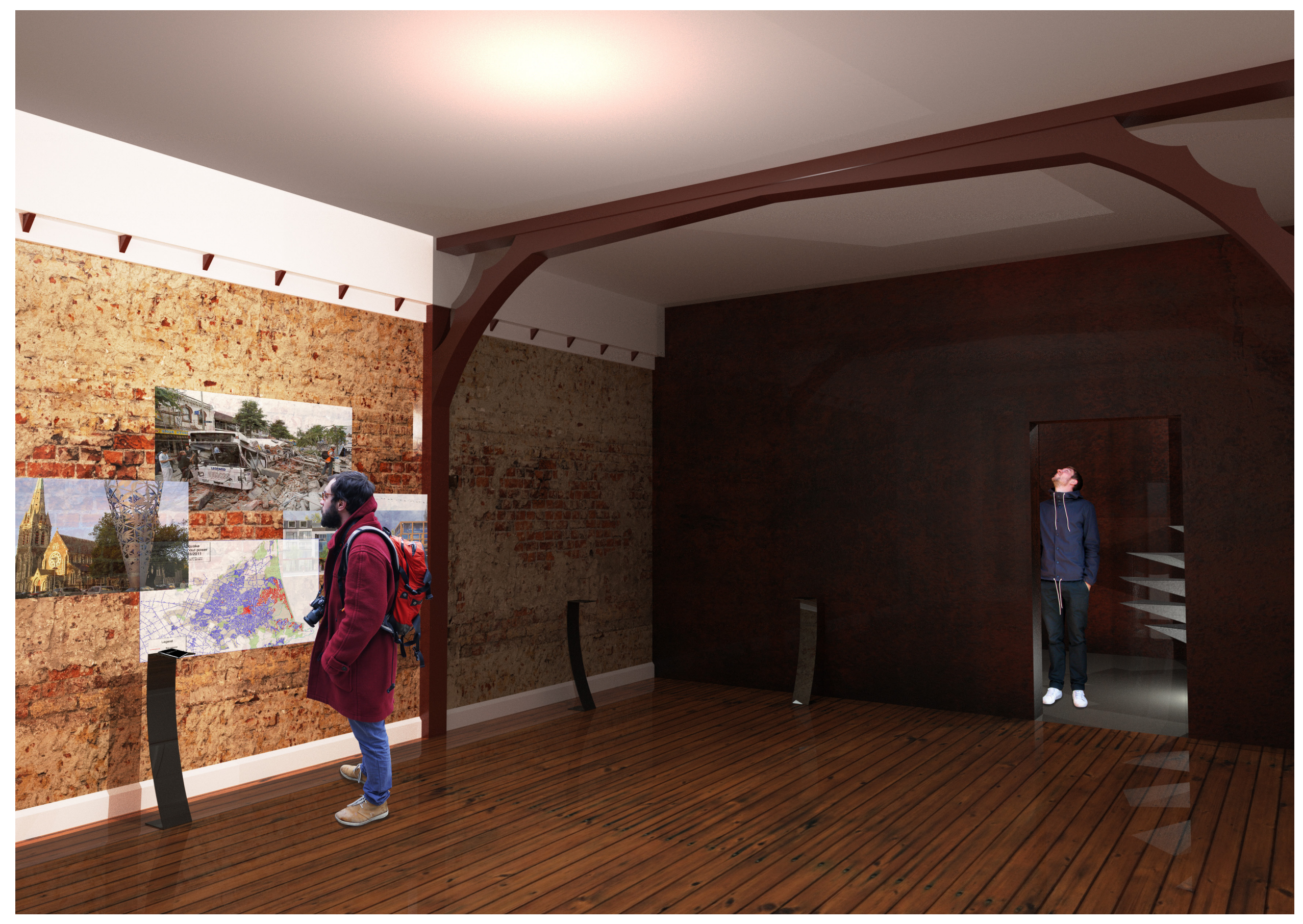




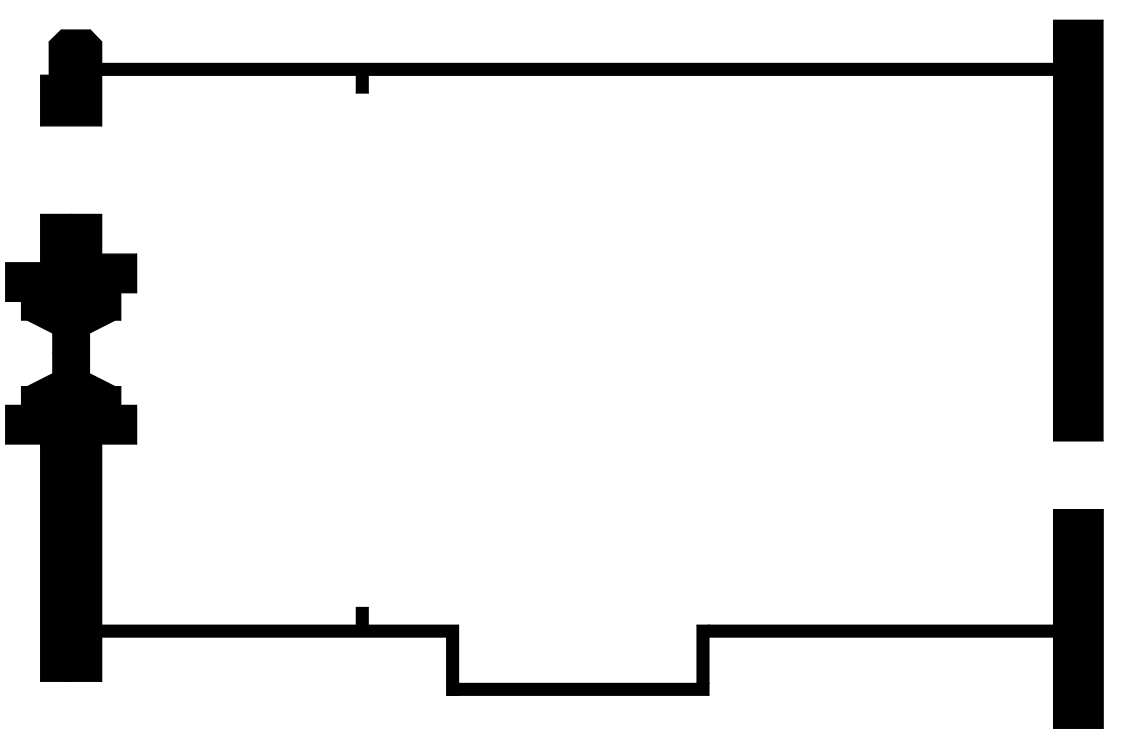



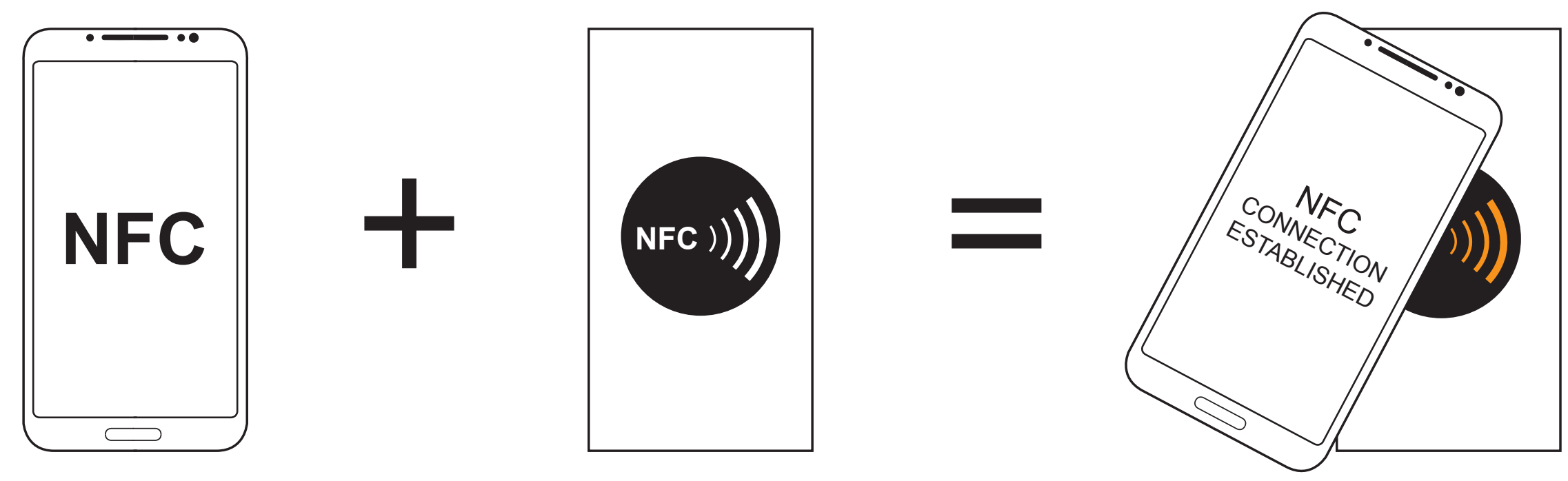


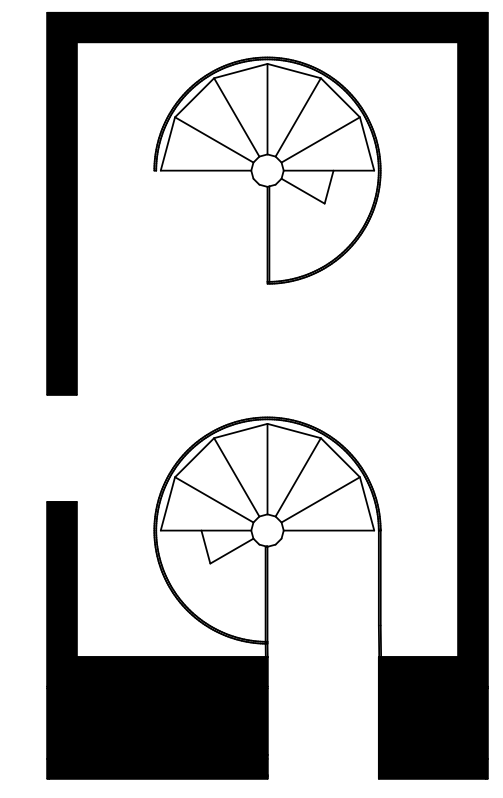

The second tower and final space

realms.

the public engages with is the

augmented virtuality tower. Again

it was important to reinvent this

tower along the Western side

but not to act as memorial to the

past but as a flume of existence,

offering hope and revitalisation

as a means of defining and

informing on the past, present

and future of Canterbury and it's

architectural heritage. The tower

is made up of Cor-Ten steel

plate and blackened steel plate.

Through the centre, two tall,

concrete spiral staircases rise

into the sky and are encapsulated

by glass cylinders. The centre of the glass is bathed in light and

allows for an inviting yet long journey to the top. Only one of the spiral staircases leads to the top while the other acts as an exit point from the viewing deck. The way this space works is to fundamentally force the user to access the top platform, it is a simple yet effective way of forming user circulation to experience the final stage of the design. Natural light pierces through the voids in the blackened steel and also leaves a hint of exposure to the outside elements to remind that mixed reality covers its entire 4 pointed 







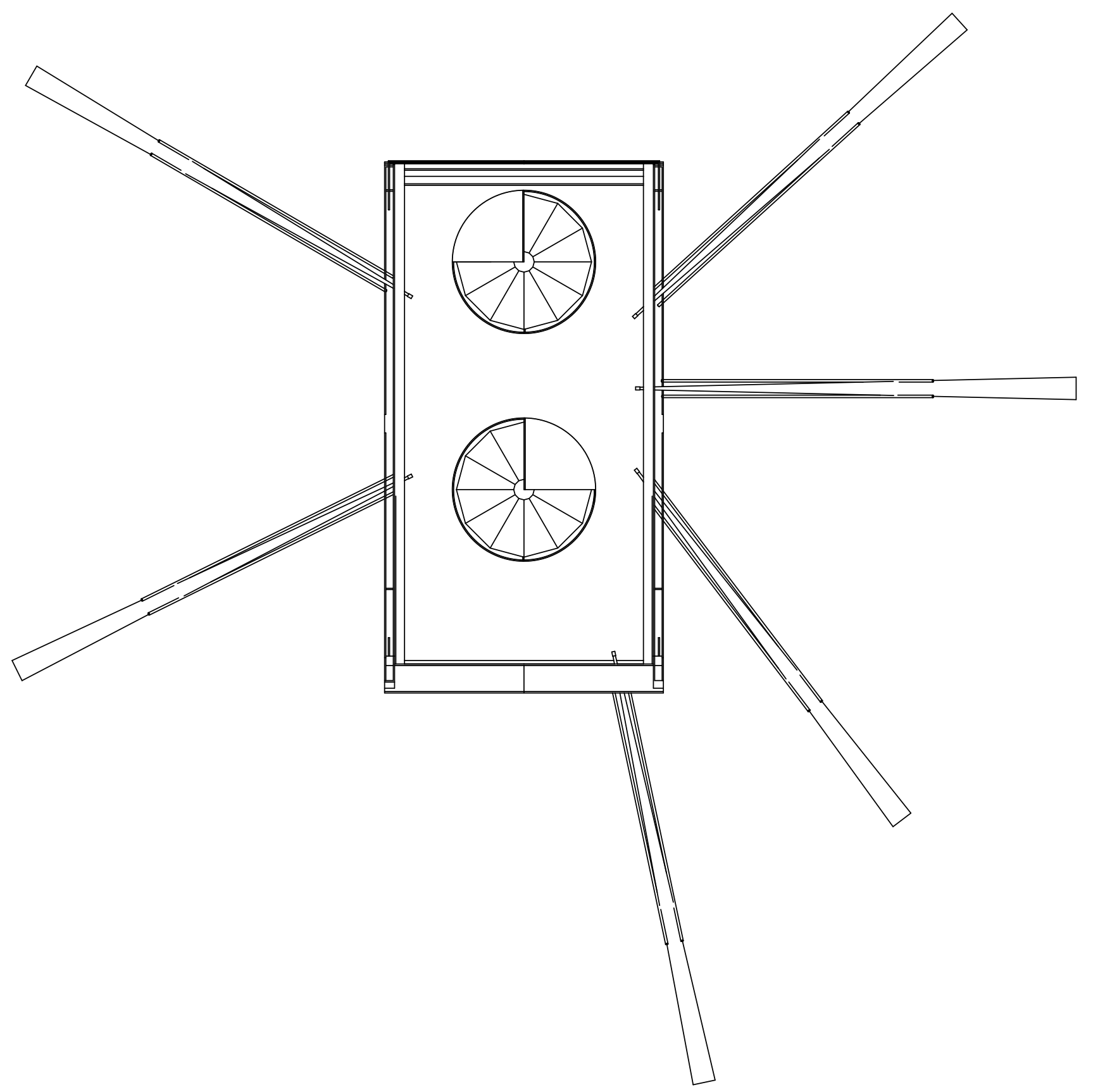

The final stage in the memorial museum is the augmented virtuality viewing deck. Six viewing apertures penetrate the skin of the tower and perform as the most significant piece in pertaining to the ideas of the past, present and future of Canterbury. Each viewing aperture points at six key areas of architectural and social importance to the city of Christchurch:

- $\quad$ Oxford Terrace, site specifically 'The Strip'

- $\quad$ The Arts Centre of Christchurch

- Christ's College

- Victoria Street

- $\quad$ Christchurch Town Hall

- $\quad$ The Cathedral

These areas were chosen to not only fit in with the geographical location of the tower but also as areas of particular public interest. Victoria Street and Oxford Terrace are two locations that cover a lot of area and are seen as the two major areas 






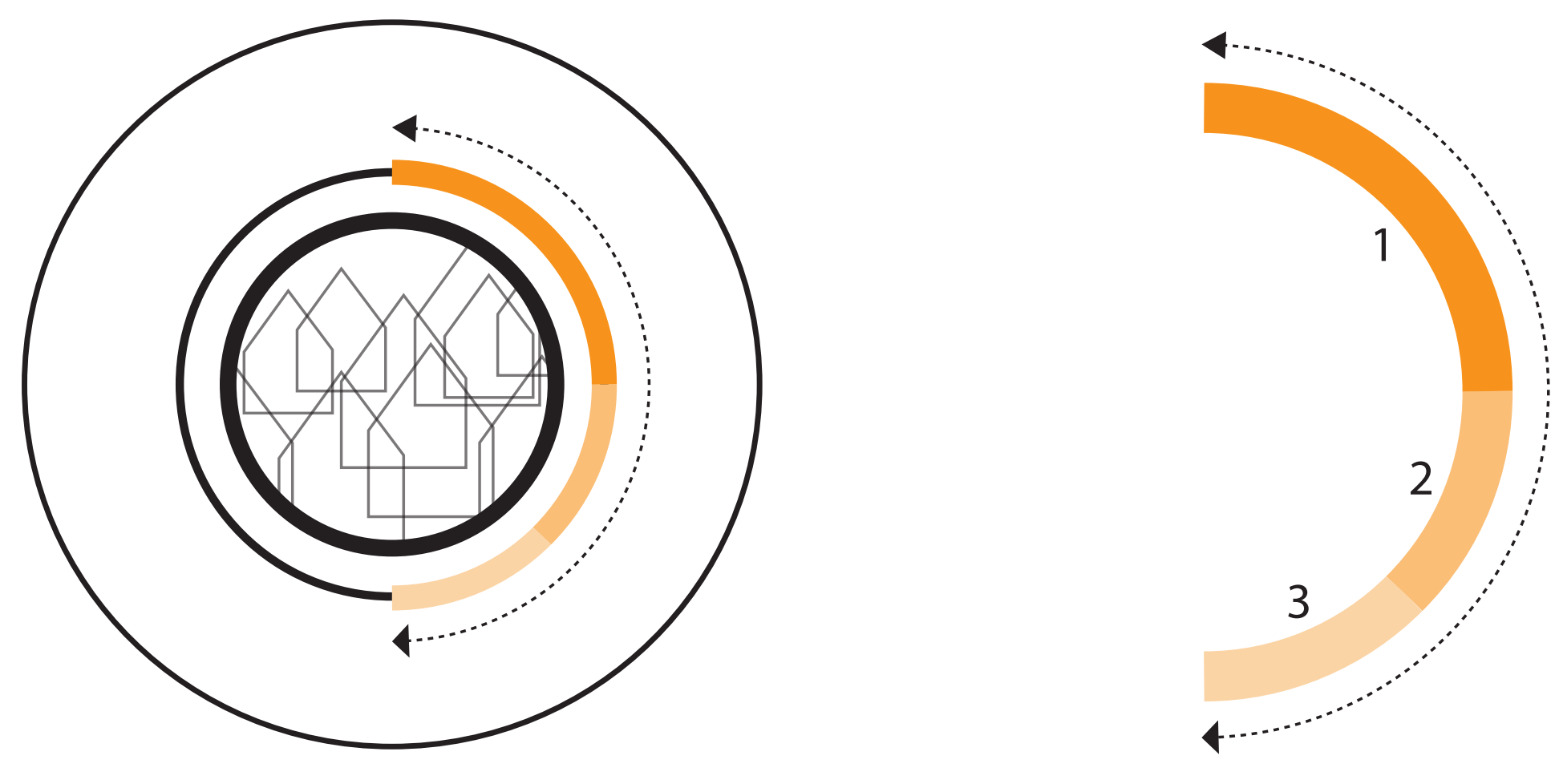


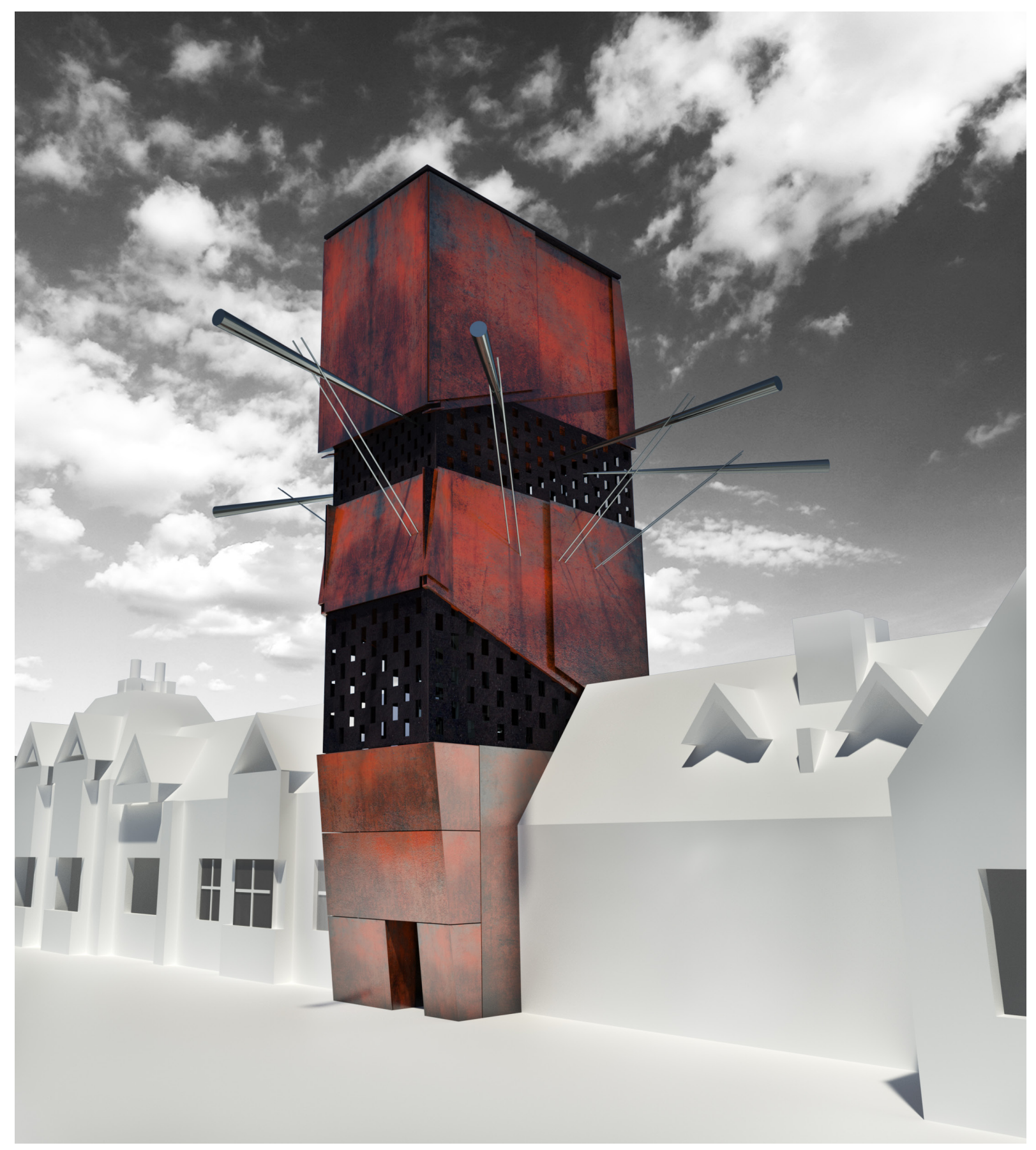

for public socialisation. The four buildings are regarded as some of Canterbury's finest architecture and the people of Christchurch have a huge amount of invested and general interest in these particular sites.

The viewing cones that pierce through onto this final level play no part in viewing anything in a real/physical sense; they are purely markers that signify a line of sight towards the specific location. What you view through the cones is all via a digital method whether it by a digital representation of the past, a live video link of the present or a conceptual digital representation of the future. By turning the apertures eye piece differing views through time will appear in a digital sense through the viewing mechanism.

What you see through the three aperture settings:

1. Past - Digital representation of what existed before the earthquakes.

2. Present - A camera fixed in place at the specific site will display a real-time image of what is going on at that point in time.

3. Future - A digital representation of conceptual designs for that specific site will be over laid on the real-time feed.

The infographic attached on the previous page offers a guide of how to scroll through the differing views. 


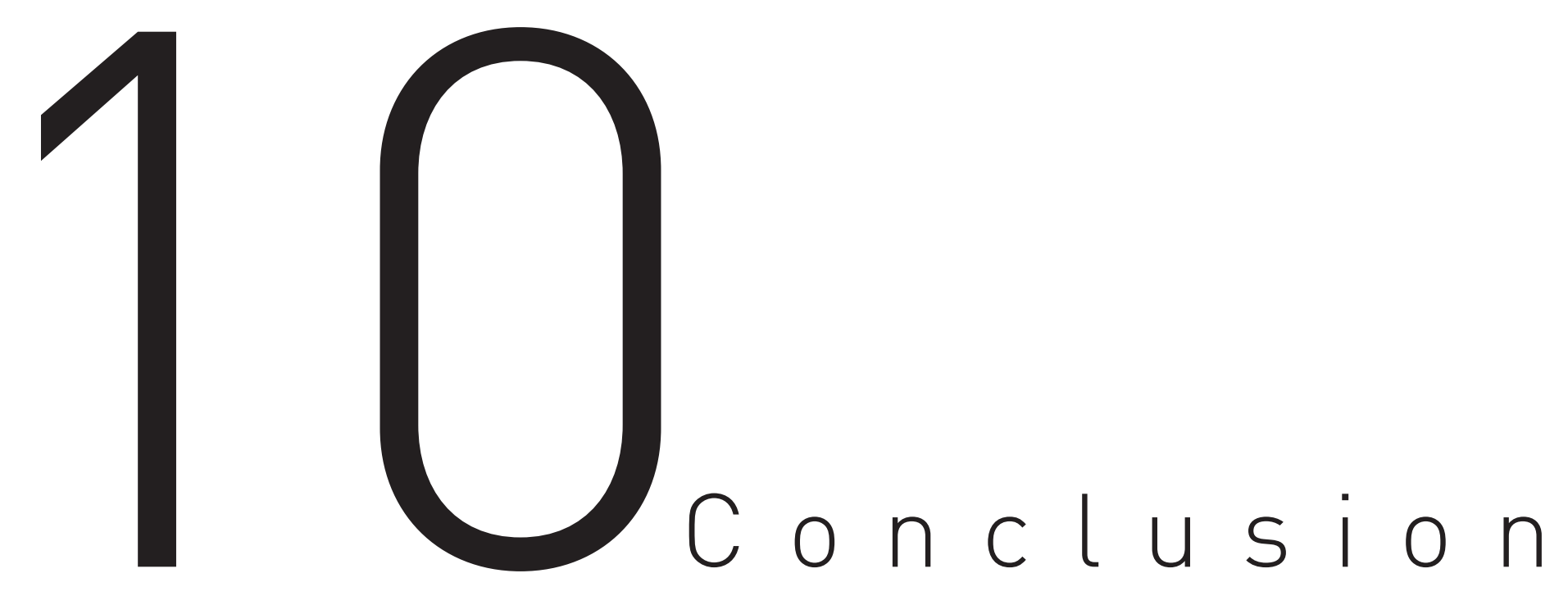


The design of a mixed reality memorial museum inside the number one registered historical trust building in Christchurch required careful and appropriate consideration of a number of aspects.

Precedents for this architectural intervention were not abundant when dealing with digital media technologies and the application of those technologies to a destructed building. It was imperative that for this thesis to subsist there was going to have to be significant research in available digital technologies that could be applied to the space with a light tactility. The physical architectural moves that are seen through the interior of the spaces also had to be informative enough to show perceptibility of the thesis intention but applied gently to not disturb the physical and visual information gathered from the building itself.

This thesis is an architectural study that provides the reader with a development of a Christchurch memorial museum using mixed reality technology. The reader follows a clear narrative of the design intent in a design led research composition to understand a fusion of historical digital and physical worlds. The ability this thesis provides is a product of a linear guideline obtained through the design research. It applies fresh thinking on the physical subtleties of spatial development and instructs confident digital technology applications for the awakening of physical and digital history whilst allowing them to intertwine.

The design has been developed to form a narrative along the mixed reality continuum, where a dilapidated historical building, strong architectural interventions and forefront technology combine to delineate the past, present and future of Christchurch's rich heritage. This design engages with a memorial museum of spatial scales, from the inserting of single lights that bathe a room in its intense character to grand towers that instigate architectural awareness of the city.

This thesis has explored interior architecture as a tool for learning, for awareness and for discovery about Christchurch and its earthquakes. This thesis in its conception was dedicated to interior architecture but in recrafting the lost interiors it was only appropriate and definitive that architecture of the exterior and interior would augment this research. It is hoped that this thesis provides a valued contribution towards informing and retaining Christchurch's built and broken architectural heritage. 

A p p e n d ix 


\section{1 \\ Bibliography}

Bimber, O., \& Raskar, R. (2005). Spatial Augmented Reality: Merging Real and Virtual Worlds. Masssachusetts: A K Peters, Ltd.

Carmody, T. (2010, November 3). How Motion Detection Works in Xbox Kinect. Retrieved from Wired: http://www. wired.com/2010/11/tonights-release-xbox-kinect-how-does-it-work/all/

de Goeij, A. (2011, January 28). Projects: Warehouse 17c Matadero Madrid. Retrieved from MIMOA: Mi Modern Architecture : http://www.mimoa.eu/projects/Spain/Madrid/Warehouse\%2017c\%20Matadero\%20Madrid

Drell, L. (2012, December 20). Augmented Reality City. Retrieved from Mashable: http://mashable.com/2012/12/19/ augmented-reality-city/

Franco, A. (2011, Octoberr 28). Work: Arturo Franco. Retrieved from Arturo Franco: http://www.arturofranco.es/obra. asp? $|\mathrm{DC}=1 \&| \mathrm{D}=3 \& \mid \mathrm{DM}=3$

Hansen, M. B. (2006). Bodies in Code Interfaces with digital media. New York: Taylor \& Francis Group.

Metaio. (2010, February 17). Lego Digital Box; Augmented Reality Kiosk. Retrieved from Metaio: http://www.metaio. $\mathrm{com} / \mathrm{press} /$ press-release/2011/lego-digital-box/

Milgram, P., \& Kishino, F. (1994, August 25). A Taxonomy of Mixed Reality Visual Displays. Retrieved August 12, 2014, from Ergonomics in Teleoperation and Control Laboratory: http://etclab.mie.utoronto.ca/people/paul_dir/IEICE94/ ieice.html

Nosowitz, D. (2011, March 1). Everything You Neeed To Know About Near Field Communication . Retrieved from Popular Science: http://www.popsci.com/gadgets/article/2011-02/near-field-communication-helping-yoursmartphone-replace-your-wallet-2010

Poor, A. (2012, October 17). How it works: The technology of touch screens. Retrieved from Computer World: http:// www.computerworld.com/article/2491831/computer-hardware/how-it-works--the-technology-of-touch-screens. 
html

Rowe, P. G. (1989). Rodolfo Machado and Jorge Silvetti. Cambridge, Massachusetts: Harvard University Graduate School of Design.

Schedeen, J. (2010, April 23). The History of 3D Movie Tech. Retrieved from Imagine Games Network: http://au.ign.com/ articles/2010/04/23/the-history-of-3d-movie-tech?page $=1$

Silvetti, J. (1986). Four Public Squares in the City of Leonforte, Sicily. Assemblage, 54-71.

Ternier, S., Klemeke, R., Kalz, M., Ulzen, P., \& Specht, M. (2012). ARLearn: Augmented Reality Meets Augmented . Journal of Universal Computer Science, 2143-2164.

Whyte, J. (2002). Virtual Reality and the Built Environment. Oxford: Architectural Press.

Images List:

Image 1: http://1.bp.blogspot.com/x46H5wKtY6s/TWPprkxVN9I/AAAAAAAAGFY/AfVoxfiGVEY/s1600/March+061+rs.jpg

Image 2: Google Maps

Image 3: http://4.bp.blogspot.com/-SHSS7kPrUbE/TWNNQccu21I/AAAAAAAACGI/alkIe-64D2U/s1600/CanterburyProvincial+Chambers.jpg Image 4: Files obtained from Christchurch City council

Image 5: http://www.clarkchart.com/wp-content/uploads/2013/07/flatworld-1.jpg

Image 6: http://wpuploads.appadvice.com/wp-content/uploads/2012/04/weather2x_v11_iph4_screen3-4large.jpg

Image 7: http://smcsites.com/ispr/files/2010/04/Lego.jpg

Image 8: http://static.giantbomb.com/uploads/original/8/85733/2010818-2010710-kinect_sports_season_two_baseball2.jpg

Image 9: http://www.virtualrealityreviewer.com/wp-content/uploads/2014/03/2731_large_virtualPA_468x335.jpg

Image 10 and 11: http://www.gibson.co.nz/assets/_resampled/resizedimage600385-Aften-13mindre-1-Web-copy.jpg

Image 12 and 13: http://qfuse.com/blog/wp-content/uploads/2013/07/Museum-of-London2.jpg

Image 14: http://www.refikanadol.com/wp-content/uploads/2012/11/Photo-01.jpg

Image 15: Photocopy from Machado and Silvetti, Four public squares.

Image 16, 17, 18 and $19:$ http://www10.aeccafe.com/blogs/arch-showcase/2011/06/14/the-warehouse-17c-in-madrid-spain-by-arturo-franco-office/

Image 20, 21 and $22:$ http://www.archdaily.com/263158/the-waterhouse-at-south-bund-neri-hu/

Image 23: http://www.gadget.pdamu.com/wp-content/uploads/2011/10/NFC-Technology-by-Sony-FeliCa.jpg

Image 24: http://www.evoluce.com/index_htm_files/1967.jpg 

